\title{
Phylogenetic relationships of the genus Mischonyx Bertkau, 1880, with taxonomic changes and three new species description (Opiliones: Gonyleptidae)
}

\author{
Caio Gueratto ${ }^{\text {Corresp., } 1}$, Alípio Benedetti ${ }^{2}$, Ricardo Pinto da Rocha ${ }^{1}$ \\ 1 Departamento de Zoologia/ Instituto de Biociências, Universidade de São Paulo, São Paulo, São Paulo, Brazil \\ 2 Centro Universitário Metodista Izabela Hendrix, Belo Horizonte, Minas Gerais, Brazil \\ Corresponding Author: Caio Gueratto \\ Email address: caio.gueratto@gmail.com
}

The type species of Mischonyx Bertkau 1880, Mischonyx squalidus, was described based on a juvenile. The holotype is lost. Based on a revision of publications, the genus includes 12 species, all in Brazil. The objectives of this research are: to propose a phylogenetic hypothesis for Mischonyx based on Total Evidence (TE); propose taxonomic changes based on the phylogeny; and analyze the phylogenetic hypothesis biogeographically. Using the exemplar approach to taxon selection, we studied 54 specimens, 15 outgroups and 39 ingroup taxa using seven molecular markers (28S, $12 \mathrm{~S}$ and $16 \mathrm{~S}$ ribosomal genes, citochrome oxidase subunit I gene, carbamoyl-phosphate synthetase gene, internal transcribed spacer subunit 2 and histone $\mathrm{H} 3$ gene), totaling 3742 bp., and 128 morphological characters. We analyzed the dataset under three optimality criteria: Maximum likelihood (ML), Maximum parsimony (MP) and Bayesian. We discuss the transformation of character states throughout the phylogeny, the different phylogenetic hypotheses using different datasets and the congruence of evidence between the clades obtained by the phylogenetic analysis and the biogeographical hypothesis for the Atlantic Forest areas of endemism. We estimate that Mischonyx clade diverged 50.53 Mya, and inside the genus there are two major clades. One of them cointains species from Paraná, Santa Catarina, South of São Paulo and Serra do Mar Areas of Endemism and the other has species from Espinhaço, Bocaina, South coast of Rio de Janeiro and Serra dos Órgãos Areas of Endemism. The first split inside these two clades occurred at 48.94 and $44.80 \mathrm{Mya}$, respectively. We describe three new species from Brazil: Mischonyx minimus sp. nov. (type locality: Petrópolis, Rio de Janeiro), Mischonyx intervalensis sp. nov. (type locality: Ribeirão Grande, São Paulo) and Mischonyx tinguaensis sp. nov (type locality: Nova Iguaçu, Rio de Janeiro). The genus Urodiabunus Mello-Leitão, 1935 is considered a junior synonym of Mischonyx. Weyhia spinifrons Mello-Leitão, 1923; Weyhia clavifemur MelloLeitão, 1927 and Geraeocormobius reitzi Vasconcelos, 2005b were transferred to 
Mischonyx. Mischonyx cuspidatus Roewer, 1913 is a junior synonym of M. squalidus Bertkau, 1880. In the results of the phylogenetic analyses, Gonyleptes antiquus MelloLeitão, 1934 (former Mischonyx antiquus) does not belong in Mischonyx and its original combination re-established. As it is now defined, Mischonyx comprises 17 species, with 7 new combinations. 
1 Phylogenetic relationships of the genus Mischonyx Bertkau, 1880, with

2 taxonomic changes and three new species description (Opiliones:

3 Gonyleptidae).

4

5 Caio Gueratto ${ }^{1}$, Alípio Benedetti ${ }^{2}$, Ricardo Pinto-da-Rocha ${ }^{1}$

6

$7 \quad{ }^{1}$ Departamento de Zoologia, Instituto de Biociências, Universidade de São Paulo, 05508-090,

8 Rua do Matão, travessa 14, número 321, São Paulo, SP, Brazil.

92 Centro Universitário Metodista Izabela Hendrix, 30160-012, Rua da Bahia, 2020, Belo

10 Horizonte, MG, Brazil.

11

12 Corresponding Author:

13 Caio Gueratto ${ }^{1}$

14 Departamento de Zoologia, Instituto de Biociências, Universidade de São Paulo, 05508-090, Rua

15 do Matão, travessa 14, número 321, São Paulo, SP, Brazil.

16 caio.gueratto@gmail.com

17

18

19

20

21

22

23

24

25

26

27

28

29

30

31

32

33

34

35

36

37

38

39

40

41

42

43

44

45

46 
47

48

49

50

51

52

53

54

55

56

57

58

59

60

61

62

63

64

65

66

67

68

69

70

71

72

73

74

75

76

77

78

79

80

81

82

83

84

85

86

87

88

89

90

91

92

\section{Abstract}

The type species of Mischonyx Bertkau 1880, Mischonyx squalidus, was described based on a juvenile. The holotype is lost. Based on a revision of publications, the genus includes 12 species, all in Brazil.

The objectives of this research are: to propose a phylogenetic hypothesis for Mischonyx based on Total Evidence (TE); propose taxonomic changes based on the phylogeny; and analyze the phylogenetic hypothesis biogeographically. Using the exemplar approach to taxon selection, we studied 54 specimens, 15 outgroups and 39 ingroup taxa using seven molecular markers (28S, $12 \mathrm{~S}$ and $16 \mathrm{~S}$ ribosomal genes, citochrome oxidase subunit I gene, carbamoyl-phosphate synthetase gene, internal transcribed spacer subunit 2 and histone $\mathrm{H} 3$ gene), totaling $3742 \mathrm{bp}$., and 128 morphological characters. We analyzed the dataset under three optimality criteria: Maximum likelihood (ML), Maximum parsimony (MP) and Bayesian.

We discuss the transformation of character states throughout the phylogeny, the different phylogenetic hypotheses using different datasets and the congruence of evidence between the clades obtained by the phylogenetic analysis and the biogeographical hypothesis for the Atlantic Forest areas of endemism. We estimate that Mischonyx clade diverged 50.53 Mya, and inside the genus there are two major clades. One of them cointains species from Paraná, Santa Catarina, South of São Paulo and Serra do Mar Areas of Endemism and the other has species from Espinhaço, Bocaina, South coast of Rio de Janeiro and Serra dos Órgãos Areas of Endemism. The first split inside these two clades occurred at 48.94 and 44.80 Mya, respectively.

We describe three new species from Brazil: Mischonyx minimus sp. nov. (type locality: Petrópolis, Rio de Janeiro), Mischonyx intervalensis sp. nov. (type locality: Ribeirão Grande, São Paulo) and Mischonyx tinguaensis sp. nov (type locality: Nova Iguaçu, Rio de Janeiro). The genus Urodiabunus Mello-Leitão, 1935 is considered a junior synonym of Mischonyx. Weyhia spinifrons Mello-Leitão, 1923; Weyhia clavifemur Mello-Leitão, 1927 and Geraeocormobius reitzi Vasconcelos, 2005b were transferred to Mischonyx. Mischonyx cuspidatus Roewer, 1913 is a junior synonym of M. squalidus Bertkau, 1880. In the results of the phylogenetic analyses, Gonyleptes antiquus Mello-Leitão, 1934 (former Mischonyx antiquus) does not belong in Mischonyx and its original combination re-established. As it is now defined, Mischonyx comprises 17 species, with 7 new combinations.

Keywords. Atlantic Rainforest; Cladistics; Gonyleptoidea.

\section{Introduction}

Laniatores is the most diverse suborder within Opiliones. There are more than 4,200 species in the group (Kury, 2020), of which at least 2,400 are from the Neotropical region (Kury, 2003). The evolution and phylogenetic relationships of most families and genera within the suborder have been poorly studied.

Modern taxonomists try to base their classifications on cladistics hypotheses (e.g., Bragagnolo \& Pinto-da-Rocha, 2009; Da Silva \& Gnaspini, 2010; Pinto-da-Rocha, 2002; Pintoda-Rocha \& Bragagnolo, 2010) using a number of markers, including molecular data (e.g., Bragagnolo et al., 2015; Pinto-da-Rocha et al., 2014). This also applies to the taxonomy of

Peer] reviewing PDF | (2020:08:52148:2:0:NEW 1 Jun 2021) 
93 Laniatores to a certain extent, but despite recent progress, the classification system devised by

94 Carl F. Roewer (1881- 1963) still prevails in this group. Roewer based his nomenclature and

95 groups on a few arbitrary characters. As a result, he created a lot of monotypic genera and placed

96 closely-related species in distinct clades (Pinto-da-Rocha et al., 2012).

97

\section{Mischonyx background}

Bertkau (1880) described Mischonyx squalidus, type species of the genus by monotypy, from Copacabana, Rio de Janeiro, Brazil. Rower (1923) pointed out that the holotype was a juvenile, evidenced by the incomplete tarsal segmentation. After Bertkau (1880), the genus remained monotypic until Kury (2003), who synonymized other genera (cited below) within Mischonyx.

In the first half of the 20th century, Carl Roewer and Candido Mello-Leitão described genera of interest for this research, namely, Ilhaia Roewer, 1913, Weyhia Roewer, 1913, Xundarava Mello-Leitão, 1927, Eduardoius Mello-Leitão, 1931, Geraecormobiella MelloLeitão, 1931 and Giltaya Mello-Leitão, 1932. In addition, Mello-Leitão described and transferred species into these genera and recognized Weyhia as a synonym of Geraeocormobius (Mello-Leitão, 1940).

In the second half of the 20th century, B. Soares and H. Soares synonymized Ilhaia with Eduardoius (Soares, 1943), Geraecormobiella with Geraeocormobius Holmberg, 1887 (Soares, 1945) and Ilhaia with Xundarava (Soares \& Soares, 1987). Along with that, the authors synonymized some species of these genera and described more species.

Kury (2003) synonymized Ilhaia and Giltaya with the almost forgotten genus Mischonyx. Besides that, he transferred G. antiquus (then in Paragonyleptes) to Mischonyx. Since the holotype of Mischonyx squalidus is lost, Kury based his conclusions on Roewer's drawings and description. In his catalog, Kury considers Mischonyx as including 11 species.

Finally, in Vasconcelos $(2004,2005$ a) the two last Mischonyx species were described: Mischonyx kaisara, from the coast of the state of São Paulo, and Mischonyx poeta, from the northern portion of the state of Rio de Janeiro. He also described Gearaeocormobius reitzi Vasconcelos, 2005b. Besides these publications, there is one unpublished M.Sc. dissertation on the taxonomy of Mischonyx taxonomy (E Vasconcelos, 2003, unpublished data). 
139

140

141

142

143

144

145

146

147

148

149

150

151

152

153

154

155

156

157

158

159

160

161

162

163

164

165

166

167

168

169

170

171

172

173

174

175

176

177

178

179

180

181

182

183

184

The last published research containing taxonomical remarks on the genus, Pinto-da-Rocha et al. (2012), considered 12 valid species within Mischonyx: M. anomalus (Mello-Leitão, 1936); M. antiquus (Mello-Leitão, 1934); M. cuspidatus (Roewer, 1913); M. fidelis (Mello-Leitão, 1931); M. insulanus (Soares, 1972); M. intermedius (Mello-Leitão, 1935); M. kaisara Vasconcelos, 2004;; M. poeta Vasconcelos, 2005a; M. processigerus (Soares \& Soares, 1970); M. scaber (Kirby, 1819); M. squalidus Bertkau, 1880 and M. sulinus (Soares \& Soares, 1947).

The biology of Mischonyx cuspidatus has been extensively studied, including the chemical composition of the odoriferous glands (Rocha et al., 2013), defensive behavior (Dias \& Willermart, 2013; Dias et al., 2014; Willemart \& Pellegatti-Franco, 2006), odor sensitivity (Dias, 2017) and synanthropic behavior (Mestre \& Pinto-da-Rocha, 2004). Although there has been a lot of discussion on the taxonomy of Mischonyx, no phylogenetic hypothesis has yet been proposed for the genus.

The main goal of this work is to propose a phylogenetic hypothesis for Mischonyx, based on total evidence combining sequences from seven genes and morphological characters that include the external morphology and genitalia. In addition, we propose taxonomical changes, describe new species and make remarks on biogeography based on the phylogenetic hypothesis.

\section{Material and Methods}

\section{Species distribution and areas of endemism}

To build an updated map of the geographical distribution of Mischonyx species, we used DIVA-GIS to plot the geographical coordinates of the specimens available in the collection of Museu de Zoologia da Universidade de São Paulo (MZSP) and the LAL tissue collection. We also included the type localities and records extracted from Kury (2003). The nomenclature used for the areas of endemism of the Atlantic Rainforest and their delimitation follows Da Silva, Pinto-da-Rocha \& Morrone (2017).

\section{Type specimens and ingroup selection}

We analyzed (see table 1) at least one type specimen from each valid Mischonyx species listed in Kury (2003), except the holotype of Mischonyx squalidus, which has been lost. Type specimens were compared with the harvestmen tissue collection of the Arachnology Lab (Instituto de Biociências - Universidade de São Paulo). Additionally, we collected fresh specimens for DNA extraction. Individuals that resembled Mischonyx species but did not match described species were also included in the analysis. The ingroup used in the phylogenetic analysis is listed in Table 02 .

\section{Outgroup selection}

Besides the ingroup specimens mentioned above, we included in our matrix specimens from different gonyleptid subfamilies, as follows: Caelopyginae Sørensen, 1884, Gonyleptinae, Hernandariinae Sørensen, 1884, Mitobatinae Simon, 1879, Pachylinae Sørensen, 1884, Progonyleptoidellinae Soares \& Soares, 1985, Sodreaninae Soares \& Soares, 1985. Following the exemplar approach to taxon selection, we included up to two species from of these subfamilies. The species used as outgroups are showin in Table 01 . 
185

186

187

188

189

190

191

192

193

194

195

196

197

198

199

200

201

202

203

204

205

206

207

208

209

210

211

212

213

214

215

216

217

218

219

220

221

222

223

224

225

226

227

228

229

230

\section{Molecular data acquisition}

Specimens for the molecular analysis were kept at $92-98 \%$ ethanol and at $-20^{\circ} \mathrm{C}$. Our lab has a database with gene sequences originated from different projects. We used sequences from that source and sequenced the DNA from additional species using muscular tissue from coxa IV (Pinto-da-Rocha et al., 2014). Alternatively, when the individual to be sequenced was small, we used tissues from the chelicerae and pedipalps. We used the kit Agencourt ${ }^{\circledR}$ DNAdvance System (Beckman Coulter, California, EUA) for extractions and modified the protocols according to Pinto-da-Rocha et al. (2014).

From the extracted DNA, we amplified seven molecular loci: the ribosomal nuclear gene 28S rRNA; the ribosomal mitochondrial genes 12S rRNA and 16S rRNA; the nuclear sequences of the internal transcribed spacer subunit 2 (ITS2), carbamoylphosphate synthetase 2 gene (CAD) and the histone $\mathrm{H} 3$ gene (H3); and the mitochondrial cytochrome oxidase subunit I gene (COI). For polymerase chain reactions (PCRs), we used Thermo-fisher Taq kit, following the concentration present in Pinto-da-Rocha et al. (2014).

The primers used to amplify the genes were:

- 28S rRNA: overlap of two primer sets: 28SRDIAF - 28SRD4B (Arango \& Wheeler, 2007 and Edgecombe \& Giribet, 2006, respectively) and 28SD3AP - 28SB (Reyda \& Olson, 2003 and De Ley et al., 1999, respectively);

- 16S rRNA: 16SpotFN - 16SBR (Pinto-da-Rocha et al., 2014 and Palumbi, 1996, respectively);

- 12S rRNA: 12SAIN - 12SOP2RN (Pinto-da-Rocha et al., 2014);

- COI: dgLCO1490 - dgHCO2198 (Meyer 2003). Alternatively, LCO1490 - HCO2198 (Folmer et al., 1994) and LCO1490 - HCOout (Folmer et al., 1994 and Prendini, Weygoldt \& Wheeler, 2005, respectively);

- H3: H3AF - H3AR (Colgan et al., 1998). Alternatively, H3AF_edit (5'GCVMGVAAGTCYACVGGMGG-3') - H3AR_edit (5'-ATGGTSACTCTCTTGGCGTGR-3'), made at the Molecular Systematics Laboratory of IBUSP;

- ITS2: 5.8SF - CAS28Sb1d (Ji, Zhang \& He, 2003);

-CAD: op_cad_F1 -op_cad_R1 (Peres et al., 2018).

We conducted PCR reactions in an Eppendorf Mastercycler ${ }^{\circledR}$ gradient thermal cycler and the cycles and temperature used in this work are the same as in Pinto-da-Rocha et al. (2014). Afterwards, we inspected the PCR products using agarose gel electrophoresis ( $2 \%$ agarose), purified the products using Agencourt Ampure XP (Beckman Coulter) and quantified the products using a Thermo Scientific NanoDrop spectrophotometer. In order to prepare the products for sequencing, we used the BigDye ${ }^{\circledR}$ Terminator v3.1 Cycle Sequencing Kit (Applied Biosystems). The precipitation was with sodium acetate and the sequencing process was in an ABI PRISM® 3100 Genetic Analyser/HITACHI (Applied Biosystems).

We assembled the contiguous sequences using Consed/PhredPhrap package (Ewing \& Green, 1998; Ewing et al., 1998; Gordon, Abajian \& Green, 1998; Gordon, Desmarais \& Green, 2001). We queried the contigs against the online NCBI BLAST database to check for contamination from other external sources. we aligned the sequences using MAFFT (Katoh et al., 2002), visualized, and edited the results in Aliview (Larsson, 2014). We searched for stop

Peer) reviewing PDF | (2020:08:52148:2:0:NEW 1 Jun 2021) 
231 codons in the coding genes (COI, CAD and H3) in Aliview. We trimmed the coding genes

232 sequences to match the first base of the sequences with the first codon position. All sequences

233 are at GenBank and their respective access codes are in Tables 01 and 02.

234

235

236

237

238

239

240

241

242

243

244

245

246

247

248

249

250

251

252

253

254

255

256

257

258

259

260

261

262

263

264

265

266

267

268

269

270

271

272

273

274

275

276

\section{Morphological data acquisition, terminology and new species drawings}

We coded the external morphological characters after analyzing the type material and other individuals of the species when available under a Zeiss Stemi DV4 stereomicroscope. Analyzis of the male genitaliac characters was conducted under a Scanning Electron Microscopy (SEM). We followed the protocol of Pinto-da-Rocha (1997) to dissect and prepare the genitalia for Scanning Electron Microscope (Zeiss DSM940, from Instituto de Biociências, Universidade de São Paulo) and built the character matrix using Mesquite 3.51 (Maddison \& Maddison, 2017). We coded most characters as binary to avoid redundancy and tried to ensure that all characters were independent from each other (Strong \& Lipscomb, 1999). Nonetheless, to avoid building non-comparable characters, in some cases, we used multistate characters and treated them as unordered. The character descriptions follow Sereno (2007). The complete character matrix is available online, at MorphoBank (http://morphobank.org/permalink/?P3599 - for reviewers, the password is Squalidus).

The general terminology follows DaSilva \& Gnaspini (2010). Granules refer to minute elevations, concentrated on a particular region or article. Tubercles are elevations that are clearly distinguishable from granules by their height and width and can have blunt or acuminated apex. Spines are acuminated elevations present on the ocularium. Apophyses, which have different shapes, are the armatures present on coxa IV, free tergites, anterior and posterior margins. The terminology for the shape of the dorsal scutum follows Kury \& Medrano (2016). The terminology for the penial macrosetae follows Kury \& Villareal (2015).

We used a stereomicroscope coupled with a camara lucida to make our drawings. After that, we digitalized them and made corrections on the background using Adobe Photoshop Lightroom $6.0 \circledR$.

\section{Nomenclatural acts and collecting license}

The electronic version of this article in Portable Document Format (PDF) will represent a publication according to the International Commission on Zoological Nomenclature (ICZN), and hence the new names contained in the electronic version are effectively published under that Code from the electronic edition alone. This published work and the nomenclatural acts it contains have been registered in ZooBank, the online registration system for the ICZN. The ZooBank LSIDs (Life Science Identifiers) can be resolved and the associated information can be viewed using any standard web browser by appending the LSID to the prefix http://zoobank.org/. The LSIDs for this publication are: urn:lsid:zoobank.org:act:A6F34641-1AF1-4BE2-A16A4A4497ECA1FC; urn:lsid:zoobank.org:act:3DDE0A87-E9F6-4504-9C54-6DC37D202A0E; urn:1sid:zoobank.org:act:5FA4CC13-EC27-4E3A-AB19-81A97FE74177. The online version of this work is archived and available from the following digital repositories: PeerJ, PubMed Central and CLOCKSS.

Field expeditions and collections were approved by Ministério do Meio Ambiente (MMA), Instituto Chico Mendes de Conservação da Biodiversidade (ICMBio), Sistema de Autorização e Informação em Biodiversidade (SISBIO) (License number: 57281-2).

PeerJ reviewing PDF | (2020:08:52148:2:0:NEW 1 Jun 2021) 
277

278

279

280

281

282

283

284

285

286

287

288

289

290

291

292

293

294

295

296

297

298

299

300

301

302

303

304

305

306

307

308

309

310

311

312

313

314

315

316

317

318

319

320

321

322

\section{Molecular dating}

First, we used only the COI to estimate how long ago Mishconyx diverged from its ancestor. We did this because there are more Gonyleptidae sequences of this gene than any other on GenBank. Only one sequence from each species was included, totaling 122 terminal sequences. To set the priors for the BEAST 2.5 analysis (Bouckaert et al., 2019), we employed the program BEAUti. We used the Beast Model Test to set the site model, a lognormal relaxed clock with substitution rate of 0.005 (according to Bragagnolo et al., 2015 and Peres et al., 2019) with Yule tree and constrained the root using a normal distribution. In this initial analysis three clades were dated: Gonyleptidae, with $\mathrm{T}_{\mathrm{MRCA}} 140 \pm 40$ Mya, based on Sharma \& Giribet (2011); Sodreaninae Kury, 2003 clade (sensu Peres et al., 2019), with $\mathrm{T}_{\mathrm{MRCA}} 31.5 \pm 10$ Mya, based on Peres et al. (2019); Promitobates Rower, 1913, with $\mathrm{T}_{\mathrm{MRCA}} 58.5 \pm 3.9 \mathrm{Mya}$, based on Bragagnolo et al. (2015). We then ran two independent analyses, with 10 million generations each, sampling trees every 10,000 generations. Both analyses were verified in TRACER 1.7 (Rambaut et al., 2018) and checked for EES $>200$. The results were combined in

\section{LOGCOMBINER 2.5.}

Next, we applied the $\mathrm{T}_{\mathrm{MRCA}}$ estimated for Mischonyx to calibrate the multilocus species tree using *BEAST, with the seven genes cited above and the terminals from Table 02, also using BEAST 2.5. We pruned the dataset to one sequence per haplotype per species, used all the priors from the first step and performed two independent analyses with 100 million generations, sampling trees each 5,000 generations. The output from the analyses was checked using Tracer 1.7 and combined trees using LOGCOMBINER 2.5. The maximum clade credibility was annotated and the first 10\% was discarded, using TREEANNOTATOR 2.5. The final tree was analyzed using FigTree 1.4.4 (Rambaut, 2010).

\section{Phylogenetic inferences}

Three separate analyses were carried as follows: 1) morphological data alone, 2) molecular data alone; and 3) combined molecular and morphological matrixes (Total Evidence Analysis). Each matrix was analyzed using Maximum parsimony (MP) and maximum likelihood (ML). In all analyses, we used Promitobates ornatus Mello-Leitão, 1922 to root our trees because its is consisisten with Pinto-da-Rocha et al. (2012) phylogeny, in which this species is the furthest from Mischonyx clade, when compared to the other species used as outgroups in our research.

\section{Bayesian inference}

In the morphological analysis, we activated the morph-models package on BEAUti 2.5 and imported the matrix, with the option "add MK morphological data" while importing. The Lewis MK was chosen as the substitution model, and the relaxed log normal clock and fossilized birth and death model were chosen as the tree prior.

For analysis using strictly molecular data, the trees for all genes were linked. The Beast Model Test was selected for calculations of the best model for each gene, estimating the mutation rate. The relaxed log normal clock, with the estimates of clock rate for each gene, followed Bragagnolo et al. (2015) and Peres et al. (2019). The selected tree model was the Birth and Death model was. 
The same parameters used for the molecular data analysis were used in the total evidence (TE). We chose Fossilized Birth and Death Model as the tree prior, with 0.05 as the starting value for the tree diversification rate, with estimation of Rho parameter. To estimate the morphological and molecular clock rates we chose the LogNormal distribution.

All Bayesian analyses were carried out on BEAST 2.5, performing two independent analyses, with 100 million generations each, sampling trees every 10,000 generations. We checked the output from the analyses, using Tracer 1.7, checked for EES $>200$ and combined trees using LOGCOMBINER 2.5. The maximum clade credibility was annotated and the first $10 \%$ was discarded, using TREEANNOTATOR 2.5 . The final tree was analyzed using FigTree 1.4.4 (Rambaut, 2010).

Maximum likelihood. For morphological analysis (ML1), we inserted the dataset as input in the IQ-TREE version 1.6.10 (Nguyen et. al., 2015), using the best model found by the program, which uses BIC (Bayesian information criterion) (Schwarz, 1978) to analyze which model is the best for that specific dataset. The analysis displayed by the program is the same described for the molecular data below. To analyze character changes, we inserted the phylogeny output from IQ-TREE on YBIRÁ (Machado, 2015)).

The DNA sequences were aligned in MAFFT and analyzed with Aliview. The FASTA file contained all the sequences concatenated using SequenceMatrix 1.8 (Vaidya, Lohman \& Meier, 2011). The analysis was carried out in IQ-TREE version 1.6.10 (Nguyen et. al., 2015). All the partitions coming from the seven different genes present in the concatenated FASTA file (and the morphological dataset for TE) were first analyzed on IQ-TREE through the partition model (Chernomor, von Haeseler \& Minh, 2016), using the "-spp" command. The program selected the best substitution model for each gene partition under the BIC (Schwarz, 1978), using the program ModelFinder (Kalyaanamoorthy et al., 2017), through the command "-m TESTNEWMERGE". Maximum Likelihood analysis was based on 10,000 search iterations, using the command "-s -n 10000". Confidence was measured using bootstrap analysis based on 1,000 iterations of ultrafast bootstrap using the command "-bb 1000" (Minh et al., 2013). The output was analyzed using FigTree 1.4.4 (Rambaut, 2010). We used the parsimony method to analyze character changes because, as pointed by Cheng \& Kuntner (2014), the aim is to "understand the evolutionary changes of characters rather than the probability of particular ancestral states on the phylogeny".

Maximum parsimony. The morphological analysis (MP1) was carried out using TNT (Goloboff, Farris \& Nixon, 2008). The search was heuristic with TBR branch-swapping (10,000 replicates) while retaining 100 trees per replicate. The command "collapse branches after search" was used to eliminate non-supported nodes, and searches using Ratchet (Nixon, 1999) and Tree Fusing (Goloboff, 1999). The characters were treated as unordered and unweighted. To analyze character changes throughout the phylogeny, we used Winclada 1.61.

The molecular (MP2) and TE (MP3) analyses were implemented using the program POY 5.1.1 (Varón, Vinh \& Wheeler, 2010), which searches using direct optimization (hereafter DO) of unaligned sequences (Wheeler, 1996), a strategy referred as Dynamic Homology (Wheeler $2001 \mathrm{a}, \mathrm{b})$. This strategy differs from the traditional static homology search in that the former integrates both alignment and tree searches, while the last treats them as two separated searches. DO is able to test dynamically, in a static matrix, the hypotheses of homology among unaligned 
369 nucleotides, optimizing these sequences directly on the available trees and, concomitantly, 370 converting the transformation series of pre-aligned sequences (Kluge \& Grant, 2006; Grant \& 371 Kluge, 2009; Sánchez-Pacheco et al., 2017).

372

373

374

375

376

377

378

379

380

381

382

383

384

385

386

387

388

389

390

391

392

393

394

395

396

397

398

399

400

401

402

403

404

405

406

407

408

409

410

411

412

413

An exploratory DO analysis was carried out five times, specifying search time (from two to ten hours, totaling 30 hours of search), to check which one yielded the lowest tree scores as outputs and, consequently, the optimal search time for DO ("max time" parameter). The best tree scores for our dataset were obtained with a maximum search time of $2 \mathrm{~h}$. After that the dataset was analyzed treating $\mathrm{H} 3, \mathrm{COI}$ and $\mathrm{CAD}$ sequences as pre-aligned, because they are coding genes, and 28S, 12S, 16S and ITS to be aligned using dynamic homology methods ("transform" command in POY). The program performed five rounds of searches using the "max_time" (with "search" command). In POY each "search" round implements Tree Bisection and Reconnection (TBR), Wagner tree building, Subtree Pruning and Regrafting (SPR), Branch Swapping (RAS+swapping, as in Goloboff, 1999), Tree fusing (Goloboff, 1999) and Parsimony Ratchet (Nixon, 1999). We used the final trees from this previous analysis in an exact iterative pass (IP) analysis (Wheeler, 2003). Costs for all the previous optimal trees were calculated and POY generated the implied alignment of this final analysis (Wheeler, 2003). TNT 1.5 (Goloboff $\&$ Catalano, 2016) was used to calculate Bootstrap values and Bremer support, with "hold" command of 10000000 trees, "mult" command of 1000 replicates, holding 10 trees per replicate. Finally, we analyzed the character changes over the optimal tree using parsimony on Winclada 1.61.

\section{Results}

\section{Molecular data and maximum likelihood models}

In total, 54 individuals of Mischonyx species were sequenced in this work, encompassing almost all species with two exceptions: Urodiabunus arlei and Mischonyx scaber. The following fragments were sequenced: 28S (972 bp), 16S (386 bp), 12S (408 bp), CAD (639 bp), COI (570 bp), H3 (309 bp) and ITS (456 bp), totaling 3742 bp for all sequences. Collectivelly, we were able to sequence $88 \%$ of the fragments of the 54 exemplar specimens. In this analysis we only included terminal taxa for which we were able to obtain at least five out of the seven sequenced fragments (see Table 2).

The best evolutionary model found under BIC for morphological data was MK+FQ+G4. For 12S rRNA, 16S rRNA, 28S rRNA, CAD, COI, H3 and ITS2, the best models are, respectively, $\mathrm{TIM} 3+\mathrm{F}+\mathrm{I}+\mathrm{G} 4, \mathrm{TMP} 2 \mathrm{u}+\mathrm{F}+\mathrm{I}+\mathrm{G} 4, \mathrm{TN}+\mathrm{F}+\mathrm{I}$, JTDDCMut+G4, mtMAM+I+G4, DCMut and TIM2+F+I+G4.

\section{Morphological data}

The morphological matrix totals 128 characters, some of which were taken from the literature and are distributed as follows: 45 characters from the dorsal scutum, 44 characters from the appendages, 6 characters from free tergites, 27 characters from the male genitalia and two characters from the general habitus.

414

List of Morphological Characters and States 
415 1. Dorsal scutum, shape (males) (Kury \& Medrano, 2016): 0, Gamma P; 1, Gamma R; 2,

416 Gamma; 3, Gamma T; 4, Non-Gamma;

417 2. Dorsal scutum, shape (females) (Kury \& Medrano, 2016): 0, Alfa; 1, Gamma; 2, Gamma T; 3,

418 Gamma P; 4, Non-Gamma;

419 3. Pedipalp, length: 0, Short (shorter than the dorsal scutum); 1, Long (longer than the dorsal

420

421

422

423

424

425

426

427

428

429

430

431

432

433

434

435

436

437

438

439

440

441

442

443

444

445

446

447

448

449

450

451

452

453

454

455

456

457

458

459

460

4. Pedipalp, tibia and tarsus, thickness: 0 , Same thickness of femur; 1 , Clearly more expanded than femur;

5. Dorsal scutum, anterior margin, lateral tubercles (Mendes, 2011): 0, Absence; 1, Presence;

6. Dorsal scutum, anterior margin, lateral tubercles, number: 0, Three on each lateral; 1, Two on each lateral; 2, Four or more on each lateral;

7. Dorsal scutum, anterior margin, lateral tubercles, size: 0 , All tubercles with the same size; 1 , One of the tubercles clearly more developed than the others;

8. Dorsal scutum, frontal hump, elevation: 0 , Low (smaller than the ocularium height, without considering the median armature); 1, Elevated (bigger than the ocularium height, without considering the median armature) (Figs. $01-09$ );

9. Dorsal scutum, frontal hump, tubercles: 0 , Absent; 1 , Present;

10. Dorsal scutum, frontal hump, tubercles, number: 0 , One (single armature); 1, Two (one pair) (Fig. 04C); 2, Four (2 pairs);

11. Dorsal scutum, number of areas: 0 , Three; 1 , Four;

12. Dorsal scutum, ocularium, median armature: 0 , Absent; 1 , Present;

13. Dorsal scutum, ocularium, median armature, number: 0, One; 1, Two (one pair) (Figs. $01-$ 09); 2, Three pairs;

14. Dorsal scutum, ocularium, median armature, size: 0 , Tubercle (smaller than the ocularium height) (Fig. 01D); 1, Spine (longer than the ocularium height) (Fig. 04C);

15. Dorsal scutum, ocularium, median armature, merge: 0, Not merged (Figs. 01 - 09); 1, Apex merged;

16. Dorsal scutum, ocularium, anterior granule: 0, Absent (Fig. 07D); 1, Present (Fig. 01C);

17. Dorsal scutum, ocularium, posterior granulation: 0, Absent (Fig. 02D); 1, Present (Fig. 03C);

18. Dorsal scutum, prosoma, lateral granulation: 0, Absent 1, Present (Fig. 01A);

19. Dorsal scutum, prosoma, posterior armature: 0 , Absent; 1 , Present;

20. Dorsal scutum, prosoma, posterior armature, number: 0, Pair of tubercles (Figs. $01-09$ ); 1, Several tubercles;

21. Dorsal scutum, mid-bulge, lateral margin, armature: 0 , Absent; 1, Present;

22. Dorsal scutum, mid-bulge, lateral margin, armature distribution: 0 , Present in the whole extension (Fig. 02B); 1, Present on the posterior half only (Fig. 03B);

23. Dorsal scutum, mid-bulge, lateral margin, armature, size: 0, Large tubercles (Fig. 09A); 1, Small tubercles (Fig. 02C);

24. Dorsal scutum, mid-bulge, lateral margin, armature, shape: 0, Rounded (Figs. 01 - 09); 1, Pointed;

25. Dorsal scutum, mid-bulge, lateral margin, armature, color (in ethanol): 0 , Clearer than the rest of the body (Fig. 09A); 1, Darker than the rest of the body (Fig. 07A); 2, Same color of the rest of the body (Fig. 01B);

26. Dorsal scutum, mid-bulge, lateral margin, posterior armature, merge: 0 , Merged, forming large tubercles (Fig. 09A); 1, Not merged (Fig. 02B);

27. Dorsal scutum, area I, longitudinal groove: 0 , Absent; 1, Present;

Peerj reviewing PDF | (2020:08:52148:2:0:NEW 1 Jun 2021) 
461 28. Dorsal scutum, area I, paired median armature: 0, Absent; 1, Present;

462

463

464

465

466

467

468

469

470

471

472

473

474

475

476

477

478

479

480

481

482

483

484

485

486

487

488

489

490

491

492

493

494

495

496

497

498

499

500

501

502

503

504

505

506

29. Dorsal scutum, area I, paired median armature, size: 0, Small tubercles (Fig. 02B); 1, Conspicuous tubercles (Fig. 01B);

30. Dorsal scutum, area I, paired median armature, color (in ethanol): 0, Clearer than the rest of the body (Fig. 01B); 1, Darker than the rest of the body (Fig. 01A); 2, Same color of the rest of the body;

31. Dorsal scutum, area I, paired median armature, length in comparison to median armatures of area III: 0, Larger than the median armatures from area III (Fig. 01B); 1, Smaller than the median armatures from area III (Fig. 01A); 2, Same size of the median armatures from area III;

32. Dorsal scutum, area II, paired median armature: 0, Absent; 1, Present;

33. Dorsal scutum, area II, lateral tubercle: 0, Absent (Fig. 06B); 1, Present (Fig. 03A);

34. Dorsal scutum, area II, paired median armature, color (in ethanol): 0, Paler than the rest of the body (Fig. 05A); 1, Darker than the rest of the body (Fig. 04A); 2, Same color of the rest of the body;

35. Dorsal scutum, area II, paired median armature, size in comparison to median armatures of area III: 0, Larger than the median armatures from area III (Fig. 05A); 1, Smaller than the median armatures from area III (Fig. 04A); 2, Same size of the median armatures from area III;

36. Dorsal scutum, area III, armature: 0, Absent; 1, Present;

37. Dorsal scutum, area III, median armature, number: 0, One pair; 1, Single;

38. Dorsal scutum, area III, paired median armature, color (in ethanol): 0, Paler than the rest of the body (Fig. 06A); 1, Darker than the rest of the body (Fig. 05B); 2, Same color of the rest of the body;

39. Dorsal scutum, area III, paired median armature, form: 0, Rounded; 1, Elliptic (Fig. 05B); 2, Sharp (Fig. 01D);

40. Dorsal scutum, area III, elliptic paired median armature: 0, Slightly compressed laterally (Fig. 05B); 1, Strongly compressed laterally (Fig. 09A);

41. Dorsal scutum, area III, lateral tubercles: 0, Absent; 1, Present (Fig. 09A);

42. Dorsal scutum, area III, lateral armature, size: 0, Small tubercles (Fig. 03A); 1, Welldeveloped tubercles (Fig. 09A);

43. Dorsal scutum, area III, lateral armature, color (in ethanol): 0, Clearer than the rest of the body (Fig. 06B); 1, Darker than the rest of the body (Fig. 09A); 2, Same color of the rest of the body (Fig. 01B);

44. Dorsal scutum, area III, lateral armature, form: 0, Rounded (Fig. 03A); 1, Elliptic (Fig. 05B);

45. Dorsal scutum, posterior margin, armature: 0, Absent; 1, Present;

46. Dorsal scutum, posterior margin, armature, size: 0, Small tubercles (Fig. 01A); 1, Presence of central tubercle more developed or apophysis (Fig. 09B); 2, All tubercles well-developed;

47. Dorsal scutum, granulation, density (DaSilva \& Pinto-da-Rocha, 2010): 0, Low (scattered granules, some regions of dorsal scute smooth); 1, Median (granules scattered throughout dorsal scute); 2, High;

48. Free tergite I, armature: 0, Absent; 1, Present;

49. Free tergite I, armature, size: 0, Small tubercles (Fig. 01A); 1, Presence of central tubercle more developed or apophysis (Fig. 09B); 2, All tubercles well-developed;

50. Free tergite II, armature: 0, Absent; 1, Present;

51. Free tergite II, armature, size: 0, Small tubercles (Fig. 01A); 1, Presence of central tubercle

Peer) reviewing PDF | (2020:08:52148:2:0:NEW 1 Jun 2021) 
507

508

509

510

511

512

513

514

515

516

517

518

519

520

521

522

523

524

525

526

527

528

529

530

531

532

533

534

535

536

537

538

539

540

541

542

543

544

545

546

547

548

549

550

551

552

more developed or apophysis (Fig. 06B); 2, All tubercles well-developed;

52. Free tergite III, armature: 0 , Absent; 1, Present;

53. Free tergite III, armature, size: 0, Small tubercles (Fig. 01A); 1, Presence of central tubercle more developed or apophysis (Fig. 06B); 2, All tubercles well-developed;

54. Leg II, basitarsus, segmentation, number: 0, Six; 1, Seven; 2, Eight; 3, Nine; 4, more than nine;

55. Leg III, trochanter, armature: 0, Absent; 1, Present;

56. Leg III, trochanter, armature, type: 0 , Trochanter with many tubercles; 1 , Trochanter with a prolateral basal apophysis;

57. Leg IV, coxa, apical width of males in ventral view (compared to coxa III) (modified from Benedetti \& Pinto-da-Rocha, 2019): 0, Coxae III and IV with the same width; 1, Coxa IV 2 times larger than coxa III; 2, Coxa IV 4 times larger than coxa III;

58. Leg IV, coxa, apical prolateral apophysis on males: 0, Absent; 1, Present;

59. Leg IV, coxa, apical prolateral apophysis, length (compared to trochanter IV) (modified from Benedetti \& Pinto-da-Rocha, 2019): 0, Shorter than trochanter IV (Fig. 03B); 1, Similar size of trochanter IV (Fig. 03A); 2, Longer than trochanter IV; 3, Much smaller than trochanter IV (as a tubercle);

60. Leg IV, coxa, apical prolateral apophysis, basal tubercle: 0, Absent; 1, Present (Fig. 02B);

61. Leg IV, coxa, apical prolateral apophysis, secondary subdistal lobe (Benedetti \& Pinto-daRocha, 2019): 0, Absent; 1, Present (Fig. 04A);

62. Leg IV, coxa, apical prolateral apophysis, direction in dorsal view (Benedetti \& Pinto-daRocha, 2019): 0, Slightly inclined relative to the axis of the base of coxa IV (Fig. 04A); 1, Transversal; 2, Oblique (Fig. 03B);

63. Leg IV, coxa, apical prolateral apophysis, apex width (modified from Benedetti \& Pinto-daRocha, 2019): 0, Base more than 4 times larger than the apex (Fig. 02B); 1, Base 2 times larger than the apex (Fig. 09B); 2, Base as large as the apex; 64. Leg IV, coxa, apical prolateral apophysis, thickness: 0, Robust (Fig. 05B); 1, Sharp (Fig. 05A);

65. Leg IV, coxa, apical prolateral apophysis in females (Benedetti \& Pinto-da-Rocha, 2019): 0, Absent; 1, Smaller than the male;

66. Leg IV, coxa, apical retrolateral apophysis in males (Benedetti \& Pinto-da-Rocha, 2019): 0, Absent; 1, Present (Fig. 08B);

67. Leg IV, coxa, apical retrolateral apophysis, size (Benedetti \& Pinto-da-Rocha, 2019): 0, Tubercle; 1, Apophysis;

68. Leg IV, coxa, apical retrolateral apophysis, number of branches: 0, One; 1, Two;

69. Leg IV, trochanter, prolateral armature in males: 0, Absent; 1, Present;

70. Leg IV, trochanter, retrolateral apical armature: 0, Absent; 1, Present;

71. Leg IV, trochanter, retrolateral apical armature, size: 0, Tubercle; 1, Apophysis (Fig. 01B);

72. Leg IV, trochanter, retrolateral armature, number: 0, One (Fig. 04B); 1, Two (Fig. 07B); 2 , Three (forming a line);

73. Leg IV, femur, thickness: 0, Short and robust (Fig. 05B); 1, Long and thin (Fig. 03B);

74. Leg IV, femur, prolateral curvature: 0, Straight (not curved) (Fig. 03B); 1, Curved (Fig. 06B);

75. Leg IV, femur, retrolateral basal apophysis: 0, Absent; 1, Present (Fig. 02D);

76. Leg IV, femur, dorso-basal apophysis (DBA) (Benedetti \& Pinto-da-Rocha, 2019): 0, Absent; 1, Present (Fig. 02D);

77. Leg IV, femur, dorso-basal apophysis, size: 0, Small (Fig. 08D); 1, large (longer than larger)

Peer) reviewing PDF | (2020:08:52148:2:0:NEW 1 Jun 2021) 
553

554

555

556

557

558

559

560

561

562

563

564

565

566

567

568

569

570

571

572

573

574

575

576

577

578

579

580

581

582

583

584

585

586

587

588

589

590

591

592

593

594

595

596

597

598

(Fig. 02D); 2, Very small (Tubercle) (Fig. 01D);

78. Leg IV, femur, dorso-basal apophysis, apex direction: 0, Apex anteriorly directed (Fig. 09B); 1, Apex dorsally directed (Fig. 05D); 2, Apex retrolaterally directed (Fig. 06B); 3, Apex prolaterally directed;

79. Leg IV, femur, dorso-basal apophysis, apex width: 0 , Base more than 4 times wider than apex (Fig. 02D); 1, Base 2 times wider than apex (Fig. 09B); 2, Base as wide as apex (Fig. 08D);

80. Leg IV, femur, dorso-basal apophysis, shape: 0, Digitiform (Fig. 06C); 1, Falciform (Fig. 07D); 2, Blunt; 3, Branched (Fig. 09B); 4, Conic (Fig. 02D);

81. Leg IV, femur, branched dorso-basal apophysis, larger branch: 0, Retrolateral (Fig. 06B); 1, Dorsal (Fig. 04C);

82. Leg IV, femur, prolateral row of tubercles in males: 0, Absent; 1, Present;

83. Leg IV, femur, prolateral row of tubercles, development: 0, Equally developed (Fig. 09A); 1, Median larger (Fig. 06B); 2, Apical larger (Fig. 06A);

84. Leg IV, femur, prolateral row of tubercles, single apical apophysis: 0, Absent; 1, Present (Fig. 03B);

85. Leg IV, femur, dorsal row of tubercles: 0, Absent (dorsally smooth) (Fig. 03D); 1, Present (Fig. 02C);

86. Leg IV, femur, dorsal row of tubercles, apophysis after DBA: 0, Absent (Fig. 02D); 1, Present (Fig. 02C);

87. Leg IV, femur, dorsal row of tubercles, apophysis after DBA, number: 0, One (Fig. 05D); 1, Two (Fig. 04C); 2, Three - Six (Fig. 02C); 3, More than six;

88. Leg IV, femur, row of tubercles between the dorsal and retrolateral lines: 0, Absent; 1 , Present;

89. Leg IV, femur, retrolateral row of tubercles: 0, Absent; 1, Present;

90. Leg IV, femur, retrolateral row of tubercles, position of the larger apophysis: 0, Basal third; 1, Medial third (Fig. 09A); 2, Apical Third (Fig. 05B);

91. Leg IV, femur, retrolateral row of tubercles, number of apophysis on the basal half: 0 , Absence of apophysis on the basal half) (Fig. 03B); 1, One (Fig. 03A); 2, Two (Fig. 04A); 3, Three - Six (Fig. 06A); 4, More than 6;

92. Leg IV, femur, retrolateral row of tubercles, median apophysis: 0, Absent (Fig. 06B); 1, Present (Fig. 04A);

93. Leg IV, femur, retrolateral row of tubercles, number of apophysis on the apical half: 0 , Absence of apophysis on the apical half; 1, One (Fig. 07D); 2, Two (Fig. 01A); 3, Three Six (Fig 03B); 4, More than 6;

94. Leg IV, femur, retrolateral row of tubercles, more developed apical tubercle: 0, Absent; 1 , Present (Fig. 01B);

95. General body color (in ethanol): 0, Brownish; 1, Black; 2, Yellowish; 3, Reddish;

96. Body totally or partially covered with debris (DaSilva \& Pinto-da-Rocha, 2010): 0, Absent; 1, Present;

97. Penis, ventral plate, form in lateral view: 0, Globose (Fig. 10E); 1, Thin (Fig. 11E);

98. Penis, ventral plate, form in dorsal view: 0, Longer than larger (thin) (Fig. 11D); 1, Larger than longer (developed lateral expansions) (Fig. 11A);

99. Penis, ventral plate, ventral side, T1 microsetae: 0 , Absent; 1, Present;

100. Penis, ventral plate, ventral side, T1 microsetae, distribution: 0, Sparse or present in some regions (Fig. 10F); 1, Presence in the whole extension (Fig. 12C); 
599 101. Penis, ventral plate, ventral side, medio-apical excavation: 0, Absent; 1, Present;

600 102. Penis, ventral plate, ventral side, degree of the medio-apical excavation: 0, Slightly

$601 \quad$ excavated (Fig. 10C and 10I); 1, Very excavated (Fig. 12F);

602 103. Penis, ventral plate, apical cleft (Kury, 1992): 0, Absent; 1, Present;

603 104. Penis, ventral plate, apical cleft, depth: 0, Shallow (in dorsal view, reaches at most the line

604 of the first MS C) (Fig. 11D); 1, Deep (in dorsal view it is more basal than the MS C) (Fig.

$605 \quad 13 \mathrm{G})$;

606

607

608

105. Penis, ventral plate, apical cleft, format: 0, Edges slightly sloped (Fig. 13A); 1, Edges very sloped (Fig. 13G);

106. Penis, ventral plate, Macrosetae C (MS C), number: 0, Two; 1, Three (Fig. 11D); 2, Four;

609 107. Penis, ventral plate, Macrosetae C (MS C), shape: 0, Straight; 1, Helicoidal (Fig. 10G); 2,

$610 \quad$ Curved (Fig. 11D);

611

612

613

614

615

616

617

618

619

620

108. Penis, ventral plate, Macrosetae C (MS C), position: 0, Distal (Fig. 13A); 1, Sub-distal (Fig. 11D);

109. Penis, ventral plate, Macrosetae A (MS A), number: 0, Two (Fig. 12D); 1, Three (Fig. 14G); 2, Four (Fig. 13A);

110. Penis, ventral plate, Macrosetae A (MS A), position on the ventral plate: 0, Linear in dorsoventral direction (Fig. 10A); 1, Triangle shaped (Fig. 12D); 2, Parable shaped (Fig. 10H); 3, Linear in baso-apical direction;

111. Penis, ventral plate, Macrosetae B (MS B), size: 0, Small (clearly smaller than the MS A) (Fig. 14B); 1, Large (same size of the MS A) (Fig 14G);

621

622

112. Penis, ventral plate, Macrosetae D (MS D): 0, Absent (Fig. 12E); 1, Present (Fig. 13H);

113. Penis, ventral plate, Macrosetae D (MS D), number: 0, One (Fig. 13H); 1, Two; 2, Three;

114. Penis, ventral plate, Macrosetae D (MS D), size: 0, Small (Fig. 13H); 1, Large (Fig. 14B);

623

624

115. Penis, ventral plate, Macrosetae D (MS D), position in lateral view: 0, Ventral to the MS C (Fig. 10A); 1, Dorsal to the MS C;

625

626

116. Penis, ventral plate, Macrosetae E (MS E): 0, Absent; 1, Present;

117. Penis, ventral plate, Macrosetae E (MS E), number: 0, One; 1, Two;

627

628

629

118. Penis, ventral plate, Macrosetae E (MS E), position of the most basal MS E: 0, Ventral and aligned to the MS C (Fig. 11B); 1, Ventral and medial to the MS C (Fig. 13H);

630

631

632

119. Penis, ventral plate, well-developed lateral lobes (modified from Kury, 1992): 0, Absent (Fig. 11D); 1, Present (Fig. 11A);

120. Penis, ventral plate, lateral lobes, position: 0, Medial (Fig. 11A); 1, Basal (Fig. 11D);

633

121. Penis, ventral process: 0, Absent; 1 , Present;

634 123. Penis, ventral process, flabellum, shape: 0, As long as large (Fig. 12A); 1, Longer than wide

635

636

637

638

639 (thin) (Fig. 12D);

124. Penis, ventral process, flabellum, lateral parts: 0, Serrated (Fig. 10A); 1, Smooth (Fig. 13G);

125. Penis, ventral process, flabellum, apex: 0 , Without a longer central terminal; 1 , With a longer central terminal (Fig. 10H);

640

641

642

643

644

126. Penis, stylus, apex, microsetae: 0, Absent (Fig. 13D); 1, Present (Fig. 12B);

127. Penis, stylus, apex, format: 0 , Inclined relative to the penis axis; 1 , Straight;

128. Penis, stylus, apex, keel: 0 , Absent; 1 , Present.

\section{Geographical Distribution and Areas of Endemism}


645

646

647

648

649

650

651

652

653

654

655

656

657

658

659

660

661

662

663

664

665

666

667

668

669

670

671

672

673

674

675

676

677

678

679

680

681

682

683

684

685

686

687

688

689
The geographical distribution of all Mischonyx species is depicted in Figures 15, S1 and S2. All species occur only in Brazil, from the state of Santa Catarina to the state of Espirito Santo, throughout the Atlantic Forest and in two in Cerrado areas (e.g., Minas Gerais and Mato Grosso do Sul). The species that occur in Cerrado areas are M. intermedius and M. squalidus. In general, all species are restricted to a narrow range, with the exception of M. anomalus, which occurs in the entire state of Paraná, and M. squalidus, which is widespread where other species of the genus occur and also in areas where no other species are present, for example the state of Espírito Santo. M. squalidus is synanthropic (Mestre \& Pinto-da-Rocha, 2004) and can be found in degraded areas where Pinus is grown, in pasture areas and even in cities.

Regarding the Areas of Endemism (AoE) proposed by Da Silva, Pinto-da-Rocha \& Morrone (2017), most species are endemic/restricted to one AoE. The only exception is $M$. squalidus. Mischonyx reitzi comb. nov. and M. clavifemur comb. nov. are restricted to SC AoE; M. anomalus is restricted to PR AoE; M. intervalensis sp. nov. is restricted to SSP; M. insulanus and M. kaisara are restricted to SMSP; M. processigerus is restricted to Boc; M. fidelis, $M$. scaber and $M$. parvus comb. nov. are restricted to LSRJ; M. arlei comb. nov., M. spinifrons comb. nov., M. minimus sp. nov., M. tinguaensis sp. nov. and $M$. poeta are restricted to Org. Clearly, the AoE with more endemic species is Org. The locality of each species, plotted on the map of Figures 15, S1 and S2, are in different colors, each representing one different AoE.

\section{Phylogenetic analyses}

\section{Morphological analyses}

In all analyses using morphological data alone, under the maximum likelihood (hereon ML1, fig. S3), under Bayesian (hereon B1, fig. S4) and under maximum parsimony (heron MP1, fig. S5) criteria, the first lineage branching off inside the Mischonyx clade is composed of $M$. arlei comb. nov., $M$. minimus sp. nov. and $M$. intermedius, followed by the divergence of $G$. antiquus (former Mischonyx antiquus, before this work). The only difference is that, in B1, Multumbo species are in a clade with M. intermedius, M. minimus and M. arlei. Moreover, all analyses recover the clade formed by $M$. anomalus, $M$. clavifemur comb. nov. and $M$. reitzi comb. nov., consistent with the results of the molecular and TE analyses (Figs. 16 - 18 and S6 $\mathrm{S} 12)$. B1 is the only analysis that places both Multumbo species within the Mischonyx clade. The results of ML1 and MP1 agree with our TE results (see below). All analyses were weakly supported by Bootstrap. The bootstrap values obtained for the Mischonyx clade is 25 in ML1 and 7 in MP1. All internal branches inside the genus have values below 50 in both analyses (Figs. S3 and S5). In B1, the posterior probability of the Mischonyx clade was 0.872 and most nodes inside the genus have posterior probabilities lower than 0.6 .

\section{Molecular analyses}

In all analyses using molecular data alone, Mischonyx is monophyletic if G. antiquus (former Mischonyx antiquus) is removed from the genus: under maximum likelihood (hereon ML2, fig. S6), Bayesian (hereon B2, fig. S7) and maximum parsimony (hereon MP2, fig. S8). However, in MP2, there is a clade formed by Deltaspidium and Multumbo species, which is inside the clade that holds all the other Mischonyx species. These other genera are inside the clade with species from SMSP, SSP, PR and SC AoE. This group is sister to another clade with the remaining species of Mischonyx, which are from Boc, Esp, LSRJ and Org AoE.

Peer) reviewing PDF | (2020:08:52148:2:0:NEW 1 Jun 2021) 
690

691

692

693

694

695

696

697

698

699

700

701

702

703

704

705

706

707

708

709

710

711

712

713

714

715

716

717

718

719

720

721

722

723

724

725

726

727

728

729

730

731

732

733

734

735

ML2 and B2 differ from MP2 in that the species of Deltaspidium and Multumbo are recovered inside the clade with all Mischonyx species. The only difference between ML2 and B2 is the position of M. poeta. While in ML2 this lineage is basal in the clade with species from Org and LSRJ, in B1 it is sister to M. spinifrons comb. nov. Besides this difference, the main relationships inside Mischonyx are the same as found in MP2: a clade with species from SMSP, SSP, PR and SC AoE sister to the lineage with species from Boc, Esp, LSRJ and Org AoE.

The support values were high in all three analyses: Bootstrap (in ML2 and MP2), Bremer (in MP2) and posterior probability (in B2). The bootstrap value for the Mischonyx clade in ML2 was 92 and in MP2 it was100. In MP2, the node with the lowest bootstrap value is the one holding Deltaspidium, Multumbo and some Mischonyx species (cited above). In ML2, the lowest value inside the Mischonyx clade is 67 (Figs. S6 and S8). All posterior probabilities inside the genus are higher than 0.9, except for two nodes, which have values above 0.6.

\section{Molecular dating}

The Bayesian analysis (henceforward abbreviated as BM, fig. 16) generally corroborates the topologies obtained from the other molecular analyses, except for the position of M. poeta. While in the results of BM this species is sister to M. spinifrons comb. nov., in ML2 it is sister to a larger clade that includes $M$. spinifrons comb. nov., M. fidelis, M. parvus comb. nov. and $M$. squalidus. The more inclusive clades have the same composition and same relationships in BM and ML2: one clade including the species from LSRJ, Boc, Org and SEsp AoE and another with species from SMSP, SSP, PR and SC AoE. The main divergence time of the Mischonyx clade occurred at 50.53 Mya (95\% HPD = 44.07 - 57.12), when the two speciose clades split. The first split time inside these two clades is very similar: 48.94 Mya $(95 \% \mathrm{HPD}=39.65-54.60)$, for the one holding species from SMSP, SSP, PR and SC AoE and 44.80 (95\% HPD = 35.57 - 52.32) for the other clade. Within the former clade, the lineage containing species in the SSP, PR and $\mathrm{SC}$ areas of endemism formed approximately at $28 \mathrm{Mya}$. The main divergence time after the divergence of $M$. intermedius from the remaining species of the clade occurred at $34.24 \mathrm{Mya}$ $(95 \%$ HPD $=27.07-41.38)$.

\section{Total Evidence analyses}

All TE analyses, under maximum likelihood (hereon ML3, figs. 17), Bayesian (hereon B3, figs. 18B, S9 and S10) and maximum parsimony (heron MP3, fig. 18A, S11 and S12), yielded very similar results. G. antiquus (former Mischonyx antiquus) is placed outside Mischonyx. Inside Mischonyx, there are two major clades. One contains species of SMSP AoE, as sister to the clade containing species from SSP, PR and SC AoE. The other, with a clade holding $M$. intermedius as sister to $M$. arlei comb. nov. and M. minimus sp. nov. and this lineage as sister to the clade which contains species from Boc, LSRJ and Org AoE. Inside this last clade, there are some differences among the analyses. In MP3, the species from LSRJ + M. squalidus form a clade sister to species from Org (excepting $M$. arlei comb. nov. and M. minimus sp. nov. which have already diverged). In ML3, two species from Org (M. poeta and M. scaber) branches off in a clade, followed by $M$. spinifrons comb. nov., which is sister to the lineage containing the species from LSRJ + M. squalidus. In B3, there are two clades with these species: M. poeta $+M$. spiniforns comb.nov. and the other with LSRJ species, M. scaber and M. tinguaensis sp. nov. MP3 and ML3 have bootstrap values over 50 for inner branches inside Mischonyx. Bootstrap 
736

737

738

739

740

741

742

743

744

745

746

747

748

749

750

751

752

753

754

755

756

757

758

759

760

761

762

763

764

765

766

767

768

769

770

771

772

773

774

775

776

777

778

779

780

781

values for Mischonyx node are 89 in ML3 and 81 in MP3. Bremer support in MP3 for Mischonyx clade is 4 (Fig. 18A). Posterior probabilities inside the genus are higher than 0.6 and Mischonyx clade posterior probability is 0.971 (Fig. 18B).

Henceforward, we are going to consider ML3 as our working phylogeny to present the further results regarding character state changes and to discuss relationships and character evolution.

\section{Character changes through ML3}

In ML3, Mischonyx is supported by the following character changes: Lateral tubercles on anterior margin of dorsal scutum subequal in size (\#7-0), elliptic tubercles on area III (\#39-1), absence of prolateral apophysis in females (\#65-0), femur prolaterally curved (\#74-1), three to six apophyses on apical half of retrolateral row on femur IV (\#93-3) and general body color brown (\#95-0). The clade with species from SMSP, SSP, PR and SC AoE is supported by the presence of median apophysis on retrolateral row of femur IV (\#92-1). Inside this clade, the lineage with species from SMSP is supported by basitarsus II with nine segments (\#54-3) and falciform DBA (\#80-1). The clade containing species from SSP, PR and SC is supported by median armature on ocularium longer than the high (\#14-1), small tubercles on free tergite II (\#51-0), thin ventral plate (\#98-0) and MSA forming a parable (\#110-2). The group with species from PR and SC is supported by (\#25-1), (\#47-2), retrolateral apophysis on trochanter IV (\#711), two apophyses on apical half on retrolateral row of femur IV (\#93-2) and ventral plate thin in lateral view (\#97-1).

The other lineage inside the clade, with species from Boc, Esp, LSRJ, and Org, is supported by flabellum as long as large (\#123-0). Inside this clade, the lineage formed by $M$. arlei comb. nov., $M$. intermedius and $M$. minimus sp. nov. is supported by median armature on area I larger than median armatures on area III (\#31-0), median armature on area II larger than median armatures on area III (\#35-0), low density of granulation on dorsal scutum (\#47-0), prolateral apophysis on coxa IV shorter than trochanter IV (\#59-0), prolateral apophysis on coxa IV oblique in dorsal view (\#62-2) and ventral plate thin (\#98-0). The clade containing $M$. arlei comb. nov. and $M$. minimus sp. nov. is supported by large tubercles on lateral margin of dorsal scutum (\#23-0), median armature on area III of the same color as the rest of the body (\#38-2), femur straight (\#74-0), absence of retrolateral basal apophysis on femur IV (\#75-0). The less inclusive clade holding species from Boc, LSRJ and remaining species from Org AoE is supported by rounded lateral armatures on area III (\#44-1), branched DBA (\#80-3) and without apophysis after DBA (\#86-0). Inside this last group, the lineage with species from LSRJ and remaining Org species is supported by small tubercles on free tergite II (\#51-0) and sparse T1 microsetae on ventral side of ventral plate (\#100-0). The clade with M. scaber, M. poeta, M. spinifrons comb.nov. and species from LSRJ is supported by basal tubercle on prolateral apophysis on coxa IV (\#60-1), absence of a more developed apical tubercle on retrolateral row on femur IV (\#94-0) and ventral plate thin in dorsal view (\#98-0). The lineage holding M. scaber and $M$. poeta is supported by absence of secondary distal lobe on prolateral apophysis of coxa IV (\#61-0), without retrolateral basal apophysis on femur IV (\#75-0), small DBA (\#77-0) and one apophysis on apical half of retrolateral row of femur IV (\#93-1). The group with M. spinifrons comb. nov. and species from LSRJ is supported by ventral plate thin on lateral view (\#97-1), weakly developed lateral lobes on ventral plate (\#119-0) and flabellum longer than wide (\#1231). The clade with species from LSRJ is supported by DBA with base four times wider than apex (\#79-0) and lateral parts of flabellum smooth (\#124-1). Finally, the clade holding M. squalidus

Peer] reviewing PDF | (2020:08:52148:2:0:NEW 1 Jun 2021) 
782

783

784

785

786

787

788

789

790

791

792

793

794

795

796

797

798

799

800

801

802

803

804

805

806

807

808

809

810

811

812

813

814

815

816

817

818

819

820

821

822

823

824

825

826

827

and M. parvus comb. nov. is supported by presence of lateral tubercles on area II (\#33-1), free tergite II with more developed central tubercle/ apophysis (\#51-1), free tergite III with more developed central tubercle/apophysis (\#53-1) and absence of retrolateral basal apophysis on femur IV (\#75-0).

\section{Taxonomic changes}

\section{Mischonyx: new combinations and diagnosis}

Before this publication, Mischonyx included the following 13 species, listed in Kury (2003) and Pinto-da-Rocha et al. (2012): M. anomalus (Mello-Leitão, 1936); M. antiquus (Mello-Leitão, 1934); M. cuspidatus (Roewer, 1913); M. fidelis (Mello-Leitão, 1931); M. insulanus (Soares, 1972); M. intermedius (Mello-Leitão, 1935); M. kaisara Vasconcelos, 2004; Mischonyx meridionalis (Mello-Leitão, 1927); M. poeta Vasconcelos, 2005a; M. processigerus (Soares \& Soares, 1970); M. scaber (Kirby, 1819); M. squalidus Bertkau, 1880 and M. sulinus (Soares \& Soares, 1947).

Based on the ML3 hypothesis, we propose new combinations, composition and diagnosis for this genus:

\section{Mischonyx Bertkau, 1880}

Mischonyx Bertkau, 1880: 106 (type species: Mischonyx squalidus Bertkau, 1880, by monotypy); Mello-Leitão, 1935: 22; Soares \& Soares, 1949: 221; Kury, 2003: 132; Vasconcelos, 2004: 129; 2005: 229; Pinto-da-Rocha et al. 2012: 51.

Ilhaia Roewer, 1913: 221; (type species Ilhaia cuspidata Roewer, 1913, by monotypy). Junior subjective synonym of Mischonyx, Bertkau, 1880: by Kury, 2003. In the present paper considered as a junior objective synonym of Mischonyx, Bertkau, 1880.

Jhaia (misspelling): Roewer, 1930: 362.

Eugonyleptes Roewer, 1913: 219 (type species Gonyleptes scaber Kirby, 1819, by monotypy). Junior subjective synonym of Mischonyx Bertkau, 1880: by Pinto-da-Rocha et al, 2012.

Xundarava Mello-Leitão, 1927: 19 (type species Xundarava holacantha Mello-Leitão, 1927, by original designation). Junior subjective synonym of Mischonyx Bertkau, 1880: by Kury, 2003. Gonazula Roewer, 1930: 417 (type species Gonazula gibbosa Roewer, 1930, by monotypy). Junior subjective synonym of Mischonx Bertkau, 1880: by Pinto-da-Rocha et al., 2012. Eduardoius Mello-Leitão, 1931: 94 (type species Eduardoius fidelis Mello-Leitão, 1931, by original designation). Junior subjective synonym of Mischonyx, Bertkau, 1880: by Kury, 2003. Cryptomeloleptes Mello-Leitão, 1931: 137 (type species Criptomeloleptes spinosus MelloLeitão, 1931, by original designation). Junior subjective synonym of Mischonyx, Bertkau, 1880: by Kury, 2003.

Geraecormobiella Mello-Leitão, 1931: 127; B. Soares, 1945: in a footnote [= Geraeocormobius Holmberg, 1887] (type species Geraecormobiella convexa Mello-Leitão, 1931, by original designation). Syn.nov.

Ariaeus Sørensen, 1932; Vasconcelos, 2005b: 2 [= Geraeocormobius Holmberg, 1887] (type species Ariaeus tuberculatus Sørensen, 1932, by monotypy). Syn.nov.

Giltaya Mello-Leitão, 1932: 466 (type species Giltaya solitaria Mello-Leitão, 1932, by original designation). Junior subjective synonym of Mischonyx, Bertkau, 1880: by Kury, 2003.

Peer) reviewing PDF | (2020:08:52148:2:0:NEW 1 Jun 2021) 
828 Bunoleptes Mello-Leitão, 1935: 398. (type species Bunoleptes armatus Mello-Leitão, 1935, by 829 original designation). Junior subjective synonym of Mischonyx, Bertkau, 1880: by Kury, 2003. 830 Arleius Mello-Leitão, 1935: 22 (type species Arleius incisus Mello-Leitão, 1935, by original 831 designation). Junior subjective synonym of Mischonyx, Bertkau, 1880: by Kury, 2003.

832 Urodiabunus Mello-Leitão, 1935: 396; 1935: 104; Soares \& Soares, 1949: 219. (type species

833 Urodiabunus arlei Mello-Leitão, 1935, by original designation). Syn.nov.

834 Penygorna Mello-Leitão, 1936: 30 (type species Penygorna infuscata Mello-Leitão, 1936, by

835

836

837

838

839 original designation). Junior subjective synonym of Mischonyx, Bertkau, 1880: by Kury, 2003.

Composition: Mischonyx. anomalus (Mello-Leitão, 1936); Mischonyx arlei (MelloLeitão, 1935b) comb. nov., Mischonyx clavifemur (Mello-Leitão, 1927a) comb. nov.; Mischonyx fidelis (Mello-Leitão, 1931b); Mischonyx insulanus (H. Soares, 1972); Mischonyx

840

841

842 intermedius (Mello-Leitão, 1935b); Mischonyx intervalensis sp. nov.; Mischonyx kaisara Vasconcelos, 2004; Mischonyx minimus sp. nov.; Mischonyx parvus (Roewer, 1917) comb. nov.; Mischonyx poeta Vasconcelos, 2005a; Mischonyx processigerus (Soares \& Soares, 1970);

843

844

845

846 Mischonyx reitzi (Vasconcelos, 2005b) comb. nov.; Mischonyx scaber (Kirby, 1819); Mischonyx spinifrons (Mello-Leitão, 1923) comb. nov.; Mischonyx squalidus Bertkau, 1880; Mischonyx tinguaensis sp. nov..

Taxonomic remarks: we transferred Geraeocormobius reitzi Vasconcelos, 2005b, Urodiabunus arlei Mello-Leitão, 1935, Weyhia clavifemur Mello-Leitão, 1927, Weyhia

848

849 spinifrons Mello-Leitão, 1923 and Weyhia parva Roewer, 1917 to Mischonyx based on molecular and morphological evidence. The other new combinations are also based on the

850

851 morphological analysis of the types, with one exception, M. squalidus. Since we were not able to study the holotype of this species, the new synonym had to be based on original figures and description from Bertkau. Vasconcelos (2003, unpublished data), in his master's dissertation, and Benedetti (2017, unpublished data), in his $\mathrm{PhD}$ thesis, had already proposed most of these combinations. However, they did not publish their conclusions. According to the ICZN (1999), nomenclatural acts in theses or dissertations are not valid if they are not officially published.

Besides that, based on our phylogenetic analysis, we re-establish the original combination of Gonleptes antiquus Mello-Leitão, 1934, removing the species from Mischonyx. This species was considered a member of Mischonyx by Kury (2003) and Pinto-da-Rocha et al. (2012). Now

859

860

861

862

863

864

865

866 it returns to the genus in which it had been originally described. Consequently, we remove the genus Anoploleptes Piza, 1940 from subjective the junior synonym list of Mischonyx, as established by Kury (2003), since Anoploleptes dubium (type species of Anoploleptes) is a junior synonym of Gonyleptes antiquus (see B. Soares, 1943). Therefore, Anoploleptes is a junior synonym of Gonyleptes as established by B. Soares (1943).

As pointed out by Acosta, Kury \& Juárez (2007) "the correct (original) spelling of the generic name is Geraeocormobius".

Diagnosis. Small Gonyleptinae ( $3-6 \mathrm{~mm}$ of dorsal scutum length). Dorsal scutum outline $\gamma \mathrm{P}$ in males, with coda involved by the mid-bulge, which is very distinct.

869 Females have dorsal scutum outline $\alpha$, with coda long and clearly separated from mid-bulge.

870 Anterior margin with lateral armature, normally two or three tubercles on each side. Frontal

871 hump high and narrow, with a pair of median tubercles (except in M. processigerus, which has

872 two pairs). Lateral margin of prosoma with several granules, posterior to ozopore. Ocularium

873 narrow and not very high, armed with median spines or tubercles. Some species have small 
874 tubercles anterior or posterior to the eye (or both). Posterior margin of prosoma with a pair of 875 tubercles. Dorsal scutum with three areas. Mesotergal area I is divided by a longitudinal groove. 876 Areas I and II armed with median tubercles (which are large and whitish in M. arlei comb. nov. 877 and M. minimus sp. nov.). Area III with a pair of median elliptic tubercles (except in $M$. arlei

878

879

880

881

882

883

884

885

886

887

888

889

890

891

892

893

894

895

896

897

898

899

900

901

902

903

904

905

906

907

908

909

910

911

912

913

914

915

916

917

918

919

comb. nov. and $M$. minimus sp. nov.), which can vary in size and lateral compression. Some species have other elliptic tubercles besides the median ones (e.g., M. spinifrons comb. nov.). Lateral margin of dorsal scutum (mid-bulge) with rounded tubercles, which are fused in some species (e.g., M. spinifrons comb. nov.). Distitarsi of all legs with three segments. Basitarsus of leg I with three or four segments. Basitarsus II with four - eight segments. Basitarsi III and IV with four or five segments. Ventral surface of coxae I generally with more developed tubercles than the ones on the other coxa. Coxa IV with apical prolateral apophysis, generally robust, in some speciemens with ventral process and a basal tubercle. Trochanter IV short and robust, with a blunt prolateral apophysis and at least one retrolateral armature. Femur IV with DBA, which can be small (as in M. arlei comb. nov. and M. minimus sp. nov.), or large (most species). DBA can be branched or not and varies in shape and size in every species. Retrolateral row of tubercles generally with some large apophysis. Penis with ventral plate trapezoidal with an apical parabolic groove; three pairs of MS A and one pair of MS B on lateral projections; three pairs of helicoidal MS C, two pairs of reduced MS E, one pair of MS D, venter of ventral plate with microsetae type $\mathrm{T} 1$ covering its whole extension or the basal half. Glans with ventral process, flabellum can be serrated or smooth. Stylus with microsetae, inclined in relation to axis of penis and with ventral groove.

\section{Species new combinations}

Besides the combinations and synonyms present in Kury (2003) and Pinto-da-Rocha et al. (2012), the following new combinations are here proposed:

Mischonyx. anomalus (Mello-Leitão, 1936) (Figs. 01A, 01C, 13A - C)

Xundarava anomala Mello-Leitão, 1936: 13, fig 10; B. Soares, 1945d: 192; 1945h: 366;

H. Soares, 1945a: 210; Soares \& Soares, 1949b: 220 (Male and female syntypes, Brazil, Paraná, Antonina; MNRJ 42282).

Ilhaia anomala: Soares \& Soares, 1987: 7.

Mischonyx anomalus: Kury, 2003: 133; Pinto-da-Rocha et al, 2012: 52.

Ilhaia sulina Soares \& Soares, 1947: 215 (Male lectotype and female paralectotype;

Brazil Paraná, Florestal; MHNCI 3618 and MHNCI 3619, respectively). Syn. nov. Mischonyx sulinus: Kury, 2003: 134; Pinto-da-Rocha et al., 2012: 52.

Diagnosis. Mischonyx anomalus resembles M. clavifemur comb. nov. in the following: prolateral apophysis of coxa IV with apex directed posteriorly; prolateral apophysis of trochanter IV small when compared to other species; retrolateral row of femur IV with median apophysis larger than the other armatures of this row; ventral plate of penis with MS A forming a basoapical, reduced MS B, MS E slightly medial when compared to the MS C, ventral side entirely covered with microsetae, lateral lobes basal. It differs from M. clavifemur comb. nov. in the following: reduced size (4-4.5 mm of dorsal scutum length) $(5-6 \mathrm{~mm}$ in M. clavifemur comb. nov.); Dorsal scutum narrower than in M. clavifemur comb. nov.; Mesotergal Area III with a pair of large median tubercles (reduced in M. clavifemur comb. nov.); retrolateral side of

Peer) reviewing PDF | (2020:08:52148:2:0:NEW 1 Jun 2021) 
920 trochanter IV with a row of small tubercles (two tubercles in M. clavifemur comb. nov., with the

921 apical more developed than the other); ventral plate longer than wider (as wide as long in $M$.

922 clavifemur comb. nov.) dorsal row of femur IV with small tubercles only after DBA (three large

923 tubercles after DBA in M. clavifemur comb. nov.) apical groove reaching the line of the second

924 MS C (reaching deeper than the MS C in M. clavifemur comb. nov.).

925

926

927

928

929

930

931

932

933

934

935

936

937

938

939

940

941

942

943

944

945

946

947

948

949

950

951

952

953

954

955

956

957

958

Mischonyx arlei (Mello-Leitão, 1935b) comb.nov. (Fig. 01B, 01D, 13D - F)

Urodiabunus arlei Mello-Leitão, 1935: 397, fig 22 (1 Male 1 female syntypes; Brazil, Rio de Janeiro, Petrópolis; MNRJ 42476).

Diagnosis. Mischonyx arlei comb. nov. resembles $M$. minimus sp. nov. by the following combinations of characters: mesotergal area I with a pair of well-developed median tubercles, which are paler (whitish) than the rest of the dark brown body ; median armatures on mesotergal area III are spines; lateral margin of dorsal scutum with several small tubercles; Free Tergite II with a well-developed median apophysis; prolateral apophysis on coxa IV small and pointing posteriorly; retrolateral side of trochanter IV with two armatures; femur IV with several small apophyses on dorsal and retrolateral row of tubercles; femur IV with a well-developed terminal tubercle on pro and retrolateral rows of tubercles; ventral plate with three subdistal MS C on each side; MS B smaller than MS A; flabellum with serrated ends. It differs from M. minimus sp. nov. in the following: size $(7-8 \mathrm{~mm})(3-3.5 \mathrm{~mm}$ in $M$. minimus sp. nov. $)$; mesotergal area II with median tubercles small and darker than the rest of the body (median tubercles whitish and as large as the median tubercles on mesotergal area I in M. minimus sp. nov); basitarsus II with seven segments (four in M. minimus sp. nov); leg IV curved in dorsal view (straight in $M$. minimus sp. nov); MS D reduced (well-developed in M. minimus sp. nov).

Mischonyx clavifemur (Mello-Leitão, 1927) comb.nov. (Figs. 02A, 02C, 13G - I) Weyhia clavifemur Mello-Leitão, 1927a: 416; Roewer, 1930: 356; Mello-Leitão, 1932: 286, fig 177 (Male holotype; Brazil, Santa Catarina, Blumenau; MNRJ 1496). Geraeocormobius clavifemur: Mello-Leitão, 1940b: 22; B. Soares, 1945h: 354; Soares \& Soares, 1949b: 169; Vasconcelos, 2005b: 3, figs. 1 -9; Pinto-da-Rocha et al, 2014: 12, 16. Ilhaia meridionalis Mello-Leitão, 1927a: 417 (female holotype; Brazil, Santa Catarina, Blumenau; MNRJ 1474); Vasconcelos, 2005b:3. Synonymy established by Vasconcelos, $2005 \mathrm{~b}$. Jlhaia meridionalis (misspelling): Roewer, 1930: 363.

Mischonyx meridionalis: Kury, 2003: 133 -134.

Ariaeus tuberculatus Sørensen, 1932: 282 (female holotype; Brazil, Santa Catarina, Blumenau; BMNH); Vasconcelos, 2005b: 3. Synonymy established by Vasconcelos, $2005 \mathrm{~b}$.

Diagnosis. Mischonyx clavifemur comb. nov. resembles M. anomalus. in the following: prolateral apophysis of coxa IV with apex directed posteriorly; prolateral apophysis of trochanter

959 IV small when compared to other species; retrolateral row of femur IV with median apophysis

960 larger than the other armatures of this row; ventral plate of penis with MS A forming a baso-

961 apical, reduced MS B, MS E slightly medial when compared to the MS C, ventral side entirely 962 covered with microsetae, lateral lobes basal. It differs from M. anomalus by: its size (5-6 mm 963 of dorsal scutum) (4-4.5 $\mathrm{mm}$ in $M$. anomalus); mesotergal area III with small median tubercles 964 (more developed in M. anomalus); retrolateral side of trochanter IV with two tubercles, with the 965 apical more developed than the other (a row of small tubercles in M. anomalus); ventral plate of 
966 the penis as wide as long (longer than wider in M. anomalus) dorsal row of femur IV with three

967

968

969

970

971

972

973

974

975

976

977

978

979

980

981

982

983

984

985

986

987

988

989

990

991

992

993

994

995

996

997

998

999

1000

1001

1002

1003

1004

1005

1006

1007

1008

1009

1010

1011

large tubercles after DBA (small tubercles only after DBA in M. anomalus), apical groove

reaching deeper than the line of the last MS C (reaching the line of the second MS C in $M$. anomalus).

\section{Mischonyx fidelis (Mello-Leitão, 1931) (Figs. 02B, 02D, 10A -C)}

Eduardoius fidelis Mello-Leitão, 1931a: 95; 1932: 344 (2 syntypes; Brazil, Rio de

Janeiro, Piraí; MNRJ 1408).

Ilhaia fidelis: B. Soares, 1943f: 56 [by implication]; 1945h: 358; Soares \& Soares, 1946a:

76; 1949b: 186.

Mischonyx fidelis: Kury, 2003: 133; Pinto-da-Rocha et al, 2012: 52.

Diagnosis. $M$. fidelis resembles $M$. parvus comb. nov. in the following: pair of tubercles on frontal hump and lateral margins of dorsal scutum whitish (in ethanol); median tubercles on mesotergal area III large and elliptic; prolateral apophysis of trochanter IV large when compared to other species (e.g. M. spinifrons comb. nov.); DBA conic and the tallest of the genus (almost as tall as the whole body), with a tubercle on anterior side of apophysis; prolateral row of femur IV with median tubercles more developed than the others on this row; retrolateral row of femur IV with the largest tubercle on distal third; apex of penis truncus not globose in lateral view; ventral plate with microsetae only on basal half; apical groove shallow, reaching the line of the most apical MS C; lateral projections basal; MS A forming a dorso-ventral line; MS E basal when compared to the MS C; flabellum with median large projection. It differs from M. parvus comb. nov. in the following: prolateral apophysis on coxa IV with small ventral lobe (ventral lobe as developed as the main projection in M. parvus comb. nov.); retrolateral side of trochanter IV with three small tubercles (two large tubercles in $M$. parvus comb. nov.); dorsal row of femur IV with an elevation basal to the DBA (absence of an elevation basal to the DBA in M. parvus comb. nov.); dorsal row of femur IV with small tubercles only after DBA (one large tubercle after DBA in $M$. parvus comb. nov.); retrolateral row of femur IV with three large tubercles on the basal half (without large tubercles tubercles on the basal half in M. parvus comb. nov.); ventral plate of the penis as large as wide (larger than wider in M. parvus comb. nov.); lateral lobes projected (not projected in M. parvus comb. nov.); MS B ventral to MS A (MS B apical to the MS A in M. parvus comb. nov.); MS C more distal than in M. parvus comb. nov..

\section{Mischonyx insulanus (H. Soares, 1972) (Figs. 03A, 03C, 10D - F)}

Ilhaia insulana H. Soares, 1972: 65, figs 1 - 4 (Male holotype, 1 female paratype; Brazil, São Paulo, São Sebastião; HSPC 361). Mischonyx insulanus: Kury, 2003: 133; Pinto-da-Rocha et al, 2012: 52.

Diagnosis. $M$. insulanus resembles $M$. processigerus in the following combinations of characters: median tubercles on ocularium smaller than height of ocularium; ocularium with small tubercles on anterior and posterior sides; mesotergal area III with small median tubercles when compared to other species (e.g. M. fidelis); Free Tergites II and III with median apophysis; prolateral row of femur IV with median tubercles larger than the others in this row; dorsal row of femur IV with small tubercles after DBA; retrolateral row of femur IV with the largest apophysis on the distal third; ventral side of the ventral plate of the penis with microsetae only on the laterals; lateral lobes well-developed; apical groove of the ventral plate reaching the line of the

Peer) reviewing PDF | (2020:08:52148:2:0:NEW 1 Jun 2021) 
1012 second MS C; MS A forming a dorso-ventral line; reduced MS B. It differs from $M$.

1013 processigerus by: prolateral apophysis of coxa IV with ventral lobe as large as the main

1014 projection and close to each other (ventral lobe smaller and more separated from the main

1015 projection of the apophysis in $M$. processigerus); retrolateral apophysis of coxa IV not visible in

1016 dorsal view; (visible in M. processigerus); DBA not branched (branched in M. processigerus);

1017 retrolateral row of femur IV with two large apophysis (one in M. processigerus); retrolateral row

1018 of femur IV with small tubercles besides the two apophysis (several large tubercles in $M$.

1019 processigerus); flabellum with smooth apex (serrated in M. processigeus); stylus without

1020 microsetae (stylus with microsetae in M. processigerus); MS B closer to MS E when compared

1021 to $M$. processigerus.

1022

1023

1024

1025

1026

1027

1028

1029

1030

1031

\section{Mischonyx intermedius (Mello-Leitão, 1935) (Figs. 03B, 03D, 10G - I)}

Ilhaia intermedia Mello-Leitão, 1935e: 401, fig 25; 1935b: 107 (Male holotype; Brazil, Minas Gerais, Viçosa; IBSP 46).

Penygorna infuscata Mello-Leitão, 1936b: 31, fig 26 (1 Male 2 female syntypes; Brazil,

Minas Gerais; Viçosa; MNRJ 42695). Synonymy established by B. Soares, 1944 i.

Mischonyx intermedius: Kury, 2003: 133; Pinto-da-Rocha et al, 2012: 52.

1032

1033

1034

1035

1036

1037

1038

1039

1040

Diagnosis. $M$. intermedius resembles $M$. arlei comb. nov. in the following: lateral margin of dorsal scutum with several small tubercles; mesotergal area III with median tubercles that are not elliptic; prolateral apophysis of coxa IV smaller than trochanter IV, blunt and oblique to the body axis; femur IV thin and long; retrolateral row of femur IV with an apical sharp tubercle; MS B reduced; MS E in the same dorso-basal line of the MS C; flabellum with serrated ends. It differs from $M$. arlei comb. nov. by: median tubercles on mesotergal area I smaller than the median tubercle of the other mesotergal areas and darker than the rest of the body color (in ethanol) (bigger and whitish in M. arlei comb. nov.); Free Tergite II with small tubercles only (large median apophysis in $M$. arlei comb. nov.); retrolateral apophysis of coxa IV not visible in dorsal view (visible in $M$. arlei comb. nov.) prolateral apophysis of trochanter IV large (reduced in $M$. arlei comb. nov.); retrolateral side of trochanter IV with a line of three tubercles (two n M. arlei comb. nov.); DBA large in relation to the other armature on the dorsal row and with its apex directed anteriorly (DBA almost same size as other tubercles on the row and with its apex directed dorsally in $M$. arlei comb. nov.); prolateral ros of femur IV with a large number of tubercles when compared to other species (e.g. M. spinifrons comb. nov. and M. arlei comb. nov.); retrolateral row of femur IV with tubercles increasing in size apically (retrolateral row with minute armature in $M$. arlei comb. nov.); ventral side of the ventral plate of the penis with microsetae on the basal half (ventral side entirely covered with microsetae in $M$. arlei comb. nov.); apical groove of the ventral plate of the penis reaches the line of the most basal MS C (apical groove reaches the line of the median MS C in $M$. arlei comb. nov.); MS A forming a parable (MS A forming a diagonal baso-apical line in M. arlei comb. nov.); MS D more apical, when compared to $M$. arlei comb. nov., that has the MS D medial on the ventral plate.

1052 Brazil, São Paulo, Ilha Bela; MNRJ 17437 and MZSP 23147, respectively). 
1058 Vasconcelos (2004) diagnosis for the species remains unaltered and with no necessity to add 1059 information.

1060

1061

1062

1063

Mischonyx parvus (Roewer, 1917) comb. nov. (Figs. 05B, 05D, 11D - F)

1064

1065

1066

1067 Weyhia parva Roewer, 1917: 133 (Male holotype, Brazil, São Paulo. Santos; SMF 1331). Geraeocormobius parva: Mello-Leitão, 1940b: 22. Geraeocormobius parvus: B. Soares, 1945: 355; Soares \& Soares, $1949 \mathrm{~b}: 171$. Ilhaia parva: Soares \& Soares, 1987a: 6. Cryptomeloleptes spinosus Mello-Leitão, 1931d: 138 (holotype; Brazil, Rio de Janeiro,

Rio de Janeiro; MNRJ 11392). Synonymy established by Soares \& Soares, 1987a. Arleius incisus Mello-Leitão, 1935a: 22 (holotype; Brazil, Rio de Janeiro, Rio de Janeiro; MNRJ 41759). Synonymy established by Soares \& Soares, 1987. Ilhaia incisa: Soares \& Soares, 1946a: 76; H. Soares, 1974: 354, fig 2. [= Bunoleptes armatus Mello-Leitão, 1935e; = Geraecormobius cervicornis Mello-Leitão, 1940b]. Bunoleptes armatus Mello-Leitão, 1935e: 398 (Male holotype, 2 Male paratypes; Brazil, Rio de Janeiro, Rio de Janeiro; MNRJ 42477 and MZSP 2328) Synonymy established by Soares \& Soares, 1987a. Geraecormobius cervicornis Mello-Leitão, 1940b: 17 (Male holotype lost; Brazil, Rio de Janeiro, Mangaritiba; MNRJ 53924). Synonymy established by Soares \& Soares, 1987a.

Diagnosis. $M$. parvus comb. nov. resembles $M$. fidelis in the following: pair of tubercles on the frontal hump and lateral margins of the dorsal scutum whitish (in ethanol); median tubercles on mesotergal area III large and elliptic; prolateral apophysis of trochanter IV big, when compared to other species (e.g., M. spinifrons comb. nov.); DBA conic and the tallest of the genus (almost as tall as the whole body), with a tubercle on the anterior side of the apophysis; prolateral row of femur IV with median tubercles more developed than the others on this row; retrolateral row of femur IV with the largest tubercle on distal third; penis not globose in lateral view; ventral plate with microsetae only on basal half; apical groove shallow, reaching the line of the most apical MS C; lateral projections basal; MS A forming a dorso-ventral line; MS E basal when compared to MS C; flabellum with median projection large. It differs from M. fidelis by: prolateral apophysis on coxa IV with ventral lobe as developed as the main projection (ventral lobe reduced in M. fidelis); retrolateral side of trochanter IV with two large tubercles (small in $M$. fidelis); dorsal row of femur IV without an elevation basal to the DBA (presence of an elevation basal to the DBA in M. fidelis); dorsal row of femur IV with a large tubercle after DBA (small tubercles only after DBA in M. fidelis); retrolateral row of femur IV without large tubercles on the basal half (three large tubercles on the basal half in M. fidelis); ventral plate of the penis larger than wider (as large as wide in M. fidelis); lateral lobes not very projected, with the MS A and MS B close to the penis base (projected in M. fidelis); MS B apical to MS A (MS B ventral to the MS A in M. fidelis); MS C more median than in M. fidelis.

Taxonomic remarks: Kury (2003) synonymized this species with M. squalidus. However, the distribution of $M$. parvus does not match with the original location of the described individual in Bertkau (1880). In the latter work, the location of the specimen is "Copacabana, Rio de Janeiro". By the distribution map in the figures 15, S1 and S2, the registers from this species are from Mangaratiba and Angra dos Reis, which are to the south of Rio de Janeiro state. For this reason, we removed this species from the synonymy created by Kury (2003).

Peer) reviewing PDF | (2020:08:52148:2:0:NEW 1 Jun 2021) 
1104

1105

1106

1107

1108

1109

1110

1111

1112

1113

1114

1115

1116

1117

1118

1119

1120

1121

1122

1123

1124

1125

1126

1127

1128

1129

1130

1131

1132

1133

1134

1135

1136

1137

1138

1139

1140

1141

1142

1143

1144

1145

1146

1147

1148

1149

Mischonyx poeta Vasconcelos, 2005 (Figs. 06A, 06C, 11G - I)

Mischonyx poeta Vasconcelos, 2005a: 229, fig. 1 - 9. (Male holotype; Brazil, Rio de Janeiro, Casimiro de Abreu; MNRJ 17460).

As M. poeta was recently described and there is no new combination for the species, Vasconcelos (2005a) diagnosis for the species remains unaltered and with no necessity to add information.

Mischonyx processigerus (Soares \& Soares, 1970) (Figs. 06B, 06D, 12A - C)

Ilhaia processigera Soares \& Soares, 1970: 340, figs 1 - 3 (Male holotype, 1 female paratype; Brazil, Rio de Janeiro, Itatiaia; MZUSP 4501).

Mischonyx processigerus: Kury, 2003: 134; Pinto-da-Rocha et al, 2012: 52.

Diagnosis. M. processigerus resembles M. insulanus in the following: median tubercles on ocularium smaller than the ocularium height; ocularium with small tubercles on the anterior and posterior sides; mesotergal area III with small median tubercles when compared to other species (e.g. M. fidelis); Free Tergites II and III with median apophysis; prolateral row of femur IV with median tubercles larger than the others in this row; dorsal row of femur IV with small tubercles after DBA; retrolateral row of femur IV with the largest apophysis on the distal third; ventral side of the ventral plate of the penis with microsetae only on the laterals; lateral lobes welldeveloped; apical groove of the ventral plate reaching the line of the second MS C; MS A forming a dorso-ventral line; reduced MS B. It differs from M. insulanus by: prolateral apophysis of coxa IV with ventral lobe small and separated from the main projection (ventral lobe as large as the main projection and close to each other in M. insulanus); retrolateral apophysis of coxa IV visible in dorsal view; (not visible in M. insulanus); DBA branched (not branched in $M$. insulanus); retrolateral row of femur IV with one large apophysis (two in M. insulanus); retrolateral row of femur IV with large tubercles besides the apophysis (small tubercles in $M$. insulanus); flabellum with serrated apex (smooth in M. insulanus); stylus with microsetae (stylus without microsetae in M. insulanus); MS B distant from MS E when compared to M. insulanus.

\section{Mischonyx reitzi (Vasconcelos, 2005) comb.nov. (Figs. 07A, 07C, 22A - C)}

Geraeocormobius reitzi Vasconcelos, 2005b: 6, figs. 10 - 19. (Malee holotype; Brazil, Santa Catarina, Ilhota; MNRJ 6949).

Diagnosis. M. reitzi comb. nov. resembles M. tinguaensis sp. nov. in the following: Median armature on mesotergal area III small when compared to other species (e.g. M. spinifrons comb.nov.) and elliptic; no median armature on Free Tergites I - III; prolateral apophysis on coxa IV with its apex directed laterally, as large as the trochanter IV and with ventral lobe; a small tubercles basal to DBA on the dorsal row; DBA branched; dorsal row of femur IV with small tubercles only; prolateral row with tubercles of the same size; apical groove on ventral plate of the penis reaching the line of the most basal MS C; MS A forming a baso-apical line; stylus with microsetae. It differs from M. tinguaensis sp. nov. by: lateral margin of dorsal scutum with small tubercles which have the same color of the rest of the body (whitish than the rest of the body in $M$. tinguaensis sp. nov.); median armature on ocularium smaller than the ocularium height (bigger in M. tinguaensis sp. nov.); trochanter IV with two retrolateral tubercles (three in M. tinguaensis sp. nov.); median apophysis on retrolateral row of femur IV is

Peer) reviewing PDF | (2020:08:52148:2:0:NEW 1 Jun 2021) 
1150 the largest on this row (biggest apophysis is on the apical third in M. tinguaensis sp. nov.); MS B

1151 reduced (as large as MS A in M. tinguaensis sp. nov.).

1152

1153

1154

1155

1156

1157

1158

1159

1160

1161

1162

1163

1164

1165

1166

1167

1168

1169

1170

1171

1172

1173

1174

1175

1176

1177

1178

1179

1180

1181

1182

1183

1184

1185

1186

1187

1188

1189

1190

1191

1192

1193

1194

Mischonyx scaber (Kirby, 1817) (Figs. 07B, 07D)

Gonyleptes scaber Kirby, 1819: 453 (3 males and 1 female syntypes; Brazil; NHM 1863.41).

Eugonyleptes scaber: Roewer, 1913: 219; Kury, 2003: 123.

Xundarava holacantha Mello-Leitão, 1927b: 20 (female holotype; Brazil, Rio de Janeiro, Niteroi; MNRJ 1469). Synonymy established by Pinto-da-Rocha et al., 2012.

Weyhia vellardi Mello-Leitão in litteris: Soares \& Soares, 1987a: 7.

Ilhaia holacantha: Soares \& Soares, 1987a: 7, figs $27-28$.

Weyhia absconsa Mello-Leitão, 1932: 284, fig 175; Soares \& Soares, 1987: 7 [=

Xundarava holacantha Mello-Leitão, 1927]. (Male holotype; Brazil, Rio de Janeiro, Niteroi;

MNRJ 1501). Synonymy established by implication in Pinto-da-Rocha et al., 2012.

Geraeocormobius absconsa: Mello-Leitão, 1940b: 22.

Geraeocormobius absconsus: B. Soares, 1945h: 354; Soares \& Soares, 1949b: 167.

Geraeocormobius carioca Mello-Leitão, 1940b: 18, fig 22; Soares \& Soares, 1949b: 168;

Soares \& Soares, 1987: 7 [= Xundarava holacantha Mello-Leitão, 1927]. (Male and female

syntypes; Brazil, Rio de Janeiro, Rio de Janeiro; MNRJ 53927, lost). Synonymy established by

implication in Pinto-da-Rocha et al., 2012.

Mischonyx holacanthus: Kury, 2003: 133.

Diagnosis. M. scaber resembles $M$. fidelis in the following: median tubercles on frontal hump whitish when compared to the rest of the body (in ethanol); lateral margin of dorsal scutum with whitish tubercles when compared to the rest of the body (in ethanol); dorsal row of tubercles with an elevation before DBA; DBA with its apex directed anteriorly; no apophysis after DBA on the dorsal row of femur IV; prolateral row with median tubercles larger than the others in this row; retrolateral row with the largest apophysis on the apical third. It differs from M. fidelis by: lateral margin of dorsal scutum with smaller tubercles when compared to M. fidelis; prolateral apophysis on coxa IV with its apex directed dorsally (Fig. 22D) (prolateral apophysis with apex directed posteriorly in $M$. fidelis); retrolateral apophysis on coxa IV visible in dorsal view (not visible in M. fidelis); prolateral apophysis on trochanter IV small when compared to M. fidelis; retrolateral side of trochanter IV with three large tubercles (small tubercles in M. fidelis); DBA small, much smaller than the body height (almost as large as the body height in M. fidelis); retrolateral row with tubercles increasing in size from the base to the middle of the row (small tubercles only in M. fidelis); after the apophysis on the retrolateral row, there is no large tubercles (two large tubercles in M. fidelis).

\section{Mischonyx spinifrons (Mello-Leitão, 1923) comb.nov. (Figs. 08A, 08C, 12D - F)}

Weyhia spinifrons Mello-Leitão, 1923: 137; Roewer, 1930: 355; Mello-Leitão, 1932:

283, fig. 173 (Female holotype, Brazil, Rio de Janeiro, Petrópolis; MNRJ, lost)

Geraeocormobius spinifrons: Mello-Leitão, 1940: 21; Soares \& Soares, 1949: 172;

Soares \& Soares, 1987: 7, figs. $23-26$.

Weyhia bresslaui Roewer, 1927: 344; 1930: 356, pl. 6, fig. 1; Mello-Leitão, 1931d: 127;

1195 1932: 285, fig. 178; 1933b: 143 (Male and female syntypes; Brazil, Rio de Janeiro, Teresópolis; SMF 1420). Synonymy established by Soares \& Soares, 1987. 
1196

1197

1198

1199

1200

1201

1202

1203

1204

1205

1206

1207

1208

1209

1210

1211

1212

1213

1214

1215

1216

1217

1218

1219

1220

1221

1222

1223

1224

1225

1226

1227

1228

1229

1230

1231

1232

1233

1234

1235

1236

1237

1238

1239

1240

1241
Geraeocormobius bresslaui: Mello-Leitão, 1940: 21; Soares \& Soares, 1949: 168.

Geraecormobiella convexa Mello-Leitão, 1931d: 128, fig 16 (Male lectotype, 5

paralectotypes; Brazil, Rio de Janeiro; Rio de Janeiro; MNRJ 18203). Syn. nov.

Geraeocormobius convexus: Soares \& Soares, 1949b: 169

Weyhia montis Mello-Leitão, 1935: 389, fig. 15; 1935: 106 (Male holotype, Brazil, Rio

de Janeiro, Petrópolis, Independência; MNRJ 42461). Synonymy established by Soares \& Soares, 1987.

Geraeocormobius montis: Mello-Leitão, 1940: 21; B. Soares, 1945: 355; Soares \&

Soares, 1949: 170.

Geraeocormobius cheloides Mello-Leitão, 1940b: 19, fig 23; Soares \& Soares, 1987: 4 [= Geraecormobiella convexa Mello-Leitão, 1931] (Male holotype; Brazil, Rio de Janeiro, Rio de Janeiro; MNRJ 58236). Syn. nov.

Diagnosis. Mischonyx spinifrons comb. nov. resembles Mischonyx tinguaensis sp. nov. in the following: anterior margin of dorsal scutum with two tubercles on each side; tubercles on mesotergal area III, besides the median ones, elliptic; lateral margin of dorsal scutum with the most posterior lateral tubercles fused (forming larger tubercles); all free tergites with small tubercles; retrolateral apophysis on coxa IV apparent in dorsal view; dorsal row on leg IV with a tubercle anterior to the DBA; retrolateral row on leg IV with a large median apophysis; ventral plate with three pairs of apical MS C. It differs from Mischonyx tinguaensis sp. nov. by: median tubercles on mesotergal area III strongly compressed (elliptic but not strongly compressed laterally in Mischonyx tinguaensis sp. nov); lateral margin of dorsal scutum with small tubercles (large in Mischonyx tinguaensis sp. nov); prolateral apophysis on coxa IV smaller than trochanter IV (approximately with the same length in Mischonyx tinguaensis sp. nov); DBA not branched (branched in Mischonyx tinguaensis sp. nov); dorsal row of tubercles of leg IV with three large tubercles after DBA (without large tubercles after DBA in Mischonyx tinguaensis sp. nov); retrolateral row of leg IV with large tubercles (small in Mischonyx tinguaensis sp. nov); MS B reduced much smaller than MS A (as large as the MS A in Mischonyx tinguaensis sp. nov); MS A forming a triangle and hidden behind ventral process (forming a dorso-ventral line and apparent in Mischonyx tinguaensis sp. nov.); flabelum with smooth ends (serrated in Mischonyx tinguaensis sp. nov).

\section{Mischonyx squalidus Bertkau, 1880 (Figs. 08B, 08D, 12G - I)}

Mischonyx squalidus Bertkau, 1880: 107, pl.2, fig. 38; Roewer, 1913: 468; 1923: 584; Soares \& Soares, 1949: 221; Pinto-da-Rocha et al., 2012: 52 (Female holotype; Brazil, Rio de Janeiro, Copacabana; ISNB).

Ilhaia cuspidata Roewer, 1913: 221 (Male holotype; Brazil, Rio de Janeiro, Ilha Grande, SMF 900). Syn.nov. Jlhaia cuspidata: Roewer, 1930: 363 (misspelling).

Mischonyx cuspidatus: Kury 2003: 133; Pinto-da-Rocha et al. 2012: 53; Pinto-da-Rocha et al., 2014: 4, 16 - 18. Ilhaia fluminensis Mello-Leitão, 1922: 334; B. Soares, 1943: 56 [= Ilhaia cuspidata Roewer, 1913] (13 syntypes; Brazil, Rio de Janeiro, Piraí; MZSP 503). Syn.nov. Jlhaia fluminensis: Roewer, 1930: 363, fig 4(lapsus calami). Gonazula gibbosa Roewer, 1930: 418, fig. 32; Pinto-da-Rocha et al., 2012: 53 [=Ilhaia cuspidata Roewer, 1913] (Male holotype, Brazil, Santa Catarina, Serra Azul. SMF 1328).

PeerJ reviewing PDF | (2020:08:52148:2:0:NEW 1 Jun 2021) 
1242

1243

1244

1245

1246

1247

1248

1249

1250

1251

1252

1253

1254

1255

1256

1257

1258

1259

1260

1261

1262

1263

1264

1265

1266

1267

1268

1269

1270

1271

1272

1273

1274

1275

1276

1277

1278

1279

1280

1281

1282

1283

1284

1285

1286

1287

Syn.nov.

Eduardoius granulosus Mello-Leitão, 1931a: 95; B. Soares, 1944: 171 [=Ilhaia

cuspidata Roewer, 1913] (male holotype; Brazil, Rio de Janeiro, Piraí; MNRJ 1479). Syn.nov. Ilhaia granulosa: B. Soares, 1943f: 56.

Giltaya solitaria Mello-Leitão, 1932: 467; Kury, 2003: 133 [=Ilhaia cuspidata Roewer, 1913] (Male holotype; Brazil, Rio de Janeiro, Rio de Janeiro. MNRJ 1473). Syn.nov.

Eduardoius lutescens Roewer, 1943: 44; Soares \& Soares, 1970: 340 [= Ilhaia cuspidata

Roewer, 1913] (Male and female syntypes; Brazil, Rio de Janeiro, Mendes. SMF 5392/58).

Syn.nov.

Ilhaia lutescens: B. Soares, 1943f: 56.

Taxonomic remarks: Vasconcelos (2003, unpublished data) proposed this new combination in his dissertation. We analyzed Bertkau's original drawing (Bertkau, 1880, fig. 38) and the original description of M. squalidus, but were not able to lay hands on the holotype because it is lost. It was deposited at the Institut Royal des Sciences Naturelles de Belgique. Part of the description translated from German is presented below:

“... The first abdominal dorsal segment is almost fused with the thorax, and in general the articulation skin between each segment is not very flexible. The first three [abdominal] segments have in their superior part a line of "dots", of which the median ones stand out in height, like little spines." (Bertkau, 1880, pp. 107)

The only species that has one median armature on each free tergite in females and juveniles in the region Bertkau collected the specimen (Copacabana, Rio de Janeiro) is the traditionally called M. cuspidatus. Therefore, we propose that Ilhaia cuspidata is a junior synonym of $M$. squalidus. We know the holotype is a juvenile, based on the image in Bertkau (1880), and Roewer's (1923) and Kury’s (2003) statements.

Diagnosis. $M$. squalidus resembles $M$. spinifrons comb. nov. in the following: lateral margin of dorsal scutum with whitish tubercles (in ethanol); posterior tubercles on lateral margin of dorsal scutum fused; retrolateral apophysis of coxa IV visible in dorsal view; DBA with apex directed anteriorly; dorsal row on femur IV with three tubercles after DBA, on distal half; retrolateral row on femur IV with median apophysis more developed than the others in this row; ventral side of ventral plate without microsetae on distal half; lateral projections of ventral plate projected dorsally and behind ventral projection of glans; MS A forming a triangle; MS B reduced; apical groove of ventral plate reaching the line of the most basal MS C. It differs from M. spinifrons comb. nov. in the following: median tubercles on mesotergal area III strongly compressed and large (small and elliptic but not strongly compressed laterally in $M$. spinifrons comb. nov.); prolateral apophysis on coxa IV approximately same length as trochanter IV (smaller in $M$. spinifrons comb. nov.); Free Tergites I - III with median apophysis (without median apophysis in M. spinifrons comb. nov.); prolateral row with median tubercles larger than the others in this row (all tubercles subequal in size in M. spinifrons comb. nov.); retrolateral row on femur IV with several $(7-8)$ large tubercles basal to median apophysis (three tubercles basal, followed by a gap and one tubercle after this gap in $M$. spinifrons comb. nov.).

New Species Description

Peer] reviewing PDF | (2020:08:52148:2:0:NEW 1 Jun 2021) 
Mischonyx minimus sp. nov.

1290

1291

1292

1293

(Figs. 19, 14A - C, 05A and 05C)

Type material. BRAZIL. Rio de Janeiro: Teresópolis (Parque Nacional da Serra dos Órgãos, Barragem Beija-flor, 22²6'16.4"S 4336'35.4"W), C. Gueratto \& M. Abrão leg., 29.VII.2017, male holotype (MZSP76524); same data, males and females paratypes, (IBSP); same data, A. Benedetti et al. leg., 30.IV.2014.

1296 Etymology. From the Latin adjective minimus, $a$, um meaning small, little. This is due to its reduced size when compared to other Mischonyx species, specially Mischonyx arlei comb.nov., sister species of $M$. minimus sp. nov.

1299 Diagnosis. Mischonyx minimus sp. nov. resembles $M$. arlei comb. nov. in the following: mesotergal area I with pair of well-developed median tubercles, paler (whitish) than rest of body (dark brown); median armatures on mesotergal area III are spines; lateral margin of dorsal scutum with several small tubercles; free tergite II with a well-developed median apophysis; prolateral apophysis on coxa IV small and pointing posteriorly; retrolateral side of trochanter IV with two tubercles; femur IV with several small apophyses on dorsal and retrolateral row of tubercles; femur IV with a well-developed apical tubercle on prolateral and retrolateral rows of tubercles; ventral plate of penis with three subdistal MS C on each side; MS B smaller than MS A; flabellum with serrated ends. It differs from M. arlei comb. nov. in the following: reduced size $(3-3.5 \mathrm{~mm})(7-8 \mathrm{~mm}$ in $M$. arlei comb. nov. $)$; mesotergal area II with median tubercles whitish and as large as the median tubercles on mesotergal area I (dark brown and smaller than the ones on mesotergal area I in M. arlei comb. nov.); basitarsus II with four segments (seven in M. arlei comb. nov.); leg IV not curved (straight) in dorsal view (curved in M. arlei comb. nov.); MS D well-developed (reduced in M. arlei comb. nov.). Description. Male holotype: Dorsum (Figs. 19, 05A, 05C): Measurements: Dorsal scutum: L: 3.2; W:2.9; Prosoma: L:1.3; W: 1.6. Femur IV: 4.4. Scutum outline $\gamma \mathrm{P}$, widest at mesotergal area II. Anterior margin of carapace with three tubercles on each side, approximately the same size. Frontal hump high, with two spines the same color as rest of body (in ethanol), curved towards one another. Anterior region of ocularium smooth, ocularium with one pair of median tubercles (as tall as the ocularium height). Posterior region of the ocularium with one pair of small tubercles, right behind median tubercles. Lateral margin of prosoma with numerous small tubercles. Posterior portion of prosoma with a pair of tubercles. Besides these tubercles, prosoma has a low density of granules. Dorsal scutum divided into three mesotergal areas, with low density of granules (DaSilva \& Pinto-da-Rocha, 2010). Areas: Area I divided by a median longitudinal groove, with a pair of whitish large median tubercles and no granules; area II with a pair of large whitish median tubercles, same size as the tubercles on Area I without granules; Area III with a pair of dark median sharp spines, smaller than the other armatures on other mesotergal areas, a pair of tubercles posterior to median spines. Lateral margins of dorsal scutum with a row of small tubercles, approximately the same size, extending from the middle of area I until the posterior margin of Area III; no fusion of tubercles. Posterior margin of dorsal scutum with a line of small tubercles. Free tergite I with a line of small tubercles approximately the same size. Free tergite II with a large sharp median apophysis and two large tubercles, lateral to the median apophysis; free tergite III with a line of small tubercles. Dorsal anal operculum with small sparse tubercles. Venter. Coxa I with several sparse tubercles, larger than the ones on other coxa. Coxa II with sparse numerous granules. Coxa III with an anterior and a posterior basal- 
1334 apical row of tubercles; coxa IV with sparse numerous granules. Ventral anal operculum with

1335 granules. Chelicerae. Segment II with several setae, mainly apical. Fix and movable fingers with

1336 seven teeth each. Pedipalps. Venter of trochanter with few sparse tubercles; tibia setation:

1337 prolateral IIi, retrolateral Iili. Tarsal setation: prolateral IiI, retrolateral III, ventral side with two

1338 baso-apical lines of setae. Legs. Leg I: trochanter with several ventral tubercles, femur, patella

1339 and tibia with granules. Leg II: Trochanter II with several ventral tubercles; femur, patella and

1340 tibia with granules. Leg III: trochanter with several ventral tubercles; femur, patella and tibia

1341 with granules; Leg IV: Coxa IV: robust apical oblique prolateral apophysis, smaller than the

1342 trochanter size; large retrolateral apophysis, visible in dorsal view. Trochanter IV: prolateral

1343 small blunt apophysis; retrolateral side with a line of three large tubercles, two slightly more

1344 ventral. Femur IV: long, thin and straight; all tubercles on prolateral row approximately the same

1345 size; DBA small, unbranched, conic, sharp, pointing upwards; dorsal row with several small

1346 tubercles after DBA; retrolateral row of with several small tubercles and two more developed

1347 tubercles on the apical half; all tubercles on the ventral row small. Tarsal formula: 6(3)-6(3)-4-5.

1348 Male genitalia (Figs. 14 A - C). Ventral plate: Ventral surface covered with microsetae;

1349 pronounced apical groove (reaching the line of the first basal MS C); lateral lobes basal when

1350 compared to other species (e.g. Mischonyx intervalensis sp. nov.); three sub-apical helicoidal MS

$1351 \mathrm{C}$ on each side; two MS E, ventral and in the same baso-apical orientation of MS C; long MS D

1352 when compared to other species (e.g. Mischonyx intervalensis sp. nov.), basal relative to MS C

1353 and in the same dorso-ventral orientation of MS C; three spatular MS A, forming a diagonal

1354 baso-apical line; one reduced MS B, much smaller than MS A. Glans: Small dorsal process;

1355 flabelum triangular, with serrated apex; stylus with subapical microsetae, with the apex inclined

1356 relative to the penis axis and keeled. Color. Dark brown; pedipalps and trochanters I -III yellow.

1357

1358

1359

Female. Unknown.

1360

1361

1362

1363

\section{Mischonyx intervalensis sp. nov.}

(Figs. 04A and 04C , 14D-F, 20)

Type material. BRAZIL. São Paulo: Ribeirão Grande (Parque Estadual Intervales, 24¹5'27.1"S 4816'23.0"W), C. Gueratto et al. leg., 25.III.2017, male hololtype (MZSP76525); same data,

1364 males and females paratypes (IBSP); ditto males and females paratypes (MNRJ); same data,

1365 Ribeirão Grande (Parque Estadual Intervales, 2415'27.1"S 48¹6'23.0"W), F. Carbayo et al.

1366 Leg., 12 - 14.XII.2008, males and females paratyes (SMF).

1367 Etymology. Species name derives from the type locality, Parque Estadual Intervales.

1368 "Intervales" + the suffix -ēnsis, -ènse, to form an adjective.

Diagnosis. It resembles Mischonyx anomalus in the following: Anterior margin of dorsal scutum with two tubercles on each side; Areas I and II with small median tubercles; area III with welldeveloped and elliptic median tubercles; other tubercles on area III rounded; all free tergites with small tubercles; retrolateral row of leg IV with large median apophysis; retrolateral row of leg IV with several well-developed tubercles. It differs from $M$. anomalus in the following: prolateral apophysis of coxa IV with ventral process and basal tubercle (not present in M. anomalus); retrolateral side of trochanter IV with three tubercles (one in M. anomalus); DBA of leg IV branched and dorsal branch is the largest (not branched in M. anomalus); one apophysis on the dorsal row of tubercles of leg IV after DBA (three in M. anomalus); tubercles on prolateral row of tubercles on leg IV small and subequal in size (median tubercles larger in M. anomalus); 
1380 ventral plate with the same approximate height and width (square-shaped) (higher than wider in

1381 M. anomalus); lateral processes of the ventral plate medial (basal in M. anomalus).

1382 Description. Male holotype: Dorsum (Figs. 04A and 04C, 20): Measurements: Dorsal scutum:

1383 L: 4.5; W:4.6; Prosoma: L:1.8; W: 2.4. Femur IV: 3.9. Scutum outline $\gamma$ P, widest at area II.

1384 Anterior margin of carapace with two tubercles on each side, approximately the same size.

1385 Frontal hump high, with two tubercles the same color as rest of body (in ethanol). Anterior

1386 surface of the ocularium with one pair of tubercles, one pair of median tubercles/spines (taller

1387 than the ocularium height). Anterior surface of ocularium with one pair of small tubercles, right

1388 before the eyes. Lateral margin of prosoma with numerous small tubercles. Posterior part of

1389 prosoma with a pair of tubercles. Besides these tubercles, prosoma with low density of granules.

1390 Dorsal scutum; Area I divided by median longitudinal groove, with a pair of dark median

1391 tubercles and few sparse granules; Area II with a pair of dark median tubercles slightly larger

1392 than the tubercles on Area I and few sparse granules; Area III with a pair of dark median elliptic

1393 tubercles, larger than the ones on the other mesotergal areas, a pair of rounded tubercles posterior

1394 to the median elliptic ones and few sparse granules. Lateral margins of dorsal scutum with a row

1395 of small tubercles, increasing in size posteriorly and from sulcus I to the posterior margin of area

1396 III; no fusion of tubercles. Posterior margin of dorsal scutum with a line of small tubercles, with

1397 the median ones slightly larger than the rest. Dorsal scutum with average density of granules.

1398 Free tergites I-II with a line of small tubercles of the same approximate size. Free tergite III with

1399 a row of tubercles larger than the ones on the other free tergites and central tubercle slightly

1400 larger than the others. Dorsal anal operculum with small sparse tubercles. Venter. Coxa I with

1401 several sparse tubercles, larger than the ones on other coxae. Coxae II-IV with sparse numerous

1402 granules. Ventral anal operculum with granules. Chelicerae. segment II with several setae,

1403 mainly apical. Fixed finger with eight and movable finger with 12 teeth. Pedipalps. Ventral side

1404 of trochanter with few sparse tubercles; tibia setation: prolateral IiIi, retrolateral IiI. Tarsal

1405 setation: prolateral IiI, retrolateral II, ventral side with two baso-apical lines of setae. Legs. Leg I:

1406 trochanter, femur, patellae and tibia with granules. Leg II: Trochanter II with two retrolateral

1407 tubercles; femur, patella and tibia with granules. Leg III: trochanter, femur, patella and tibia with

1408 granules. Leg IV: coxa IV: robust apical prolateral apophysis, slightly inclined relative to the

1409 axis of the base of coxa IV, with ventral process and basal tubercle, with the approximate

1410 trochanter size; retrolateral apophysis small, not visible in dorsal view. Trochanter IV: prolateral

1411 small blunt apophysis; retrolateral side with a line of three large tubercles, two slightly more

1412 ventral. Femur IV: short and robust; all tubercles on prolateral row with approximately the same

1413 size; dorsal row of tubercles with a large tubercle before the DBA, DBA branched with the

1414 largest branch pointing upwards, one large tubercle after DBA; retrolateral row of with a large

1415 median apophysis, eight large tubercles before, three large (yet smaller than the ones anterior to

1416 the median apophysis) and three small tubercles posterior to the median apophysis, intercalated;

1417 all tubercles on the ventral row small. Tarsal formula: 3(3)-7(3)-4-5. Male genitalia (Fig. 14D -

1418 F). Ventral plate: Ventral surface with microsetae on the whole extension; pronounced apical

1419 groove (reaching the line of the most basal MS C); lateral process median when compared to

1420 other species (e.g. Mischonyx tinguaensis sp. nov.); three apical helicoidal MS C on each side;

1421 two MS E, ventral and in the same baso-apical orientation of MS C; one small MS D, basal

1422 relative to MS C and in the same dorso-ventral orientation of MS C; three spatular MS A,

1423 forming a parable line; one spatular MS B, smaller than MS A. Glans: Small dorsal process;

1424 flabellum triangular, with serrated margin; stylus with subapical microsetae, with the apex

1425 inclined relative to the penis axis and keeled. Color. Brown; dorsal scutum with yellowish tones;

Peer) reviewing PDF | (2020:08:52148:2:0:NEW 1 Jun 2021) 
1426

1427

1428

1429

1430

1431

1432

1433

1434

1435

1436

1437

1438

1439

1440

1441

1442

1443

1444

1445

1446

1447

1448

1449

1450

1451

1452

1453

1454

1455

1456

1457

1458

1459

1460

1461

1462

1463

1464

1465

1466

1467

1468

1469

1470

1471

pedipalps and trochanters I- III yellow.

Female. (paratype; MZSP): Measurements: Dorsal scutum: L: 4.2; W: 4.0. Prosoma: L: 1.3; W: 2.0; Femur IV: L: 3.9. Dorsal scutum outline $\alpha$, with a constriction at the area III and evident coda; small median tubercles on each area; median tubercles on area III rounded; lateral tubercles of the dorsal scutum small and the most posterior are not fused; absence of prolateral and retrolateral apophysis on coxa IV; trochanter and femur IV unarmed.

\section{Mischonyx tinguaensis sp. nov.}

(Figs. 09A and 09B, 14G - I, 21)

Type material. BRAZIL. Rio de Janeiro: Nova Iguaçu, (Reserva Biológica Tinguá/ RPPN CEC/Tinguá, 22³5'23.9"S 4326'25.7"W), C. Sampaio, F. Uemori \& C. T. Olivares leg., $04-$ 06.IV.2012, male holotype (MZSP76526).

Etymology. Species name derives from "Tinguá", due to its first collecting locality, Reserva Biológica Tinguá, type and only locality registered for this species + the suffix -ēnsis, -ênse, in order to form an adjective.

Diagnosis. It resembles Mischonyx spinifrons comb. nov. in the following: anterior margin of dorsal scutum with two tubercles on each side; several tubercles on area III elliptical; lateral margin of dorsal scutum with the most posterior lateral tubercles fused (forming larger tubercles); all free tergites with small tubercles; retrolateral apophysis on coxa IV apparent in dorsal view; dorsal row on leg IV with a tubercle anterior to the DBA; retrolateral row on leg IV with a large median apophysis; ventral plate with three pairs of apical MS C. It differs from $M$. spinifrons comb. nov. by: median tubercles on area III elliptic but not strongly compressed laterally (strongly compressed in M. spinifrons comb. nov.); large tubercles on lateral margin of dorsal scutum (small in M. spinifrons comb. nov.); prolateral apophysis on coxa IV approximately same length as trochanter IV (smaller in M. spinifrons comb. nov.); DBA branched (not branched in M. spinifrons comb.nov.); dorsal row of tubercles of leg IV without large tubercles after DBA (three large tubercles after DBA in M. spinifrons comb. nov.); tubercles on the basal half of the retrolateral row of leg IV small (some are large in M. spinifrons comb. nov.); MS B as large as the MS A (reduced in M. spinifrons comb. nov.); MS A forming a dorso-ventral line and apparent (forming a triangle and hidden behind the ventral process); flabellum with serrated on margin (smooth in M. spinifrons comb. nov.).

Description. Male holotype: Dorsum (Figs. 09A and 09B, 21): Measurements: Dorsal scutum: L: 4.1; W:4.2; Prosoma: L:1.6; W: 2.1. Femur IV: 4.0. Scutum outline $\gamma$ P, widest at mesotergal area II. Anterior margin of carapace with two tubercles on each side, with approximately the same size. Frontal hump high, with two whitish tubercles (in ethanol). Anterior surface of the ocularium with one pair of tubercles, one pair of median tubercles (as tall as the ocularium height). Lateral margin of prosoma with numerous small tubercles. Posterior part of prosoma with a pair of tubercles. Besides these tubercles, prosoma has a low density of granules (DaSilva \& Pinto-da-Rocha, 2010). Dorsal scutum: area I divided by a median longitudinal groove, with a pair of dark median tubercles; area II with a pair of dark median tubercles slightly larger than the tubercles on area I; area III with a pair of dark median elliptic tubercles, larger than the ones on the other areas, and some sparse elliptic tubercles. Lateral margins of dorsal scutum with a row of whitish (in ethanol) large tubercles, reaching the posterior margin of area III; most posterior tubercles fused, forming large tubercles. Posterior margin of dorsal scutum with a line of white (in ethanol) small tubercles of similar size. Dorsal scutum with low density of granules. All free 
1472 tergites with a line of small tubercles of the same approximate size. Dorsal anal operculum with 1473 small sparse tubercles. Venter. Coxa I with several sparse tubercles, larger than the one in other 1474 coxa. Coxa II with sparse tubercles; the apical are larger. Coxae III and IV with granules. Ventral 1475 anal operculum with granules. Chelicerae. Middle segment with several setae, mainly in the 1476 apical. Fixed and movable fingers with nine teeth each. Pedipalps. Tibia setation: prolateral IiIi, 1477 retrolateral IiI. Tarsal setation: prolateral II, retrolateral II, ventral side with two baso-apical lines 1478 of setae. Legs. Leg I: trochanter, femur, patella and tibia with granules. Leg II: Trochanter II with two retrolateral tubercles; femur, patella and tibia with granules. Leg III: trochanter, femur, patella and tibia with granules. Leg IV: Coxa IV: robust apical transversal prolateral apophysis, with ventral process, with the approximate trochanter size; retrolateral apophysis visible in dorsal view. Trochanter IV: prolateral small blunt apophysis; retrolateral side with small tubercles. Femur IV: short and robust; all tubercles on prolateral row with approximately the same size; dorsal row of tubercles with a large tubercle before the DBA, DBA branched with the largest branch pointing upwards, small tubercles after DBA; retrolateral row of with a large median apophysis, four large tubercles before and three large tubercles posterior to the median apophysis; all tubercles on the ventral row small. Tarsal formula: 4(3)-8(3)-8-5. Male genitalia (Fig. 14G-I). Ventral plate: Ventral surface with microsetae on basal 2/3; pronounced apical groove (reaching the line of MS B); lateral process basal when compared to other species (e.g. Mischonyx intervalensis sp. nov.); three apical helicoidal MS C on each side; two MS E, ventral and slightly basal relative to MS C; small MS D, basal relative to MS C and between MS E and MS C; four spatular MS A, forming a diagonal baso-apical line; one spatular MS B, same size as MS A. Glans: Small dorsal process; flabellum triangular with serrated margin; no information regarding stylus (broken in the analyzed specimen). Color. Brown; dorsal scutum with tones of yellow; pedipalps and trochanters I - III yellow. Female. (paratype; MZSP): Measurements: Dorsal scutum: L: 3.9; W: 3.4. Prosoma: L: 1.5; W: 2.0; Femur IV: L: 3.8. Dorsal scutum outline $\alpha$, with a constriction at the chelicerae, area III and evident coda; small median tubercles on each area; median tubercles on Area III rounded; lateral tubercles of the dorsal scutum small and the most posterior are not fused; absence of prolateral apophysis on coxa IV, but with a small retrolateral apophysis; trochanter and femur IV unarmed.

\section{Gonyleptes Kirby, 1818}

1504 Gonyleptes Kirby, 1818: 450 (type species Gonyleptes horridus Kirby, 1818, by subsequent designation, Roewer, 1913)

1506 Anoploleptes Piza, 1940: 56; B. Soares, 1943: 53; Kury, 2003: 133 [= Mischonyx Bertkau, 1818] (type species Anoploleptes dubium Piza, 1940, by original designation).

REMARKS: We reestablished Anoploleptes as a subjective junior synonym of Gonyleptes as first established by B. Soares (1943).

1513 Gonyleptes antiquus Mello-Leitão, 1934: 415. fig.6; 1935: 106. B. Soares, 1943: 53 (Male

1514 holotype; Brazil, São Paulo; IBSP 11).

1515 Paragonyleptes antiquus: B. Soares, 1945: 11, fig.1.

1516 Mischonyx antiquus: Kury, 2003: 133.

1517 Anoploleptes dubium Piza, 1940: 56, fig. 4. (Male holotype; Brazil, São Paulo, Juquiá; MZSP 
1518 401).

1519

1520

1521

1522

1523

1524

1525

1526

1527

1528

1529

1530

1531

1532

1533

1534

1535

1536

1537

1538

1539

1540

1541

1542

1543

1544

1545

1546

1547

1548

1549

1550

1551

1552

1553

1554

1555

1556

1557

1558

1559

1560

1561

1562

1563

REMARKS: Gonyleptes antiquus returns to its former genus, so the original combination is reestablished (see discussion below).

\section{Identification key for Mischonyx males}

1. Median armature on area I larger and paler (in ethanol) than those on area III (paler than the general body color) (Fig. 05A) 2

Median armature on area I smaller and the same color (in ethanol) as those on area III (paler than the general body color) (Fig. 05B) 3

2. Small individuals (3-3.5 $\mathrm{mm}$ of dorsal scutum length); median armature on area II (in ethanol) and I the same color (paler than the body) (Fig. 05A)

Mischonyx minimus sp. nov.

Large individuals ( $7-8 \mathrm{~mm}$ of dorsal scutum length); median armature on area II (in ethanol) and III the same color (darker than the body) (Fig. 01B) Mischonyx arlei

3. Posterior lateral mid-bulge tubercles fused, forming larger tubercles, paler than rest of the body (Fig. 08A) 4

Lateral mid-bulge tubercles not fused (Fig. 05B) 6

4. Ellipsed tubercles on mesotergal area III strongly compressed laterally; one clearly more developed apophysis on leg IV, with retrolateral row of tubercles (Fig. 08A) Mischonyx spinifrons

Ellipsed tubercles on area III not strongly compressed laterally; more than one developed apophysis on leg IV, with retrolateral row of tubercles

5. DBA digitiform and uniramous (Fig. 06A) ............................. Mischonyx poeta
DBA birramous (Fig. 09) Mischonyx tinguaensis sp. nov.

6. At least one mesotergal area with well-developed median armature (e.g., Fig. 06B)

.

Mesotergal areas with small tubercles subequal in size (e.g., Fig 04A) 7

7. All mesotergal areas and posterior part of dorsal scutum with well-developed median armature (Fig. 08B) Mischonyx squalidus

Mesotergal areas II -III only with well-developed median armature (e.g., Fig. 06B) 8

8. DBA branched, retrolateral branch the largest; prolateral row of tubercles on leg IV with medial tubercles more developed (Fig. 06B) Mischonyx processigerus

DBA falciform, not branched; prolateral row of tubercles on leg IV with tubercles of the same size (Fig. 03A) Mischonyx insulanus

9. Median tubercles on mesotergal area III small (e.g., Fig. 07A) ….................. 10

Median tubercles on mesotergal area III well-developed (e.g., Fig 03B) ......... 11

10. Leg IV robust, with well-developed armature; DBA well-developed; dorsal row of tubercles on leg IV with four well-developed tubercles after DBA; Mischonyx clavifemur

Leg IV long and thin, with few well-developed armatures located terminally; DBA small and sharp; without dorsal row of tubercles after DBA (Fig. 03B) .

Mischonyx intermedius

Peer] reviewing PDF | (2020:08:52148:2:0:NEW 1 Jun 2021) 
1564 11. DBA branched (e.g., Fig. 04C) …………….............................................. 12

$1565 \quad$ DBA not branched (e.g., Fig. 01C) ……….................................................. 13

1566 12. Retrolateral branch of DBA evidently larger than other branch; two apophysis on the leg 1567 IV dorsal row of tubercles, after DBA; prolateral apophysis of coxa IV with a prominent ventral 1568 process (Fig. 04A) .......................... Mischonyx intervalensis sp. nov.

1569 Both branches of DBA of the same size; two well-developed apophyses on leg IV

1570 retrolateral row of tubercles (Fig. 07A) ........................................... Mischonyx reitzi

1571 13. DBA robust and sharp, with a tubercle emerging from median part and almost as high as 1572 the entire body (e.g., Fig. 02D) 14

\section{Biogeographical remarks}

In general, harvestmen in the Atlantic Forest have a high degree of endemism (Pinto-daRocha, Da Silva \& Bragagnolo, 2005). Throughout the order, species distributions are restricted to specific areas of few thousands of square kilometers, with a few exceptions (e.g. Pinto-daRocha, Da Silva \& Bragagnolo, 2005). The distribution of most species of Mischonyx are consistent with this pattern. One exception is M. squalidus. There are records of this species from the southeastern state of Espirito Santo to the southern state of Rio Grande do Sul. It occurs not only in Atlantic Rainforest but also in cerrado areas (Figs. 15, S1 and S2), where the climate is drier (Resende, Pinto-da-Rocha \& Bragagnolo, 2012). Mestre \& Pinto-da-Rocha (2004) demonstrated that this species is synanthropic. It is able to thrive in environments like residential areas and agricultural areas. This characteristic may explain its wide distribution, since it helps these hasvestmen to disperse and colonize new areas more efficiently than most other species.

The distribution area of most Mischonyx species is restricted to only one or few records that are in close proximity to each other. This is consistent with the hypothesis that harvestmen have a high degree of endemism (Da Silva, Pinto-da-Rocha \& Morrone, 2017). Serra do Órgãos, Mantiqueira, south coast of Rio de Janeiro and Serra do Mar areas of endemism hold 11 from the 16 species of the genus. According to Pinto-da-Rocha, Da Silva \& Bragagnolo (2005) and Da Silva, Pinto-da-Rocha \& Morrone (2017), the southern coast of Rio de Janeiro and Serra dos Órgãos areas are the most species rich. This is supported by our findings and is an important piece of information for conservation, since the few remaining harvestmen habitats are under the 
1610 impact of anthropic changes (Morellato \& Haddad, 2000). To maintain the diversity of the entire

1611 group, these endemic areas need to be better protected (Da Silva, Pinto-da-Rocha \& Morrone,

1612 2017, Nogueira et al. 2019a, b).

1613

1614

1615

1616

1617

1618

1619

1620

1621

1622

1623

1624

1625

1626

1627

1628

1629

1630

1631

1632

1633

1634

1635

1636

1637

1638

1639

1640

1641

1642

1643

1644

1645

1646

1647

1648

1649

1650

1651

1652

1653

1654

\section{Divergence time of Mischonyx clade}

We are going to work with the Bayesian hypothesis to discuss divergence time and biogeography. BM is the preferred optimality criteria for estimating divergence time and there were no significant differences in the relationships among the internal branches of the topologies recovered using BM and TE (MP3 and ML3).

Two previous publications on two gonyleptid genera of the Atlantic Forest dated the divergence time of clades: Bragagnolo et al. (2015), using Promitobates, and Peres et al. (2019), using Sodreana. The divergence time of Mischonyx ( 50Mya) is consistent with the estimates obtained for Promitobates. Sodreana diverged more recently $(\sim 35.5 \mathrm{Mya})$ and occurs in a more restricted area than the other two genera (from the southern state of Paraná to the southern limit of Serra do Mar in the state of São Paulo). Promitobates occurs from the state of Santa Catarina to the northern edge of the state of São Paulo and Mischonyx occurs from Santa Catarina to the northern portion of the state of Rio de Janeiro (excluding M. squalidus, which is more widely distributed). The wider distribution of the last two genera may be a function of their older diversification times.

As stated by Da Silva, Pinto-da-Rocha \& Morrone (2017), "The main geographical barriers associated with the general historical patterns are the Valleys of the Doce, Paraiba do Sul, and Ribeira do Iguape rivers and the Todos os Santos Bay". Within Mischonyx, the split between the two major lineages occurred at 45 Mya, which is consistent with the formation of Valley of Ribeira do Iguape River, 50 -56 Mya (Almeida \& Carneiro, 1998; Pinto-da-Rocha, Da Silva \& Bragagnolo, 2005; Da Silva, Pinto-da-Rocha \& Morrone, 2017).

In one of the lineages (Figure 16), the split dividing species from SMSP from the species from SSP, PR and SC occurred at $\sim 8$ Mya. This could be the result of the rise of Serra do Mar (65 -50 Mya) (Almeida \& Carneiro, 1998; Pinto-da-Rocha, Da Silva \& Bragagnolo, 2005). Still inside this lineage, the split between $M$. intervalensis sp. nov., a species occurring at the northern portion of Ribeira do Iguape River (SSP AoE), from the species from the southern portion of this river (PR and SC AoE) occurred at $\sim 28$ Mya. The timing of this split is consistent with the results of Peres et al. (2019) on the split of Sodreana species from the north and south of this valley. After the valley was formed, it passed went through uplift and denudation events persisting from the Upper Cretaceous to the Paleogene/ Neogene (Franco-Magalhães et al., 2010; Franco-Magalhães, Hackspacher \& Glasmacher, 2010), a period consistent with the split mentioned above.

Inside the other lineage (Figure 16), the first split occurred at $\sim 45$ Mya, when $M$. intermedius diverged from the remaining species. This species is the only one from Esp AoE. It is very likely that the distensive tectonic activity from the tertiary period, which separated the Rio Doce, Paraíba do Sul and São Francisco basins (Cherem et al., 2012; Morais et al., 2005), isolated it from the sister species from Org, LSRJ and Mnt AoE. Many other studies with different taxa corroborate the relevance of the Doce River disjunction in shaping biogeographical patterns (Müller, 1973; Prance, 1982; Amorim \& Pires (1996); Pellegrino et al., 2005; Sigrist \&

1655 Da Silva, Pinto-da-Rocha \& Morrone, 2017). The split of M. processigerus (Mnt AoE) from 
1656 species from LSRJ and Org occurred at 29 Mya, agreeing with the formation of the Paraíba do

1657 Sul Valley and its river change of course, during the Oligocene-Miocene (Almeida \& Carneiro,

1658 1998; Pinto-da-Rocha, Da Silva \& Bragagnolo, 2005; Cherem et al., 2012)

1659

In general, the divergence times of Mischonyx species are older than 5 Mya (except for

1660 M. clavifemur comb. nov. diverging from M. reitzi comb. nov. and M. parvus comb. nov.

1661 diverging from M. squalidus). This is consistent with the speciation events in Promitobates

1662 (Bragagnolo et al., 2015). Authors who support the Pleistocene refugia hypothesis have proposed

1663 that it happened beginning 5 Mya (Ravelo et al., 2004, Carnaval \& Moritz, 2008; Carnaval et

1664 al., 2009; Holbourn et al., 2014). Therefore, the ancient cooling of the Miocene/Pliocene

1665 probably shaped most of the divergences between species inside the genus and the Pleistocene

1666 refugia contributed to the most recent speciation events to shape the extant population diversity.

1667 Finally, it is important to stress that $M$. squalidus appears in all analyses using molecular

1668 and TE as sister to M. parvus comb. nov., inside the clade with species from LSRJ. Based on

1669 that we conclude that it probably diverged at this AoE in the past and, later, spread all over the

1670 Atlantic Forest and Cerrado areas, as discussed in the biogeographical session. Therefore, from

1671 now on, in discussions regarding the AoE and the relationship among clades, we will consider $M$.

1672 squalidus as belonging to LSRJ AoE.

1673

1674

1675

1676

1677

1678

1679

1680

1681

1682

1683

1684

1685

1686

1687

1688

1689

1690

1691

1692

1693

1694

1695

1696

1697

1698

1699

1700

The hypothesis of TE under maximum likelihood as the optimality criteria (ML3)

We choose ML3 grounded in the following arguments.

In the results of MP3, M. tinguaensis sp. nov. has more than 30 autapomorphies. This long branch encompasses almost one third of all morphological characters coded in the analysis. Additioanlly, comparing this situation with the number of morphological changes in other harvestmen phylogenies (Bragagnolo \& Pinto-da-Rocha, 2012; Da Silva \& Gnaspini, 2010; Da Silva \& Pinto-da-Rocha, 2010; Pinto-da-Rocha \& Bragagnolo, 2010), we believe that it it is unlikely that this single species has accumulated so many changes and that the results of ML3 are more likely.

Another reason to choose ML3 is the position of M. tinguaensis sp. nov. in MP3 (Fig. 18A), inside the clade formed strictly by $M$. spinifrons comb. nov.. It separates the seven sequenced specimens into two polyphyletic lineages. The polyphyly of M. spinifrons comb. nov. seems odd, since the individuals analyzed by us are morphologically identical and there are few site changes in their sequences. In contrast, ML3 (Fig. 17) places M. tinguaensis sp. nov. as the lineage diverging after M. processigerus. This odd placement of $M$. tinguanesis $\mathbf{s p}$. nov. inside the clade formed by another species' clade in MP3 seems to contribute to the fact that this species has 30 autapomorphies, as discussed in the last paragraph. Similarly, MP3 and B3 (Fig. 18B) place M. insulanus inside the clade formed by M. kaisara, splitting this last species into two polyphyletic lineages. To match this hypothesis, the character changes in this clade containing M. insulanus and M. kaisara, in B3, has several homoplastic changes, as in $M$. tinguaensis sp. nov. In ML3, instead of this split, M. kaisara is monophyletic and sister to $M$. insulanus. Therefore, we prefer ML3, since it does not separate exemplars from the same species into polyphyletic lineages.

Finally, in B3 (Fig. 18B), the clade formed by species from LSRJ AoE has two species from Org AoE, M. scaber and M. tinguaensis sp. nov.. When comparing our results with the biogeographic (e.g.: Da Silva, Pinto-da-Rocha \& Morrone, 2017), phylogeographic (e.g.: 
1702 works on Atlantic Forest harvestmen, we conclude that species from one AoE are rarely

1703 clustered with species from another AoE, given the high degree of endemism discussed in the

1704 biogeographic session (Pinto-da-Rocha, Da Silva \& Bragagnolo, 2005; Da Silva, Pinto-da-Rocha

$1705 \&$ Morrone, 2017). In conclusion, we prefer ML3 to B3, since the clades recovered by it reflect

1706 biogeographical hypothesis from other researches.

1707

1708

1709

1710

1711

1712

1713

1714

1715

1716

1717

1718

1719

1720

1721

1722

1723

1724

1725

1726

1727

1728

1729

1730

1731

1732

1733

1734

1735

1736

1737

1738

1739

1740

1741

1742

1743

1744

1745

1746

1747

\section{Diagnosis of previews authors}

Although Vasconcelos (2005a) described some characteristics of Mischonyx, and noted two possibly diagnostic characters (yellowish-reddish tubercles on lateral margin of mid-bulge and large median tubercles on area III), Pinto-da-Rocha et al. (2012) were the first to propose a diagnosis for the genus, which includes the presence of well-developed median tubercles on mesotergal areas (and add their elliptic form) and the lateral tubercles of mid-bulge paler than the rest of body, in addition to robust spines on the anterior border of dorsal scutum. Pinto-da-Rocha et al. (2012) also suggested that Mischonyx is closely-related to Hernandariinae.

In view of our results, we agree that the elliptic median tubercles on area III are diagnostic for Mischonyx. The shape of the tubercle differs in the clade containing M. arlei comb. nov., M. intermedius and M. minimus sp. nov., but is elliptic in all other species of the genus. Along with that, our character "Lateral tubercles on anterior margin of dorsal scutum subequal in size" (\#7-0) is roughtly equivalent to "robust spines on the anterior border of dorsal scutum" proposed by Pinto-da-rocha et al. (2012)

In the results of our analyses, Mischonyx is not close to the Hernandariinae species (Piassagera brieni and Pseudotrogulus telluris), even when only morphological characters are considered (Figs. S3 - S5). This is in agreement with Pinto-da-Rocha et al. (2014), who considered Mischonyx squalidus (Mischonyx cuspidatus in the article) to lie outside of Hernandariinae.

\section{Other taxonomical and topological remarks}

Recent publications on the taxonomy and systematics of harvestmen considered $G$. antiquus as a member of Mischonyx (Kury, 2003; Vasconcelos, 2005a and Pinto-da-Rocha et al., 2012). Our morphological analysis also places this species inside the genus. However, these results are not consistent with molecular and TE analyses (Figs. 16-25 and S6 - S8). In ML3, it is sister to Ampheres leucopheus, a Caelopyginae. This indicates that the morphological similarities are convergences.

On the other hand, MP2, which does not include morphological characters, places a clade with Multumbo and Deltaspidium species inside Mischonyx, as sister to the clade with species from SMSP, SSP, PR and SC AoE. This group makes no morphological or biogeographical sense, since these species are from Org and LSRJ AoE. However, when we include morphological characters, MP3 does not recover the same clade and excludes Multumbo and Deltaspidium from Mischonyx genus.

The arguments discussed in the last two paragraphs hightlight the importance of combining morphological and molecular data to solve conflicting topologies. Wiens (2004) and Baker \& Gatesy (2002) supported the hypothesis that morphological data is important especially when the results from molecular analysis seem problematic. For example, in the research of De Sá et al. (2014), questionable relationships among frog speces became elucidated when 
1748 morphological and behavioral characters from both larvae and adults were added. Here, we

1749

1750

1751

1752

1753

1754

1755

1756

1757

1758

1759

1760

1761

1762

1763

1764

1765

1766

1767

1768

1769

1770

1771

1772

1773

1774

1775

1776

1777

1778

1779

1780

1781

1782

1783

1784

1785

1786

1787

1788

1789

1790

1791

1792

1793 conclude that morphological characters also helped to strengthen the hypotheses and solve some problematic relationships in MP2, consistent with Wipfler et al. (2015), Lee \& Palci (2015) and Giribet (2015) who consider morphological characters fundamental even in the phylogenomics era, since the combination of morphological and molecular data provide independent sources of evidence.

\section{Conclusions}

The total evidence analyses in this research shows that Mischonyx sensu Pinto-da-Rocha et al. (2012) is not monophyletic. The new definition based on our data includes Michonyx arlei comb. nov and excludes Mischonyx antiquus, which is placed back in Gonyleptes. In addition, Geraecormobiella Mello-Leitão, 1931, Ariaeus Sørensen, 1932 and Urodiabunus Mello-Leitão, 1935 are junior synonyms of Mischonyx Bertkau, 1880. Geraecormobiella convexa MelloLeitão, 1931 and Geraeocormobius cheloides Mello-Leitão, 1940 are junior synonym of Weyhia spinifrons Mello-Leitão, 1923; Ilhaia cuspidata Roewer, 1913, Ilhaia fluminensis Mello-Leitão, 1922, Gonazula gibbosa Roewer, 1930, Eduardoius granulosus Mello-Leitão, 1931, Giltaya solitaria Mello-Leitão, 1932 and Eduardoius lutescens Roewer, 1943 are junior synonym of Mischonyx squalidus Bertkau, 1880; Ilhaia sulina Soares \& Soares, 1947 is a junior synonym of Xundarava anomala Mello-Leitão, 1936. We describe three new species for the genus: Mischonyx minimus sp. nov., Mischonyx intervalensis sp. nov. and Mischonyx tinguaensis sp. nov.. Geraeocormobius reitzi Vasconcelos, 2005, Weyhia clavifemur Mello-Leitão, 1927 and Weyhia spinifrons Mello-Leitão, 1923 were transferred to Mischonyx. Weyhia parva Roewer, 1917 was removed from the synonym with Mischonyx squalidus, Bertkau 1880 (see Kury, 2003: 134), considered as a valid species and transferred to Mischonyx.

The new composition of the genus after all synonyms, combinations and new species description is as follows: Mischonyx. anomalus (Mello-Leitão, 1936); Mischonyx arlei (MelloLeitão, 1935b) comb. nov., Mischonyx clavifemur, (Mello-Leitão, 1927a) comb. nov.; Mischonyx fidelis (Mello-Leitão, 1931b); Mischonyx insulanus (H. Soares, 1972); Mischonyx intermedius (Mello-Leitão, 1935b); Mischonyx intervalensis sp. nov.; Mischonyx kaisara Vasconcelos, 2004; Mischonyx minimus sp. nov.; Mischonyx parvus (Roewer, 1917) comb. nov.; Mischonyx poeta Vasconcelos, 2005a; Mischonyx processigerus (Soares \& Soares, 1970); Mischonyx reitzi (Vasconcelos, 2005) comb. nov.; Mischonyx scaber (Kirby, 1819); Mischonyx spinifrons (Mello-Leitão, 1923) comb. nov.; Mischonyx squalidus Bertkau, 1880; Mischonyx tinguaensis sp. nov.

We believe that the most plausible phylogenetic hypothesis was recovered using Total Evidence and Maximum Likelihood. Unlike the rival hypotheses, it does not require an unusual number of character changes (apomorphies) leading to M. tinguaensis sp. nov., it has high bootstrap support for Mischonyx and is well supported by morphological synapomorphies. The Mischonyx clade is supported by the following morphological characters: lateral tubercles on anterior margin of dorsal scutum with the same size, elliptic tubercles on area III, absence of prolateral apophysis on females, femur prolaterally curved, three to six apophysis on the apical half of retrolateral row on femur IV and brown as the general body color. There are two major clades inside Mischonyx: one with species from LSRJ, Mnt, Org and Esp AoE, and the other with species from SMSP, SSP, PR and SC AoE. The divergence time of these clades are in agreement with geological events. We estimate that Mischonyx clade diverged $50.53 \mathrm{Mya}$, and

Peer) reviewing PDF | (2020:08:52148:2:0:NEW 1 Jun 2021) 
1794 inside the genus there are two major clades. One of them cointains species from Paraná, Santa

1795 Catarina, South of São Paulo and Serra do Mar Areas of Endemism and the other has species

1796 from Espinhaço, Bocaina, South coast of Rio de Janeiro and Serra dos Órgãos Areas of

1797 Endemism. The first split inside these two clades occurred at 48.94 and 44.80 Mya, respectively.

1798

1799

1800

1801

1802

1803

1804

1805

1806

1807

1808

1809

1810

1811

1812

1813

1814

1815

1816

1817

1818

1819

1820

1821

1822

1823

1824

1825

1826

1827

1828

1829

1830

1831

1832

1833

\section{Acknowledgements}

We thank Marcio B. da Silva, Cristina A. Rheims for their advice and suggestions. We are grateful to Gonzalo Giribet and an anonymous reviewer for suggestions on an early draft of the manuscript. We thank Jimmy Cabra-Garcia, Brittany Damron, Daniel Chirivi , Marília Pessoa Silva, Daniel Castro and André Nogueira for their help in field trips, opinions and advices during the whole process of writing this manuscript. We also thank Jairo Moreno-González for his huge help in our phylogenies and Adriano Kury for sharing pictures and information We thank Manuel Antunes Junior, Beatriz Vieira Freire, Phillip Lenktaitis, Ênio Mattos for their help in DNA sequencing and SEM operation. This study was funded by CAPES to Caio Gueratto and FAPESP (BIOTA, 2013/50297-0), NSF (DOB 1343578), and NASA to Ricardo Pinto-da-Rocha.

\section{References}

Acosta LE, Kury AB, Juárez, ML. 2007. New records of Geraeocormobius sylvarum (Arachnida, Opiliones, Gonyleptidae), with a remarkable disjunction in northwestern Argentina. Boletín Sociedad Entomológica Aragonesa 41:303 -306.

Almeida FFM, Carneiro CDR. 1998. Origem e evolução da Serra do Mar. Revista Brasileira de Geociências 28:135-150. DOI: 10.25249/0375-7536.1998135150.

Amorim DS, Pires MRS. 1996. Neotropical biogeography and a method for a maximum biodiversity estimation. In: Bicudo CEM, Menezes NA, Ed. Biodiversity in Brazil. A First Approach. São Paulo: Conselho Nacional de Desenvolvimento Cientıfico e Tecnológico, 183-219.

Arango CP, Wheeler WC. 2007. Phylogeny of the sea spiders (Arthropoda, Pycnogonida) based on direct optimization of six loci and morphology. Cladistics 23: 255-293. DOI: 10.1111/j.1096-0031.2007.00143.x.

Baker RH, Gatesy J. 2002. Is morphology still relevant? In: DeSalle R, Wheeler W, Giribet G, ed. Molecular Systematics and Evolution: Theory and Practice, Birkhäuser, Basel, 163-174.

Benavides LR, Pinto-da-Rocha R, Giribet G. in press. The phylogeny and evolution of the flashiest of the armored harvestmen (Arachnida: Opiliones). Systematic Biology, doi: 10.1093/sysbio/syaa080.

Benedetti AR. 2017. Análise filogenética do clado K92, com ênfase em Gonyleptinae, baseada em caracteres morfológicos e moleculares (Opiliones, Gonyleptidae). D. Phil. Thesis, Universidade de São Paulo, São Paulo. doi:10.11606/T.41.2018.tde-03042018-100718.

Benedetti AR, Pinto-da-Rocha R. 2019. Description of two new species of Progonyleptoidellus (Opiliones: Gonyleptidae), with a cladistic analysis of the genus, an overview of relationships 
1834 in the K92 group, and taxonomic notes on Deltaspidium. Zootaxa 4691(5):461-490.

1835 doi:10.11646/zootaxa.4691.5.3.

1836 Bertkau P. 1880. Verzeichnis der von Prof. Ed. von Beneden auf seiner im Auftrage der Belgischen regierung untemommenen wissenschaftlichen Reise nach Brasilien und La Plata i. J. 1872-1875 gesammelten Arachniden. Mém. cour. Acad. Belgique 43:1-120.

Bouckaert R, Vaughan TG, Barido-Sottani J, Duchêne S, Fourment M, Gavryushkina A. 2019. BEAST 2.5: An advanced software platform for Bayesian evolutionary analysis. PLoS computational biology 15(4):e1006650. https://doi.org/10.1371/journal.pcbi.1006650.

1842

Bragagnolo C, Pinto-da-Rocha R. 2009. Review of the Brazilian harvestman genus Roeweria Mello-Leitão, 1923 (Opiliones: Gonyleptidae). Zootaxa 2270:39-52.

1844

Bragagnolo C, Pinto-da-Rocha R. 2012. Systematic review of Promitobates Roewer, 1913 and cladistic analysis of Mitobatinae Simon, 1879 (Arachnida: Opiliones:Gonyleptidae). Zootaxa 3308:1-48.

Bragagnolo C, Pinto-da-Rocha R, Antunes M, Clouse RM. 2015. Phylogenetics and phylogeography of a long-legged harvestman (Arachnida: Opiliones) in the Brazilian Atlantic Rain Forest reveals poor dispersal, low diversity and extensive mitochondrial introgression. Invertebrate Systematics 29:386-404. https://doi.org/10.1071/IS15009.

Brunes TO, Sequeira F, Haddad CFB, Alexandrino J. 2010. Gene and species trees of a Neotropical group of treefrogs: Genetic diversification in the Brazilian Atlantic Forest and the origin of a polyploid species. Molecular Phylogenetics and Evolution 57:1120-1133. Phenotypic evolution of an Atlantic Forest passerine (Xiphorhynchus fuscus): Biogeographic and systematic implications. Biological Journal of the Linnean Society, 113, 1047-1066.

1857 Carnaval AC, Moritz C. 2008. Historical climate modelling predicts patterns of current biodiversity in the Brazilian Atlantic Forest. Journal of Biogeography 35:1187-1201 DOI: 10.1111/j.1365-2699.2007.01870.x. genetic diversity in the Brazilian Atlantic Forest Hotspot. Science 323:785-789 DOI: 10.1126/science.1166955.

Cheng R-C, Kuntner M. 2014. Phylogeny suggests nondirectional and isometric evolution of sexual size dimorphism in argiopine spiders. Evolution 68: 2861-2872. DOI:10.1111/evo.12504. term evolution of denudational escarpments in southeastern Brazil. Geomorphology 173174:118-127. DOI:10.1016/j.geomorph.2012.06.002.

1869 Chernomor O, von Haeseler A, Minh BQ. 2016. Terrace aware data structure for phylogenomic 
1870 inference from supermatrices. Systematic Biology 65:997-1008 DOI: 10.1093/sysbio/syw037.

1871 Colgan DJ, McLauchlan A, Wilson GDF, Livingston SP, Edgecombe GD, Macaranas J, Cassis 1872 G, Gray MR. 1998. Histone H3 and U2 snRNA DNA sequences and arthropod molecular 1873 evolution. Australian Journal of Zoology 46: 419-437 DOI: 10.1071/ZO98048.

DaSilva MB, Gnaspini P. 2010. Systematic revision of Goniosomatinae (Arachnida: Opiliones: Gonyleptidae), with a cladistic analysis and biogeographical notes. Invertebrate Systematics. 23(6):530-624 DOI: 10.1071/IS09022.

DaSilva MB, Pinto-da-Rocha R. 2010. Systematic review and cladistic analysis of the Hernandariinae (Opiliones: Gonyleptidae). Zoologia 27(4):577-642 DOI: 10.1590/S198446702010000400010 .

DaSilva MB, Pinto-da-Rocha R, Morrone, JJ. 2017. Historical relationships of areas of endemism of the Brazilian Atlantic rainforest: a cladistic biogeographic analysis of harvestman taxa (Arachnida: Opiliones). Current Zoology 63(5):525-535 DOI: 10.1093/cz/zow092.

De Ley P, Félix MA, Frisse LM, Nadler SA, Sternberg PW, Thomas WK. 1999. Molecular and morphological characterization of two reproductively isolated species with mirror image anatomy (Nematoda: Cephalobidae). Nematology 2:591-612.

De Sá RO, Grant T, Camargo AW, Heyer R, Ponssa ML, Stanley E. 2014. Systematics of the Neotropical Genus Leptodactylus Fitzinger, 1826 (Anura: Leptodactylidae): Phylogeny, the Relevance of Non-molecular Evidence, and Species Accounts. South American Journal of Herpetology 9(1):1-128. DOI: 10.2994/SAJH-D-13-00022.1.

Dias BC, Souza ES, Hara MR, Willemart RH. 2014. Intense leg tapping behavior by the harvestman Mischonyx cuspidatus (Gonyleptidae): an undescribed defensive behavior in Opiliones? The Journal of Arachnology 42(1):123-125. DOI: 10.1636/Hi12-06.1.

1896

Dias BC, Willemart RH. 2013. The effectiveness of post-contact defenses in a prey with no precontact detection. Zoology 116(3):168-174 DOI: 10.1016/j.zool.2012.12.001.

1899

Dias JM. 2017. O uso do olfato nos opiliões Neosadocus maximus e Mischonyx cuspidatus (Arachnida: Opiliones: Laniatores). Masters Dissertation. Universidade de São Paulo. São Paulo. DOI: 10.11606/D.41.2018.tde-03042018-083949.

Edgecombe GD, Giribet G. 2006. A century later - a total evidence re-evaluation of the phylogeny of scutigeromorpha centipedes (Myriapoda: Chilopoda). Invertebrates Systematics

1902 Ewing B, Green P. 1998. Base-calling of automated sequencer traces using Phred. II, Error probabilities. Genome Research 8:186-194.

1904 Ewing B, Hillier L, Wendl MC, Green P. 1998. Base-calling of automated sequencer traces 
1906 Franco-Magalhães AOB, Hackspacher PC, Glasmacher UA, Saad AR. 2010. Rift to post-rift evolution of a "passive" continental margin: The Ponta Grossa Arch, SE Brazil. International

1908 Journal of Earth Sciences 99:1599-1613. DOI: 10.1007/s00531-010-0556-8.

1909

1910

1911

1912

1913

1914

1915

1916

1917

1918

1919

1920

1921

1922

1923

1924

1925

1926

1927

1928

1929

1930

1931

1932

1933

1934

1935

1936

1937

1938

1939

1940

Franco-Magalhães AOB, Hackspacher PC, Saad AR. 2010. Exumação tectônica e reativação de paleolineamentos no Arco de Ponta Grossa: termocronologia por traços de fissão em apatitas. Revista Brasileira de Geociências 40:184-195 DOI: 10.25249/0375-7536.2010402184195.

Folmer O, Black M, Hoeh W, Lutz R, Vrijenhoek R. 1994. DNA primers for amplification of mitochondrial cytochrome c oxidase subunit I from diverse metazoan invertebrates. Molecular Marine Biology and Biotechnology 3:294-299.

Giribet G. 2015. Morphology should not be forgotten in the era of genomics - a phylogenetic perspective. Zoologischer Anzeiger - A Journal of Comparative Zoology 256:96-103 DOI: 10.1016/j.jcz.2015.01.003.

Goloboff PA. 1999. Analyzing large data sets in reasonable times: solutions for composite optima. Cladistics 15:415-428 DOI: 10.1006/clad.1999.0122.

Goloboff PA, Catalano SA. 2016. TNT version 1.5, including a full implementation of phylogenetic morphometrics. Cladistics 32: 221-238 DOI: 10.1111/cla.12160.

Goloboff P, Farris J, Nixon KC. 2008. TNT, a free program for phylogenetic analysis. Cladistics 24:774-786 DOI: 10.1111/j.1096-0031.2008.00217.x.

Gordon D, Abajian C, Green P. 1998. Consed: a graphical tool for sequence finishing. Genome Research 8:195-202 DOI: 10.1101/gr.8.3.195.

Gordon D, Desmarais C, Green P. 2001. Automated finishing with autofinish. Genome Research 11:614-625 DOI: 10.1101/gr.171401.

Grant T, Kluge A. 2009. Parsimony, explanatory power, and dynamic homology testing. Systematics and Biodiversity 7:357-363 DOI: 10.1017/S147720000999017X.

Holbourn A., Kuhnt W, Lyle M, Levay L, Romero O, Andersen N. 2014. Middle Miocene climate cooling linked to intensification of eastern equatorial Pacific upwelling. Geology 42:19-22. DOI: 10.1130/G34890.1.

ICZN 1999. International Code of Zoological Nomenclature. Fourth Edition. The International Trust for Zoological Nomenclature, London, UK.

Ji Y-J, Zhang D-X, He L-J. 2003. Evolutionary conservation and versatility of a new set of primers for amplifying the ribosomal internal transcribed spacer regions in insects and other invertebrates. Molecular Ecology Notes 3:581-585 DOI: 10. 1046/j.1471-8286.2003.00519.x.

Kalyaanamoorthy S, Minh BQ, Wong TKF, von Haeseler A. 2017. ModelFinder: Fast Model Selection for Accurate Phylogenetic Estimates. Nature Methods 14:587-589 DOI: $10.1038 /$ nmeth.4285.

PeerJ reviewing PDF | (2020:08:52148:2:0:NEW 1 Jun 2021) 
1941 Katoh K, Misawa K, Kuma K, Miyata T. 2002. MAFFT: a novel method for rapid multiple sequence alignment based on fast Fourier transform. Nucleic Acids Research 33:511-518

1943 DOI: $10.1093 /$ nar/gkf436.

1944

Kluge A, Grant T. 2006. From conviction to antisuperfluity: old and new justifications of parsimony in phylogenetic inference. Cladistics 22: 276-288 DOI: 10.1111/j.10960031.2006.00100.x.

Kury AB. 1990. Synonymic notes on Mitobates Sundevall, with redescription of the type species, M. conspersus (Perty) (Opiliones, Gonyleptidae, Mitobatinae). Bulletin of the British Arachnological Society 8(6):194-200.

Kury AB. 1992. A review of Metamitobates Roewer (Opiliones, Gonyleptidae, Mitobatinae). Mitteilungen aus dem Zoologisches Museum in Berlin 68(1):157-166.

Kury AB. 2003. Annotated catalogue of the Laniatores of the New World (Arachnida, Opiliones). Revista Ibérica de Aracnología 1:5-337.

1954

Kury AB, Villareal MO. 2015. The prickly blade mapped: establishing homologies and chaetotaxy for macroseatae of penis ventral plate in Gonylepoidea (Arachinida, Opiliones, Laniatores). Zoological Journal of Linnean Society 174(1):1-46 DOI: 10.1111/zoj.12225.

Kury A, Medrano M. 2016. Review of terminology for the outline of dorsal scutum in Laniatores (Arachnida, Opiliones). Zootaxa 4097(1):130-134 DOI: 10.11646/zootaxa.4097.1.9.

Kury AB. 2020. Classification of Opiliones. Museu Nacional/UFRJ website. Online at: http://www.museunacional.ufrj.br/mndi/Aracnologia/opiliones.html (accessed: 10th August 2020).

Larsson, A. 2014. AliView: a fast and lightweight alignment viewer and editor for large datasets. Bioinformatics. 30(22):3276-3278 DOI: 10.1093/bioinformatics/btu531.

Lee MSY, Palci A. 2015. Morphological Phylogenetics in the Genomic Age. Current Biology 25(19):922-929 DOI: 10.1016/j.cub.2015.07.009.

Maddison WP, Maddison DR. 2017. Mesquite: a modular system for evolutionary analysis.

Machado, D.J., 2015. YBYRA facilitates comparison of large phylogenetic trees. BMC Bioinformatics 16, 204.

1972

1973

Mello-Leitão CF. 1940. Sete gêneros e vinte e oito espécies de Gonyleptidae. Archivos de Zoologia do Estado de São Paulo 1(1):1-52.

Mendes AC. 2011. Phylogeny and taxonomic revision of Heteropachylinae (Opiliones:

1974 Laniatores: Gonyleptidae). Zoological Journal of the Linnean Society 163:437-483 DOI: 10.1111/j.1096-3642.2011.00706.x. 
1975 Mestre LAM, Pinto-da-Rocha R. 2004. Population dynamics of an isolated population of the 1976 harvestman Ilhaia cuspidata (Opiliones, Gonyleptidae), in araucaria forest (Curitiba, Paraná, 1977 Brazil). Journal of Arachnology 32(2):208-220 DOI: 10.1636/M02-61.

1978

1979

1980

1981

1982

1983

1984

1985

1986

1987

1988

1989

1990

1991

1992

1993

1994

1995

1996

1997

1998

1999

2000

2001

2002

2003

2004

2005

2006

2007

2008

2009

2010

Meyer CP. 2003. Molecular systematics of cowries (Gastropoda: Cypraeidae) and diversification patterns in the tropics. Biological Journal of Linnean Society 79:401-459 DOI: 10.1046/j.1095-8312.2003.00197.x.

Minh BQ, Nguyen MAT, von Haesler A. 2013. Ultrafast approximation for phylogenetic bootstrap. Molecular Biology and Evolution 30:1118-1195 DOI: 10.1093/molbev/mst024.

Morais RMO, Mello CL, Costa FO, Ribeiro CS. 2005. Estudo faciológico de depósitos terciários (formações Barreiras e Rio Doce) aflorantes na porção emersa da Bacia do Espírito Santo e na região emersa adjacente à porção norte da Bacia de Campos. In: Congresso Abequa, 10, Guarapari. http://www.abequa.org.br/trabalhos/0291_rute_morais.pdf

Morellato LPC, Haddad CFB. 2000. Introduction: the Brazilian Atlantic Forest. Biotropica 32(4b):786 - 792 DOI: 10.1111/j.1744-7429.2000.tb00618.x.

Müller P. 1973. The dispersal centers of terrestrial vertebrates in the Neotropical realm: A study in the evolution of the Neotropical biota and its native landscape. Biogeographica 2:1-250.

Nguyen LT, Schmidt HA, von Haeseler A, Minh BQ. 2015. IQ-TREE: A fast and effective stochastic algorithm for estimating maximum likelihood phylogenies. Molecular Biology and Evolution. 32:268-274 DOI: 10.1093/molbev/msu300.

Nixon KC. 1999. The parsimony ratchet, a new method for rapid parsimony analysis. Cladistics 15: 407-414 DOI: 10.1111/j.1096-0031.1999.tb00277.x.

Nixon KC. 2002. Winclada (BETA) ver. 1.00.08. New York, Published by author, Ithaca, 734745.

Nogueira AA, Bragagnolo C, DaSilva MB, Martins T, Perbiche-Neves G, Pinto-da-Rocha R. 2019a. Historical signatures in the alpha and beta diversity patterns of Atlantic Forest harvestman communities (Opiliones-Arachnida). Canadian Journal of Zoology 97:631-643 DOI: $10.1139 / \mathrm{cjz}-2018-0032$.

Nogueira AA, Bragagnolo C, DaSilva MB, Carvalho LS, Benedetti A, Pinto-da-Rocha R. 2019b. Spatial variation in phylogenetic diversity of communities of Atlantic Forest harvestmen (Opiliones, Arachnida). Insect Conservation and Diversity 12: 414-426 DOI: 10.1111/icad.12356.

Palumbi SR. 1996. Nucleic acids, II: the polymerase chain reaction. In: Hillis DM, Moritz C, Mable BK, eds. Molecular Systematics. Sinauer Associates. Sunderland 205-247.

Pellegrino KCM, Rodrigues MT, Waite AN, Morando M, Yonenaga-Yassuda Y, Sites JW. 2005. Phylogeography and species limits in the Gymnodactylus darwinii complex (Gekkonidae, Squamata): genetic structure coincides with river systems in the Brazilian Atlantic Forest. 
2012 Peres EA, Benedetti AR, Hiruma ST, Sobral-Souza T, Pinto-da-Rocha R. 2019. Phylogeography

2013

2014

2015

2016

2017

2018

2019

2020

2021

2022

2023

2024

2025

2026

2027

2028

2029

2030

2031

2032

2033

2034

2035

2036

2037

2038

2039

2040

2041

2042

2043

2044

2045

2046 of Sodreaninae harvestmen (Arachnida: Opiliones: Gonyleptidae): insights into the biogeography of the southern Brazilian Atlantic Forest. Molecular Phylogenetics and Evolution 138:1-16 DOI:10.1016/j.ympev.2019.05.028.

Peres EA, DaSilva MB, Antunes M, Pinto-Da-Rocha R. 2018. A short-range endemic species from south-eastern Atlantic Rain Forest shows deep signature of historical events: phylogeography of harvestmen Acutisoma longipes (Arachnida: Opiliones). Systematics and Biodiversity 16:171-187 DOI: 10.1080/14772000.2017.1361479.

Pinto-da-Rocha R. 1997. Systematic review of the Family Stygnidae Opiliones: Laniaores: Gonyleptoidea). Arquivos de Zoologia 33(4):163-342 DOI: 10.11606/issn.21767793.v33i4p163-342.

Pinto-da-Rocha R. 2002. Systematic review and cladistics analysis of the Caelopyginae (Opiliones, Gonyleptidae). Arquivos Zoologia 36:357-464 DOI: 10.1590/S198446702010000400010.

Pinto-da-Rocha R, DaSilva MB, Bragagnolo C. 2005. The Faunistic similarity and historic biogeography of the harvestmen of southern and southeastern atlantic rain forest of Brazil. The Journal of Arachnology 33: 290-299 DOI: 10.1636/04-114.1.

Pinto-da-Rocha R, Bragagnolo C. 2010. Systematic revision and cladistic analysis of the Brazilian subfamily Sodreaninae (Opiliones: Gonyleptidae). Invertebrate Systematics 24:509538 DOI: 10.1590/S1984-46702010000400010.

Pinto-da-Rocha R, Benedetti AR, Vasconcelos E, Hara MR. 2012. New systematic assignments in Gonyleptoidea (Arachnida, Opiliones, Laniatores). Zookeys 198: 25-68 DOI: 10.3897/zookeys.198.2337.

Pinto-da-Rocha R, Bragagnolo C, Marques FPL, Antunes Junior M. 2014. Phylogeny of harvestmen family Gonyleptidae inferred from a multilocus approach (Arachnida: Opiliones). Cladistics 30:519-539 DOI: 10.1111/cla.12065.

Prance GT. 1982. Forest refuges: Evidence from woody angiosperms. In Prance GT, ed. Biological diversification in the tropics New York: Columbia University Press, 137-158.

Prendini L, Weygoldt P, Wheeler WC. 2005. Systematics of the Damon variegatus group of African whip spiders (Chelicerata: Amblypygi): evidence from behaviour, morphology and DNA. Organisms Diversity \& Evolution 5:203-236 DOI: 10.1016/j.ode.2004.12.004.

Rambaut A. 2010. FigTree v1.3.1. Institute of Evolutionary Biology, University of Edinburgh, Edinburgh. http://tree.bio.ed.ac.uk/software/figtree/.

Rambaut A, Drummond AJ, Xie D, Baele G and Suchard MA. 2018. Posterior summarisation in Bayesian phylogenetics using Tracer 1.7. Systematic Biology 67(5):901-904 DOI: 
2048

2049

2050

2051

2052

2053

2054

2055

2056

2057

2058

2059

2060

2061

2062

2063

2064

2065

2066

2067

2068

2069

2070

2071

2072

2073

2074

2075

2076

2077

2078

2079

2080

2081

2082

Ravelo AC, Andreasen DH, Lyle M, Olivarez-Lyle A, Wara MW. 2004. Regional climate shifts caused by gradual global cooling in the Pliocene epoch. Nature 429: 263-267 DOI: 10.1038/nature02567.

Resende LPA, Pinto-da-Rocha R, Bragagnolo C. 2012. The harvestmen fauna (Arachnida: Opiliones) of the Parque Estadual Carlos Botelho, and the Floresta Nacional de Ipanema, São Paulo, Brazil. Biota Neotropica 12(4):146-155. DOI: 10.1590/S1676-06032012000400016.

Reyda FB, Olson PD. 2003. Cestodes of Peruvian freshwater stingrays. Journal of Parasitology 89:1018-1024 DOI: 10.1645/GE-3143.

Rocha DFO, Wouters FC, Zampieri DS, Brocksom TJ, Machado G, Marsaioli AJ. 2013. Harvestmen phenols and benzoquinones: characterisation and biosynthetic pathway. Molecules 18: 11429-11451 DOI: 10.3390/molecules180911429.

Roewer CF. 1923 Die Weberknechte der Erde. Systematische Bearbeitung der bisher bekannten Opiliones. Gustav Fischer, Jena, 1116 pp. Available at:

http://www.museunacional.ufrj.br/mndi/Aracnologia/pdfliteratura/Roewer/WDE\%201923.ht m (Accessed 11 August 2020).

Sánchez-Pacheco SJ, Torres-Carvajal O, Aguirre-Peñafiel V, Sales Nunes PM, Verrastro L, Rivas GA, Rodrigues MT, Grant T, Murphy RW. 2017. Phylogeny of Riama (Squamata: Gymnophthalmidae), impact of phenotypic evidence on molecular datasets, and the origin of the Sierra Nevada de Santa Marta endemic fauna. Cladistics 34(3):260-291. DOI: 10.1111/cla.12203.

Sereno PC. 2007. Logical basis for morphological characters in phylogenetics. Cladistics 23(6):565-587 DOI: 10.1111/j.1096-0031.2007.00161.x.

Sharma P, Giribet G. 2011. The evolutionary and biogeographic history of the armoured harvestmen - Laniatores phylogeny based on the molecular markers, with the description of two new families of Opiliones (Arachnida). Invertebrate Systematics 25:106-142 DOI: 10.1071/IS11002.

Sigrist MS, Carvalho CJB. 2009. Historical relationships amongst areas of endemism in the tropical South America using Brooks Parsimony Analysis (BPA). Biota Neotropica 9:79-90 DOI: $10.1590 /$ S1676-06032009000400009.

Silva SM, Moraes-Barros N, Ribas CC, Ferrand N, Morgante JS. 2012. Divide to conquer: A complex pattern of biodiversity depicted by vertebrate components in the Brazilian Atlantic Forest. Biological Journal of the Linnean Society 107:39-55 DOI: 10.1111/j.10958312.2012.01919.x.

Strong EE, Lipscomb D. 1999. Character coding and inapplicable data. Cladistics 15:363-371 DOI: 10.1006/clad.1999.0114. 
2083 Schwarz G. 1978. Estimating the dimension of a model. The Annals of Statistics 6(2):461-464.

2084 Thomé MTC, Zamudio KR, Giovanelli JGR, Haddad CFB, Baldissera FA, Alexandrino J. 2010.

2085

2086

2087

2088

2089

2090

2091

2092

2093

2094

2095

2096

2097

2098

2099

2100

2101

2102

2103

2104

2105

2106

2107

2108

2109

2110

2111

2112

2113

2114

2115

2116

Phylogeography of endemic toads and post-Pliocene persistence of the Brazilian Atlantic Forest. Molecular phylogenetics and Evolution 55:1018-1031 DOI: 10.1016/j.ympev.2010.02.003.

Varón A, Vinh LS, Wheeler WC. 2010. POY version 4: phylogenetic analysis using dynamic homologies. Cladistics 26:72-85 DOI: 10.1111/j.1096-0031.2009.00282.x.

Vasconcelos EG. 2003. Revisão Sistemática de Mischonyx Bertkau, 1880 (Opiliones: Laniatores: Gonyleptidae). Masters Dissertation, Universidade Federal do Rio de Janeiro.

Vasconcelos EG. 2004. Nova espécie de Mischonyx Bertkau, 1880 do litoral norte do Estado de São Paulo, Brasil (Opiliones, Laniatores, Gonyleptidae). Revista Ibérica de Aracnologia 10:129-132 DOI: 10.1590/S0073-47212005000300001.

Vasconcelos EG. 2005a. Nova espécie de Mischonyx do estado do Rio de Janeiro, Brasil (Arachnida, Opiliones, Gonyleptidae). Iheringia. Série Zoologia 95(3):229-232 DOI: 10.1590/S0073-47212005000300001.

Vasconcelos EG. 2005b. Notes on Geraecormobius clavifemur (Mello-Leitão, 1927) and description of Geraecormobius reitzi n.sp. (Arachnida: Opiliones: Gonyleptidae). Zootaxa 1088:1-10 DOI: 10.11646/zootaxa.1088.1.1.

Vaidya G, Lohman DJ, Meier R. 2011. SequenceMatrix: concatenation software for the fast assembly of multi-gene datasets with character set and codon information. Cladistics 27:171180 DOI:10.1111/j.1096-0031.2010.00329.x.

Wheeler WC. 1996. Optimization Alignment: the end of multiple sequence alignment in phylogenetics? Cladistics 12:1-9 DOI: 10.1006/clad.1996.0001.

Wheeler WC. 2001a. Homology and the optimization of DNA sequence data. Cladistics 17:3 11 DOI: $10.1006 /$ clad.2000.0154.

Wheeler WC. 2001b. Homology and DNA sequence data. In: Wagner GP, ed. The Character Concept in Evolutionary Biology. New York: Academic Press, 303-318.

Wheeler WC. 2003. Iterative pass optimization of sequence data. Cladistics 19:254-260 DOI: 10.1016/S0748-3007(03)00047-1.

Wiens JJ. 2004. The Role of Morphological Data in Phylogeny Reconstruction, Systematic Biology 53(4):653-661 DOI: 10.1080/10635150490472959.

Willemart RH, Pellegatti-Franco F. 2006. The spider Enoploctenus cyclothorax (Araneae, Ctenidae) avoids preying on the harvestmen Mischonyx cuspidatus (Opiliones: Gonyleptidae). The Journal of Arachnology 34(3):649-652 DOI: 10.1636/S05-70.1.

Peerj reviewing PDF | (2020:08:52148:2:0:NEW 1 Jun 2021) 
2117 Wipfler B, Pohl H, Yavorskaya MI, Beutel RG. 2016. A review of methods for analysing insect 2118 structures - the role of morphology in the age of phylogenomics. Current Opinion in Insect 2119 Science 18:60-68. DOI: 10.1016/j.cois.2016.09.004. 


\section{Table 1 (on next page)}

Sequenced genes per taxon with their respective identification vouchers and GenBank access number (Outgroup only).

Each code represents the GenBank access number for each gene sequence. Blank cells represent individuals that we could not acquire sequences. 
Sequence ID

Ampheres leucopheus 0377 Deltaspidium asperum 2201 Deltaspidium orguense 0520 Deltaspidium tenue Gonyleptes antiquus 3707 Gonyleptes antiquus 3708 Gonyleptes horridus 0103 Heliella singularis 1837 Multumbo dimorphicus 0069

Multumbo terrenus 2136 Piassagera brieni 0141 Promitobates ornatus 0054 Pseudotroglus telluris 2118 Roeweria virescens 0081 1
Sodreana sodreana 0056

\begin{abstract}
ITS
28S

COI

$16 \mathrm{~S}$
\end{abstract}

$12 \mathrm{~S}$

CAD

H3

MT957104 MT990789 MT992270 MW000844 MW000802 MW017372 MW017447

MT957119 MT990804 MT992285 MW000859 MW000818 MW017385 MW017418

MT957106 MT990791 MT992272 MW000858 MW000804 MW017374 MW017454

MT990783 MT992264 MW000857 MW000796 MW017370 MW017436

MT957132 MT990822 MT992301 MW000847 MW000834 MW017397 MW017416

MT957133 MT990823 MT992302 MW000848 MW000835 MW017398 MW017417

MT957100 MT990784 MT992265 MW000841 MW000797 $\quad$ MW017448

MT957113 MT990798 MT992279 MW000839 MW000812 MW017412

MT957096 MT990778 MT992259 MW000865 MW000791 MW017455

MT957117 MT990802 MT992283 MW000864 MW000816 MW017383 MW017425 MT990787 MT992268 MW000842 MW000800 MW017409 MT990776 MT992257 MW000837 MW000789 MW017406

MT957115 MT990800 MT992281 MW000843 MW000814 MW017381 MW017411 MT990780 MT992261 MW000838 MW000793 MW017407

MT957095 MT990777 MT992258 MW000852 MW000790 MW017366 MW017410 


\section{Table 2 (on next page)}

Sequenced genes per taxon with their respective identification vouchers and GenBank access number (Ingroup only).

Each code represents the GenBank access number for each gene sequence. Blank cells represent individuals that we could not acquire sequences. 


\section{Sequence ID}

Mischonyx anomalus 0122

Mischonyx anomalus 0693

Mischonyx anomalus 1638

Mischonyx anomalus 2953

Mischonyx clavifemur 0079

Mischonyx clavifemur 0845

Mischonyx fidelis 4115A

Mischonyx fidelis 4115B

Mischonyx insulanus 1455

Mischonyx insulanus 3066

Mischonyx intermedius 4116A

Mischonyx intermedius 4116B

Mischonyx intermedius 4117A

Mischonyx intervalensis 0099

Mischonyx intervalensis 3709

Mischonyx kaisara 0143

Mischonyx kaisara 1374

Mischonyx kaisara 2345

Mischonyx kaisara 3575

Mischonyx minimus 3649

Mischonyx parvus 3621A

Mischonyx parvus 3621B

Mischonyx parvus 3651 A

Mischonyx poeta 3650A

Mischonyx poeta 3650B

Mischonyx processigerus 0463

Mischonyx processigerus 3648 Mischonyx reitzi 0672

Mischonyx spinifrons 0111

Mischonyx spinifrons 2120

Mischonyx spinifrons 2151

Mischonyx spinifrons 2809
ITS 28S

COI

$16 \mathrm{~S}$

$12 \mathrm{~S}$

CAD

$\mathrm{H3}$

MT957102 MT990786 MT992267 MW000854 MW000799 MT957112 MT990797 MT992278 MW000840 MW000811 MW017379 MW017421 MT957122 MT990808 MT992289 MW000856 MW000821 MW017388 MW017424 MT957097 MT990779 MT992260 MW000862 MW000792 MW017367 MW017449 MT957109 MT990794 MT992275 MW000863 MW000808 MW017422 MT957135 MT990825 MT992304 MW000872 MW017400 MW017441 MT957136 MT990826 MT992305 MW000867 MW017401 MW017442 MT957111 MT990796 MT992277 MW000869 MW000810 MW017378 MT957123 MT990811 MT992290 MW000855 MW017389 MW017408 MT957137 MT990827 MT992306 MW000850 MW000831 MW017402 MW017426 MT957138 MT990809 MT992307 MW000849 MW000832 MW017403 MW017427 MT957139 MT990810 MT992308 MW000851 MW000833 MW017404 MW017428 MT957099 MT990782 MT992263 MW000845 MW000795 MW017369 MW017451 MT957134 MT990824 MT992303 MW000846 MW000836 MW017399 MW017420 MT957103 MT990788 MT992269 $\quad$ MW000801 $\quad$ MW017414 MT957110 MT990795 MT992276 MW000868 MW000809 MW017377 MW017405 MT957120 MT990805 MT992286 MW000866 MW000819 MW017386 MW017415 MT957124 MT990814 MT992293 MW000860 MW000824 MW017413 MT957128 MT990818 MT992297 MW000879 MW000828 MW017393 MW017443 MT957125 MT990815 MT992294 MW000875 MW000825 MW017390 MW017437 MT957126 MT990816 MT992295 MW000877 MW000826 MW017391 MW017438 MT957131 MT990821 MT992300 MW000876 MW000806 MW017396 MW017439 MT957129 MT990819 MT992298 MW000880 MW000829 MW017394 MW017445 MT957130 MT990820 MT992299 MW000881 MW000830 MW017395 MW017446 MT957105 MT990790 MT992271 MW000870 MW000803 MW017373 MW017450 MT957127 MT990817 MT992296 MW000871 MW000827 MW017392 MW017444 MT957107 MT990792 MT992273 MW000861 MW000805 MW017375 MW017419 MT957101 MT990785 MT992266 MW000884 MW000798 MW017371 MW017431 MT957116 MT990801 MT992282 MW000885 MW000815 MW017382 MW017432 MT957118 MT990803 MT992284 MW000886 MW000817 MW017384 MW017430 MT957121 MT990807 MT992288 MW000882 $\quad$ MW017387 MW017433 
Mischonyx spinifrons 3363

Mischonyx spinifrons 3375

Mischonyx squalidus 0085

Mischonyx squalidus 2026

Mischonyx tinguaensis 2361
MT990812 MT992291 MW000887 MW000822

MT990813 MT992292 MW000883 MW000823

MT957098 MT990781 MT992262 MW000873 MW000794 MW017368 MW017453

MT957114 MT990799 MT992280 MW000874 MW000813 MW017380

MT990806 MT992287 MW000878 MW000820
MW017434

MW017435

MW017429 


\section{Figure 1}

Mischonyx anomalus and Mischonyx arlei holotypes.

A and C. Mischonyx anomalus, dorsal and lateral views, respectively. B and D. Mischonyx arlei, dorsal and lateral views, respectively. Scale bars: $1 \mathrm{~mm}$. 

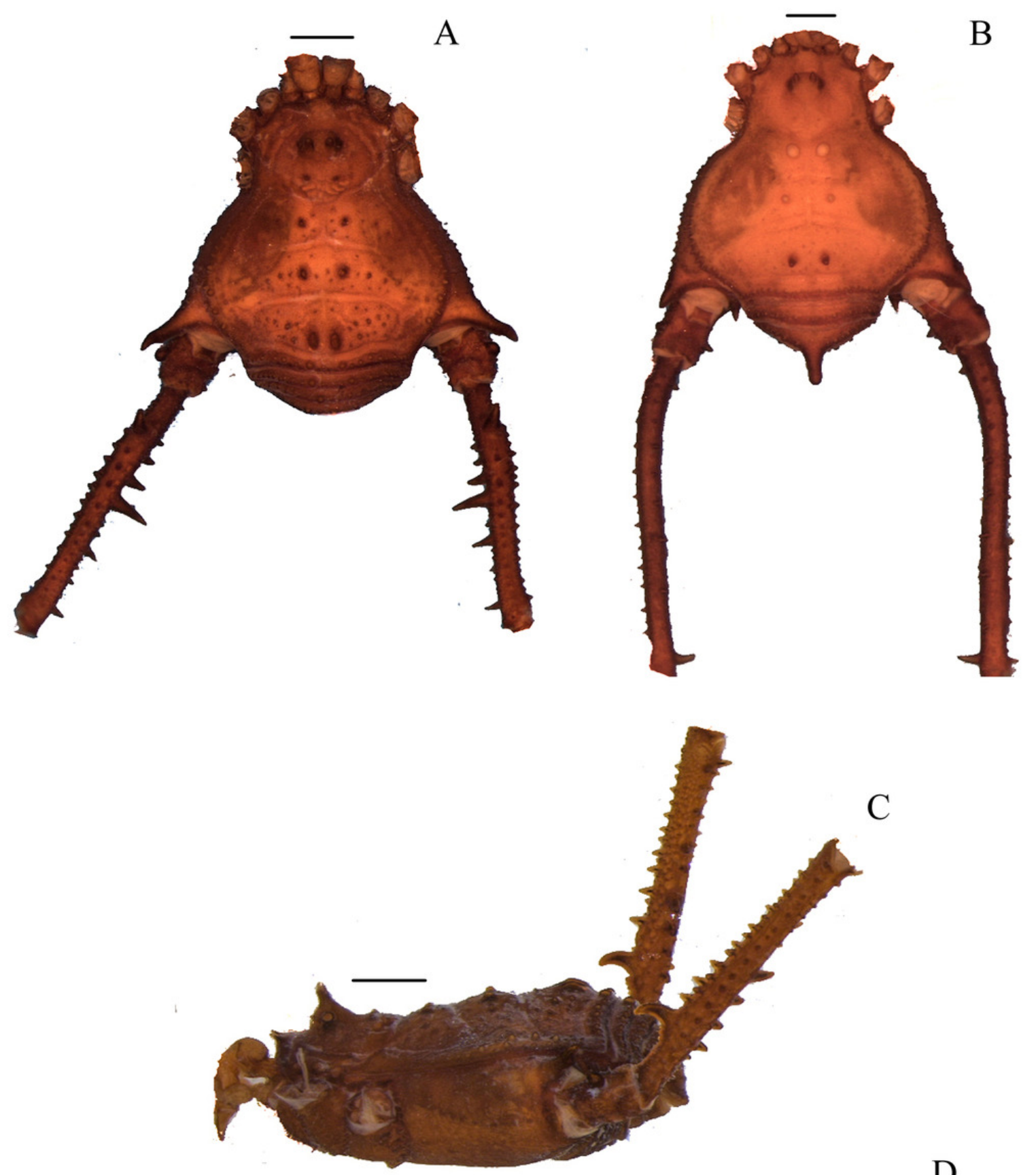

D

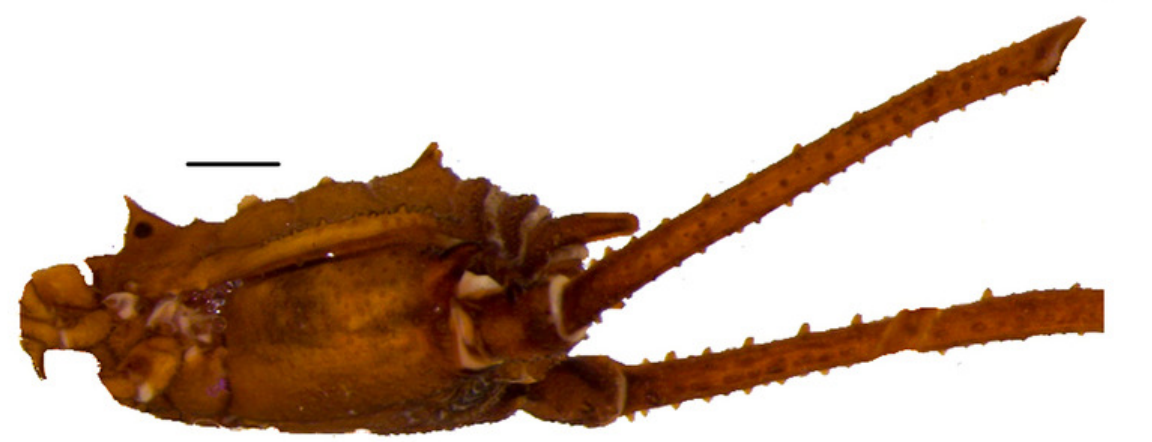


Figure 2

Mischonyx clavifemur holotype and Mischonyx fidelis (4115A).

A and C. Mischonyx clavifemur, dorsal and lateral views, respectively. B and D. Mischonyx fidelis, dorsal and lateral views, respectively. Scale bars: $1 \mathrm{~mm}$. 

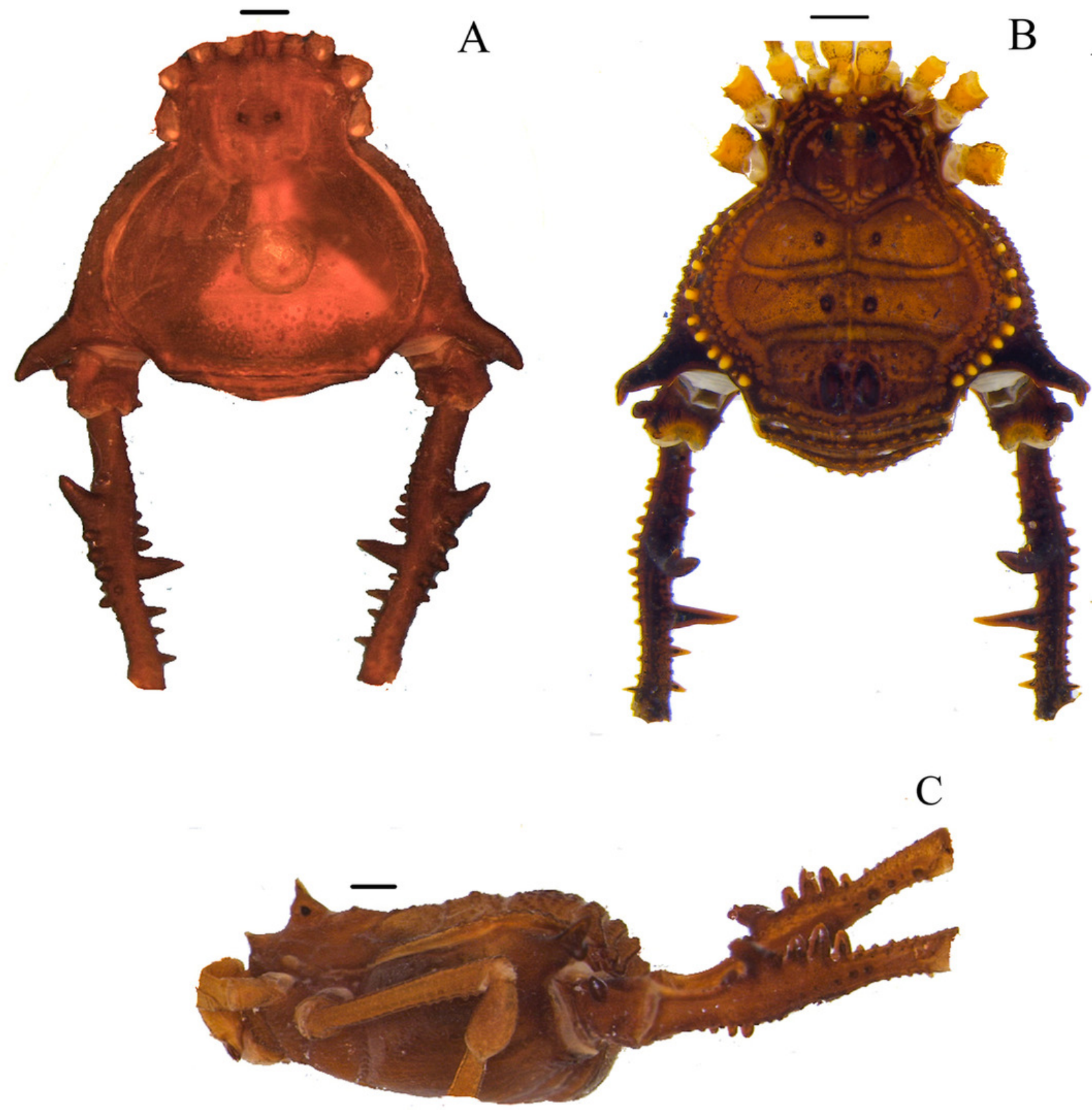

D

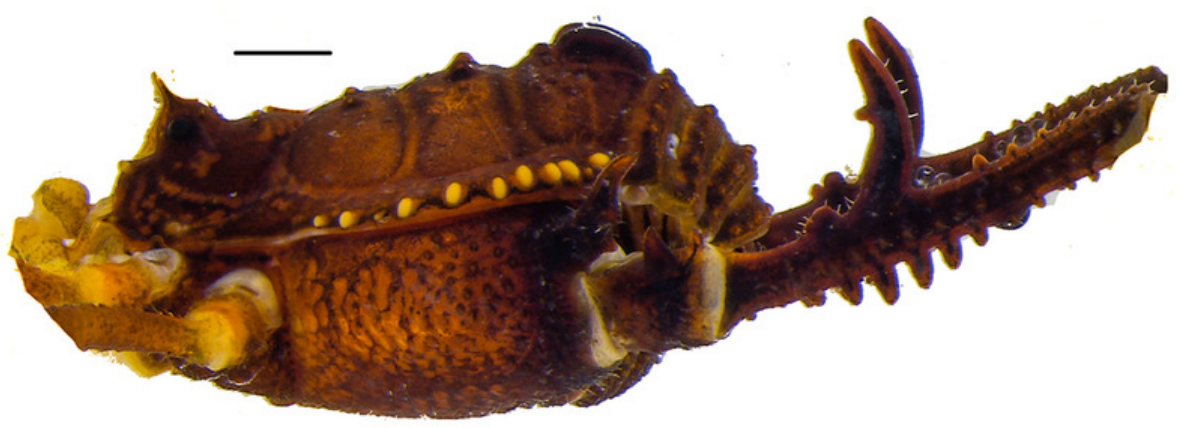


Figure 3

Mischonyx insulanus and Mischonyx intermedius holotypes.

A and C. Mischonyx insulanus, dorsal and lateral views, respectively. B and D. Mischonyx intermedius, dorsal and lateral views, respectively. Scale bars: $1 \mathrm{~mm}$. 

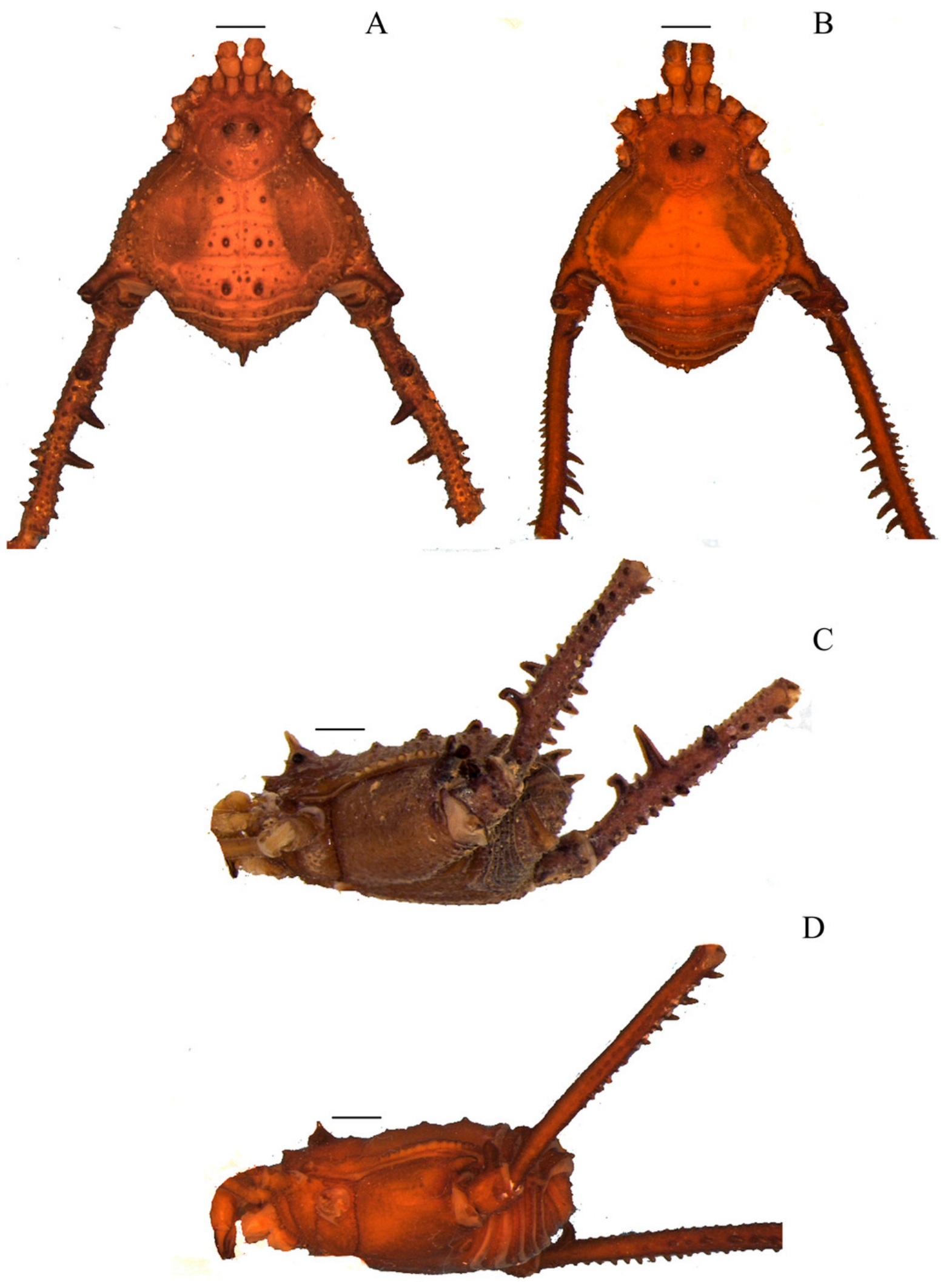

D 
Figure 4

Mischonyx intervalensis sp. nov. holotype and Mischonyx kaisara.

A and C. Mischonyx intervalensis sp. nov., dorsal and lateral views, respectively. B and D. Mischonyx kaisara, dorsal and lateral views, respectively. Scale bars: $1 \mathrm{~mm}$. 

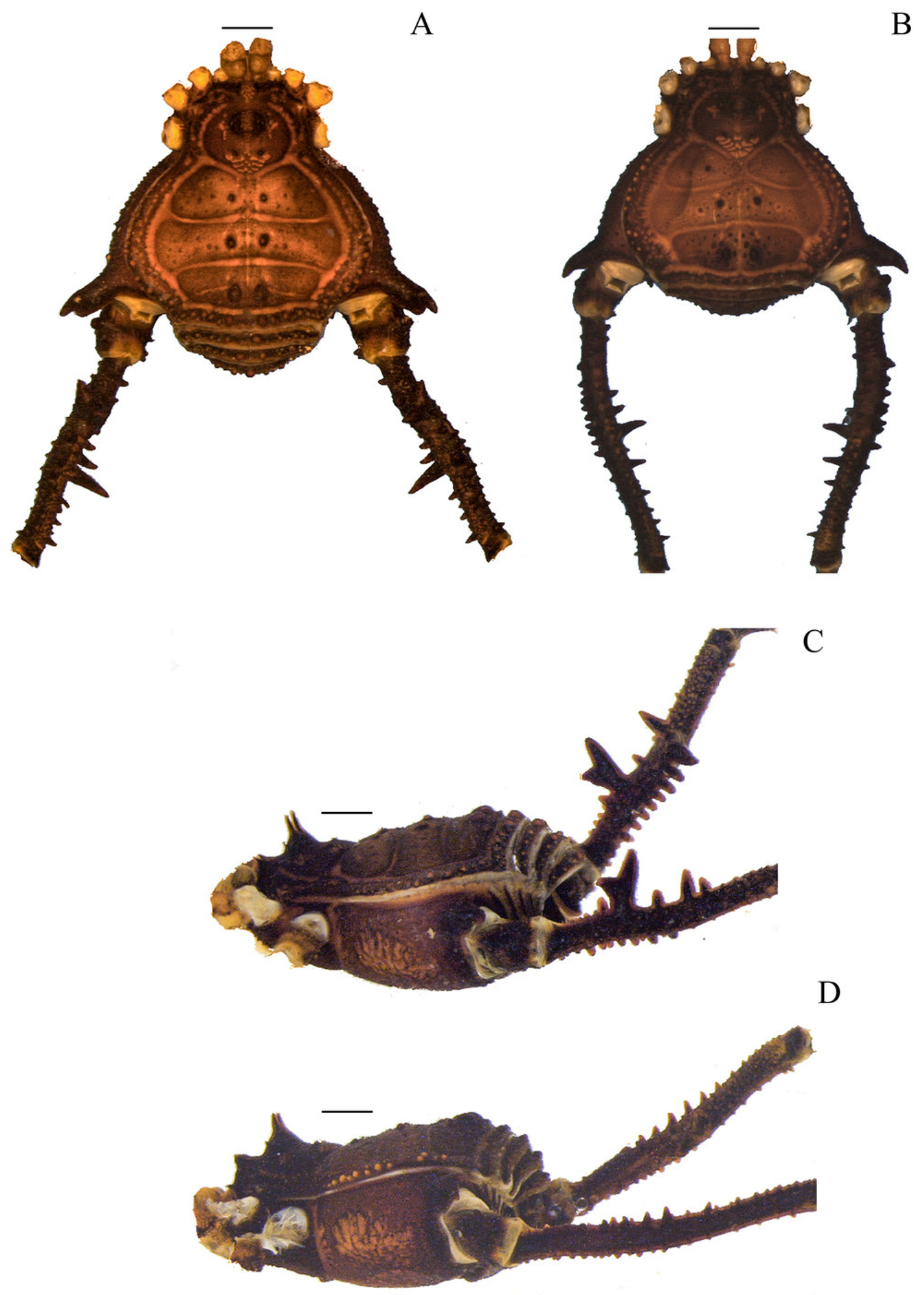
Figure 5

Mischonyx minimus sp. nov. and Mischonyx parvus holotypes.

A and C. Mischonyx minimus sp. nov., dorsal and lateral views, respectively. B and D. Mischonyx parvus, dorsal and lateral views, respectively. Scale bars: $1 \mathrm{~mm}$. 

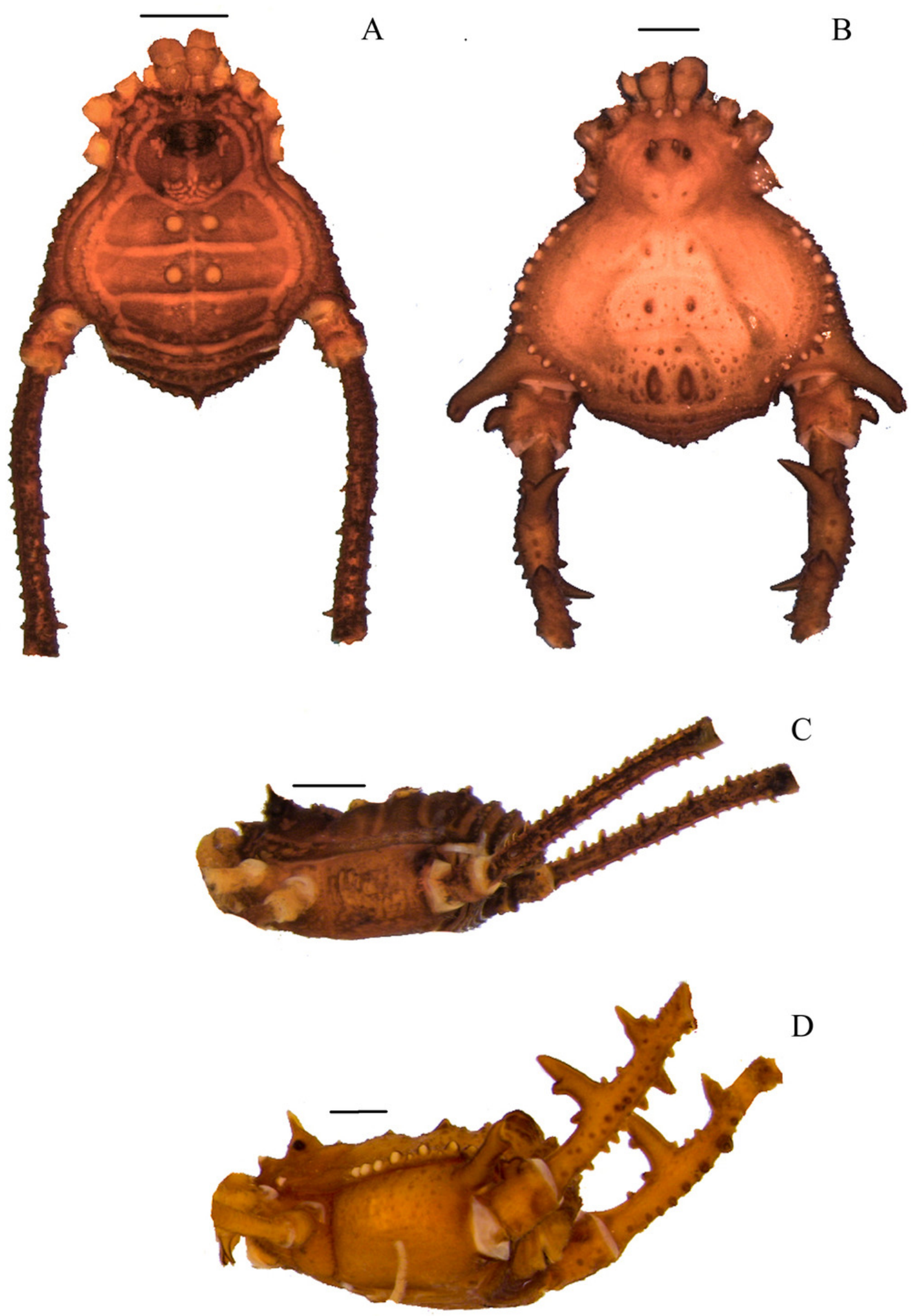
Figure 6

Mischonyx poeta and Mischonyx processigerus paratypes.

A and C. Mischonyx poeta, dorsal and lateral views, respectively. B and D. Mischonyx processigerus, dorsal and lateral views, respectively. Scale bars: $1 \mathrm{~mm}$. 

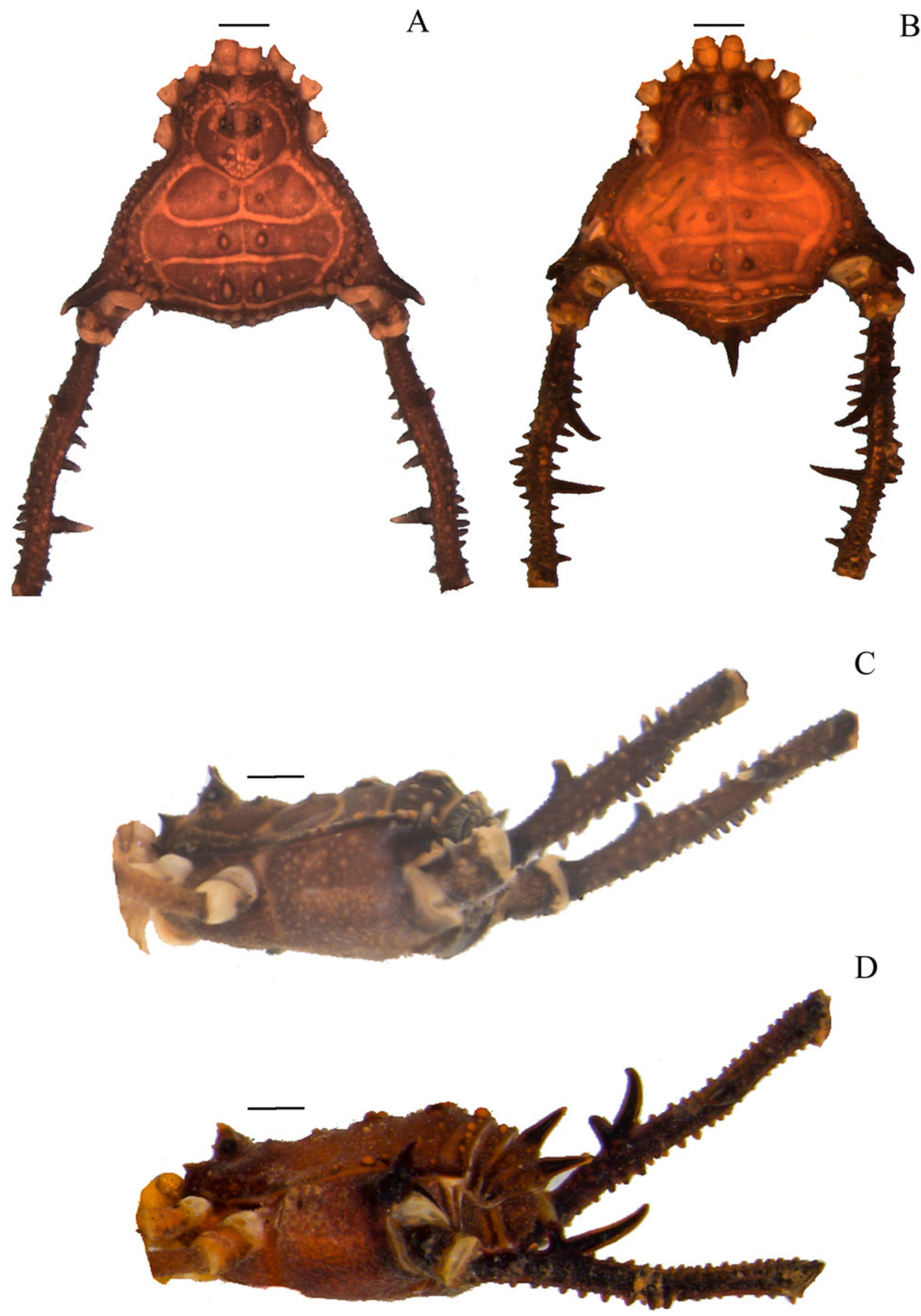
Figure 7

Mischonyx reitzi (0672) and Mischonyx scaber.

A and C. Mischonyx reitzi, dorsal and lateral views, respectively. B and D. Mischonyx scaber, dorsal and lateral views, respectively. Scale bars: $1 \mathrm{~mm}$. 

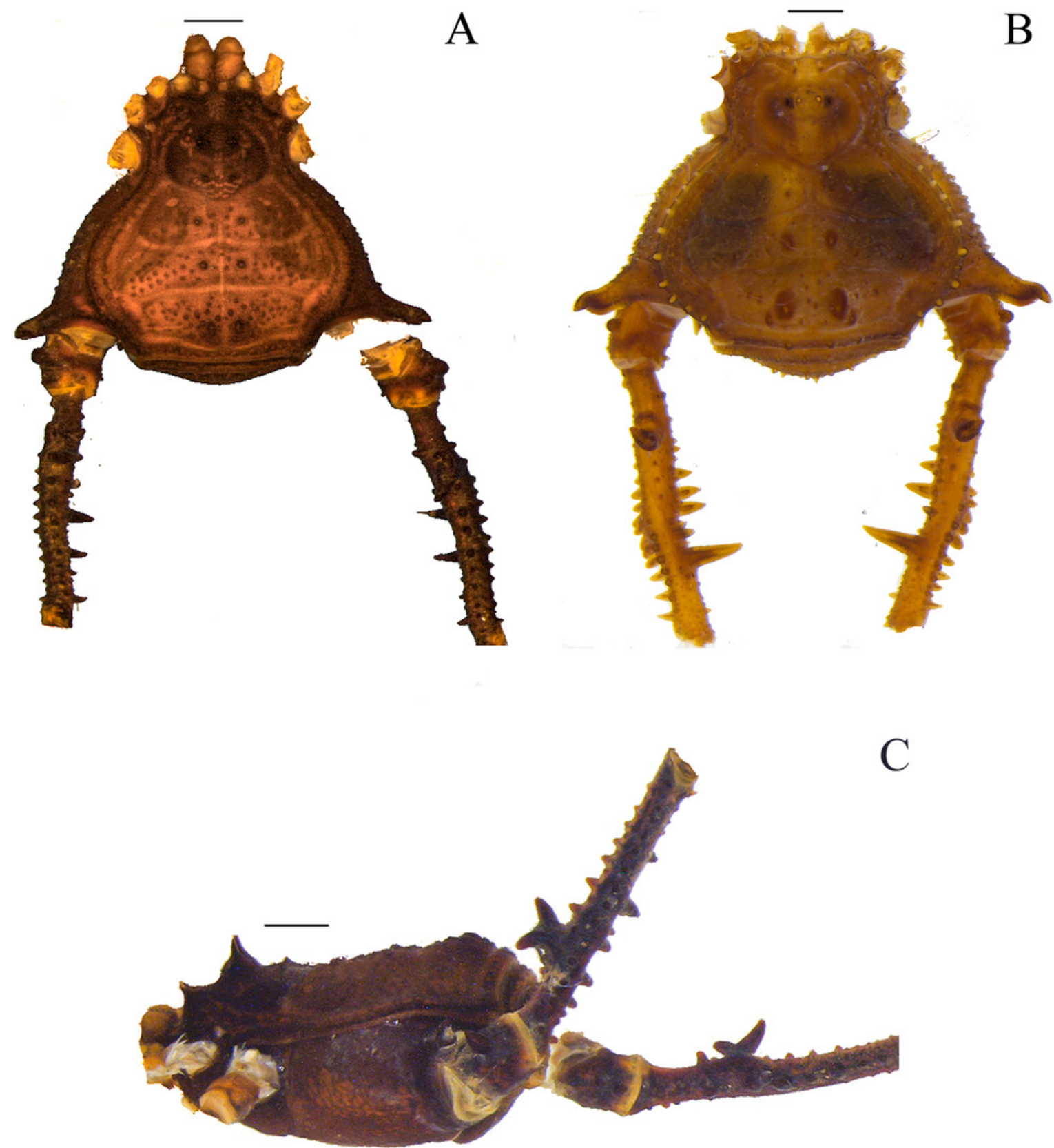

C

D

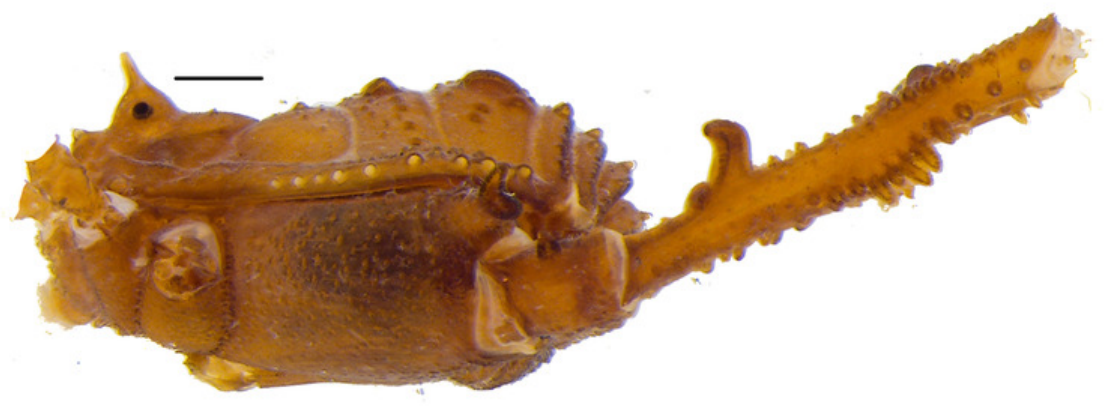


Figure 8

Mischonyx spinifrons (M. bresslaui paratype) and Mischonyx squalidus (M. cuspidatus holotype).

A and C. Mischonyx spinifrons, dorsal and lateral views, respectively. B and D. Mischonyx squalidus, dorsal and lateral views, respectively. Scale bars: $1 \mathrm{~mm}$. 

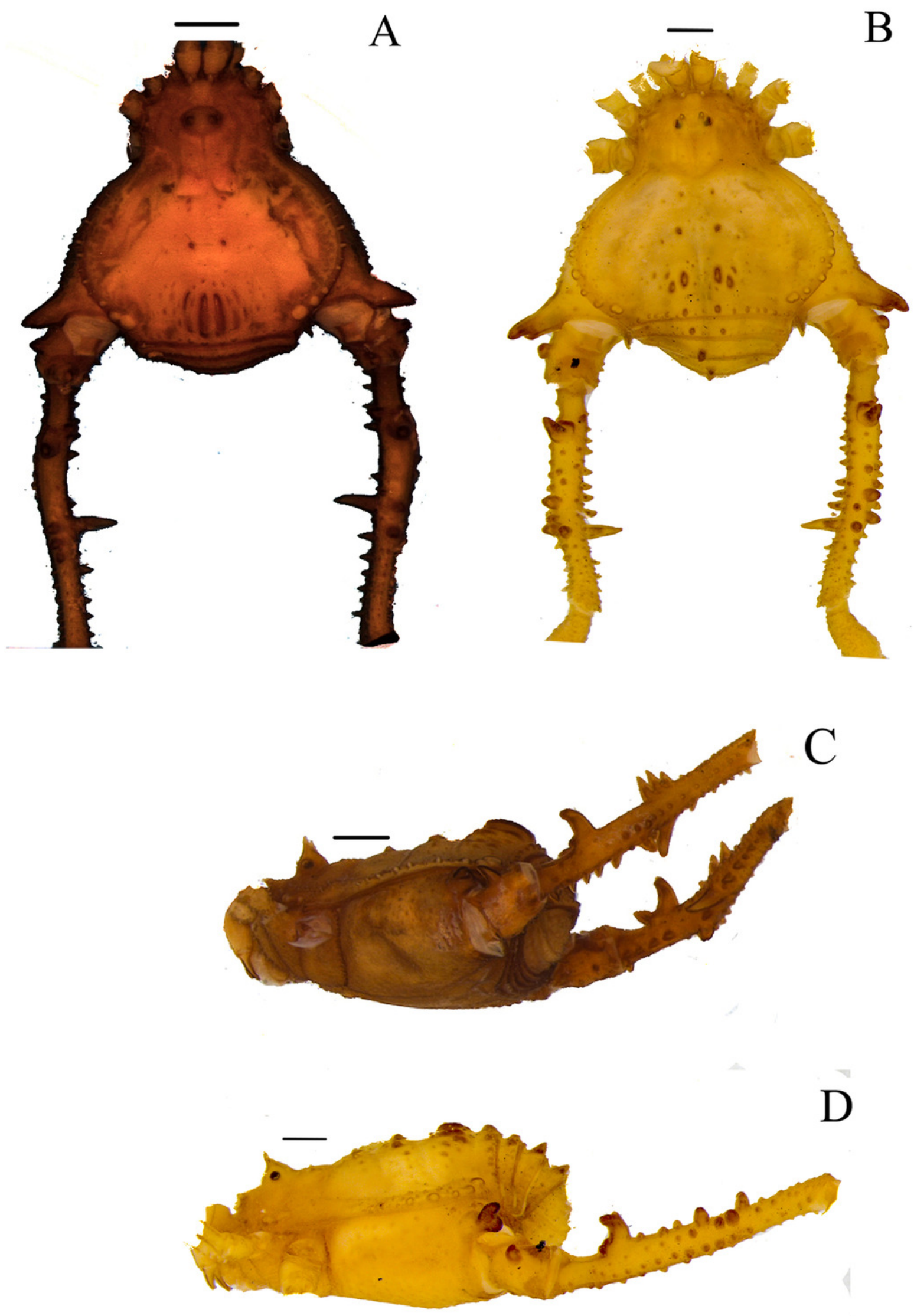
Figure 9

Mischonyx tinguaensis sp. nov. holotype.

A. dorsal view. B. lateral. Scale bars: $1 \mathrm{~mm}$. 

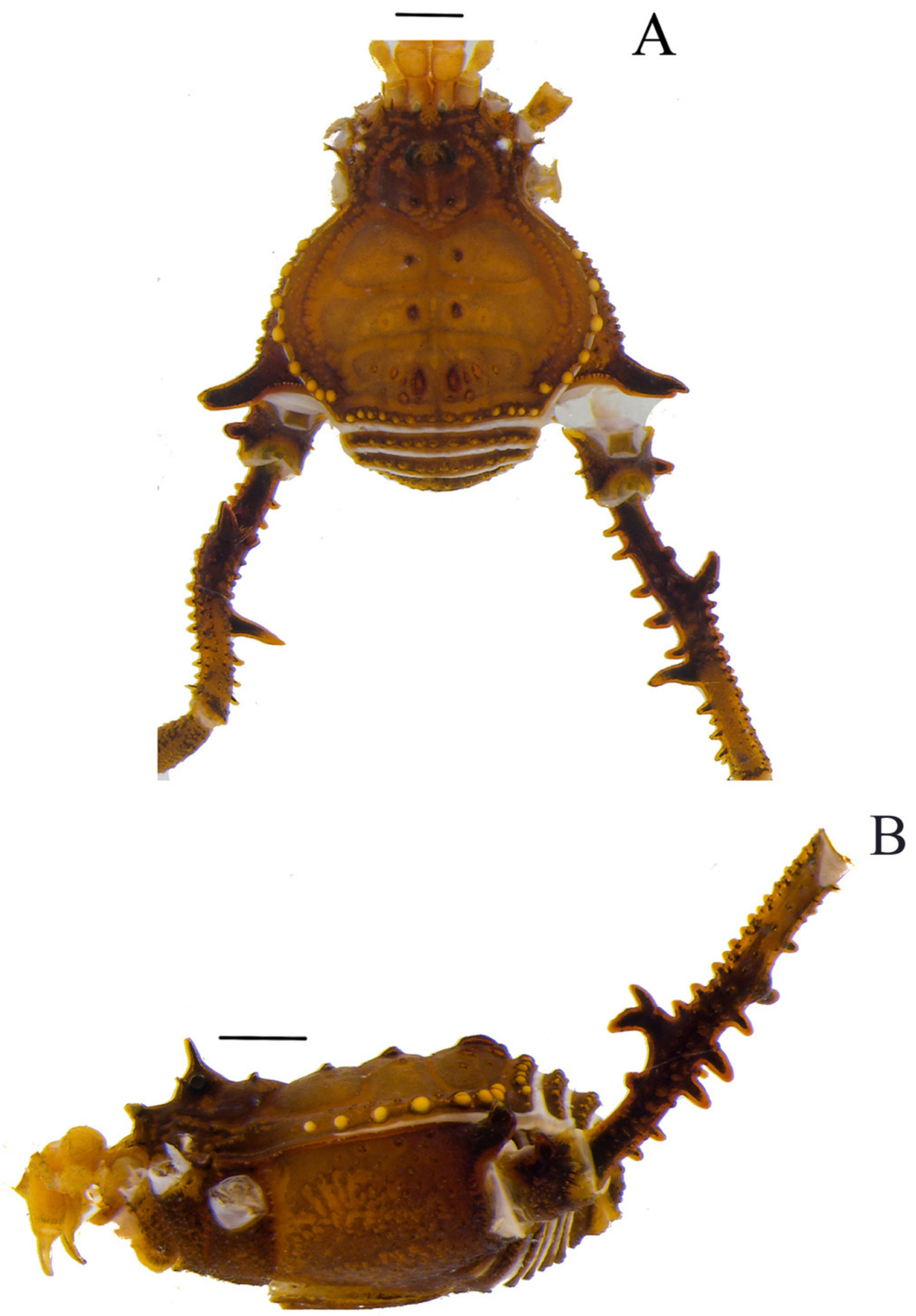


\section{Figure 10}

Penis of Mischonyx fidelis, M. insulanus and M. intermedius.

A - C. Dorsal, right lateral and ventral views, respectively, of the penis of Mischonyx fidelis. D - F. Dorsal, right lateral and ventral views, respectively, of Mischonyx insulanus. G - I. Dorsal, right lateral and ventral views, respectively, of the penis of Mischonyx intermedius. 

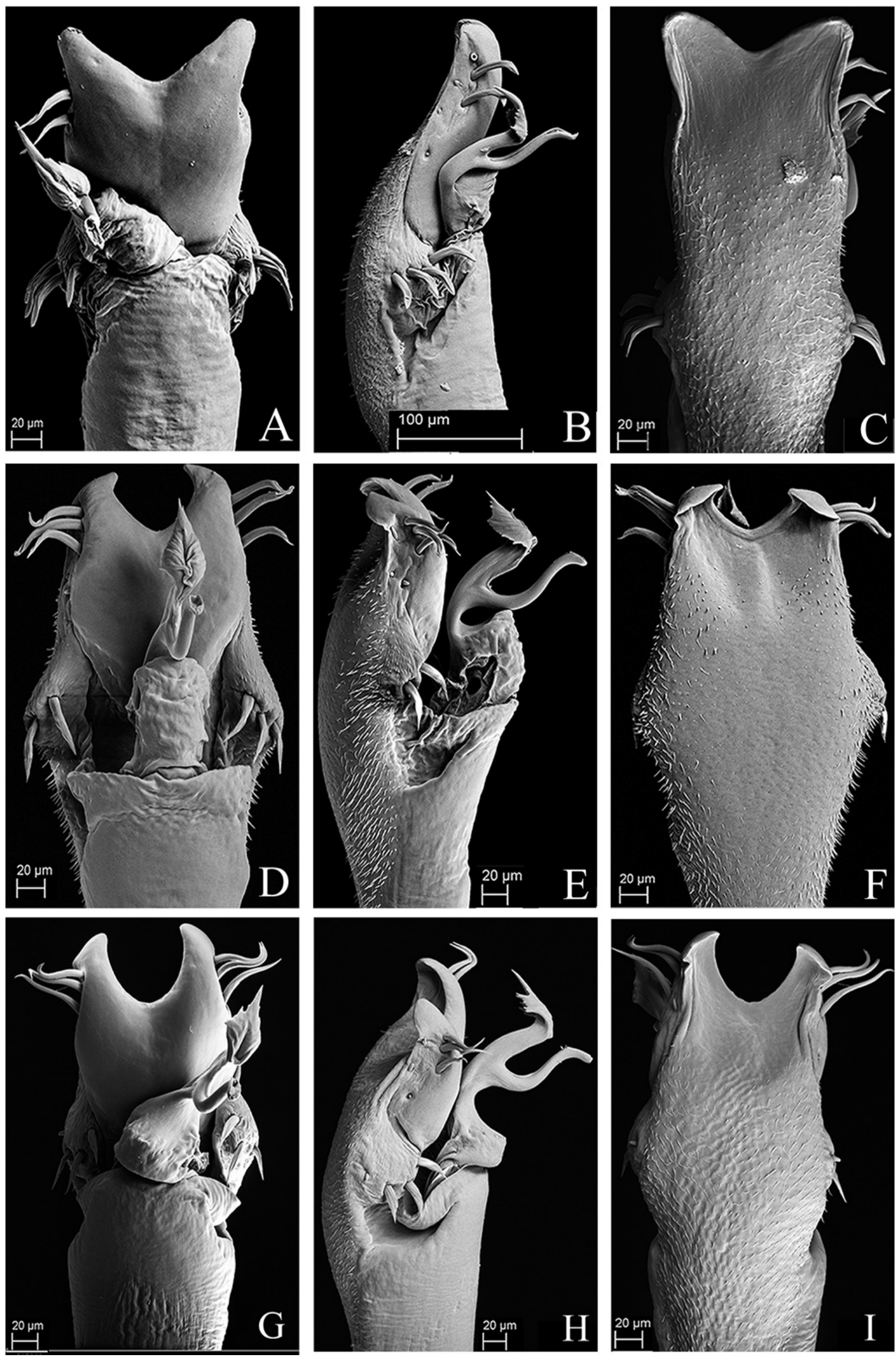

PeerJ reviewing PDF | (2020:08:52148:2:0:NEW 1 Jun 2021) 
Figure 11

Penis of Mischonyx kaisara, M. parvus and M. poeta.

A - C. Dorsal, right lateral and ventral views, respectively, of the penis of Mischonyx kaisara.

D - F. Dorsal, right lateral and ventral views, respectively, of the penis of Mischonyx parvus.

$\mathrm{G}-\mathrm{I}$. Dorsal, right lateral and ventral views, respectively, of Mischonyx poeta. 

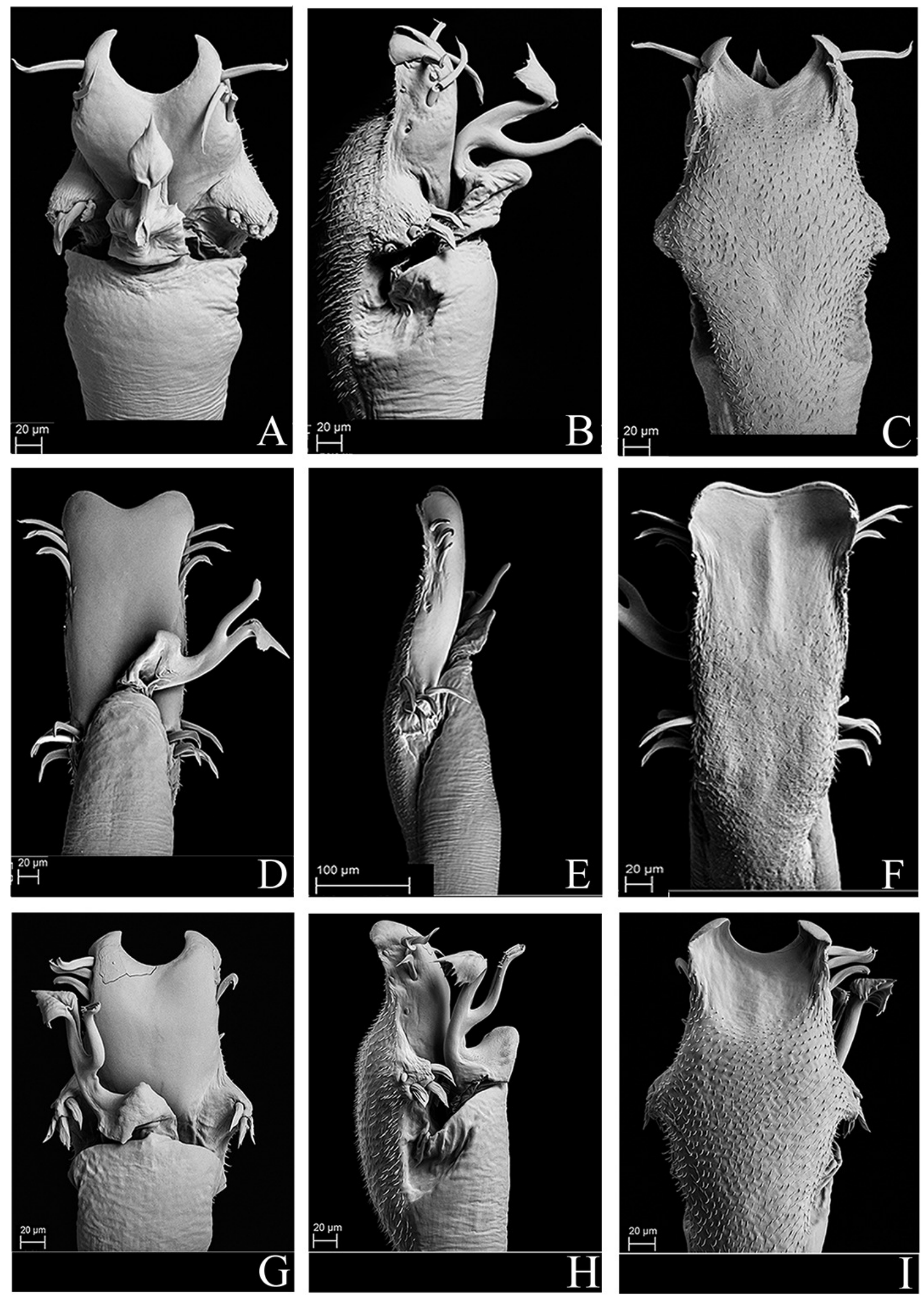

PeerJ reviewing PDF | (2020:08:52148:2:0:NEW 1 Jun 2021) 


\section{Figure 12}

Penis of Mischonyx processigerus, M. spinifrons and M. squalidus.

A - C. Dorsal, right lateral and ventral views, respectively, of the penis of Mischonyx processigerus. D - F. Dorsal, right lateral and ventral views, respectively, of the penis of Mischonyx spinifrons. G - I. Dorsal, right lateral and ventral views, respectively, of the penis of Mischonyx squalidus. 

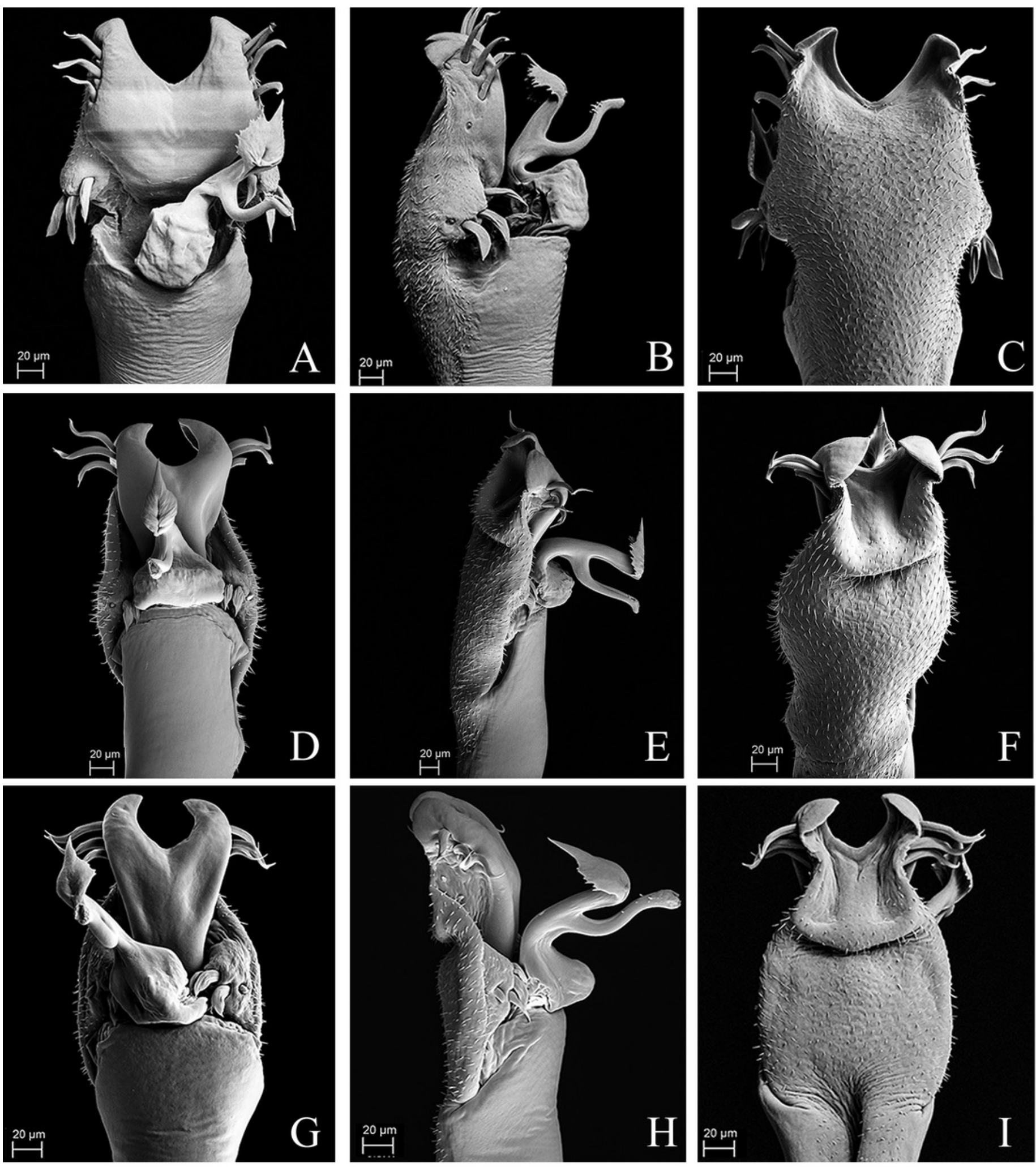


\section{Figure 13}

Penis of Mischonyx anomalus, M. arlei and M. clavifemur.

A - C. Dorsal, right lateral and ventral views, respectively, of Mischonyx anomalus. D - F. Dorsal, right lateral and ventral views, respectively, of the penis of Mischonyx arlei. G - I. Dorsal, right lateral and ventral views, respectively, of the penis of Mischonyx clavifemur. 

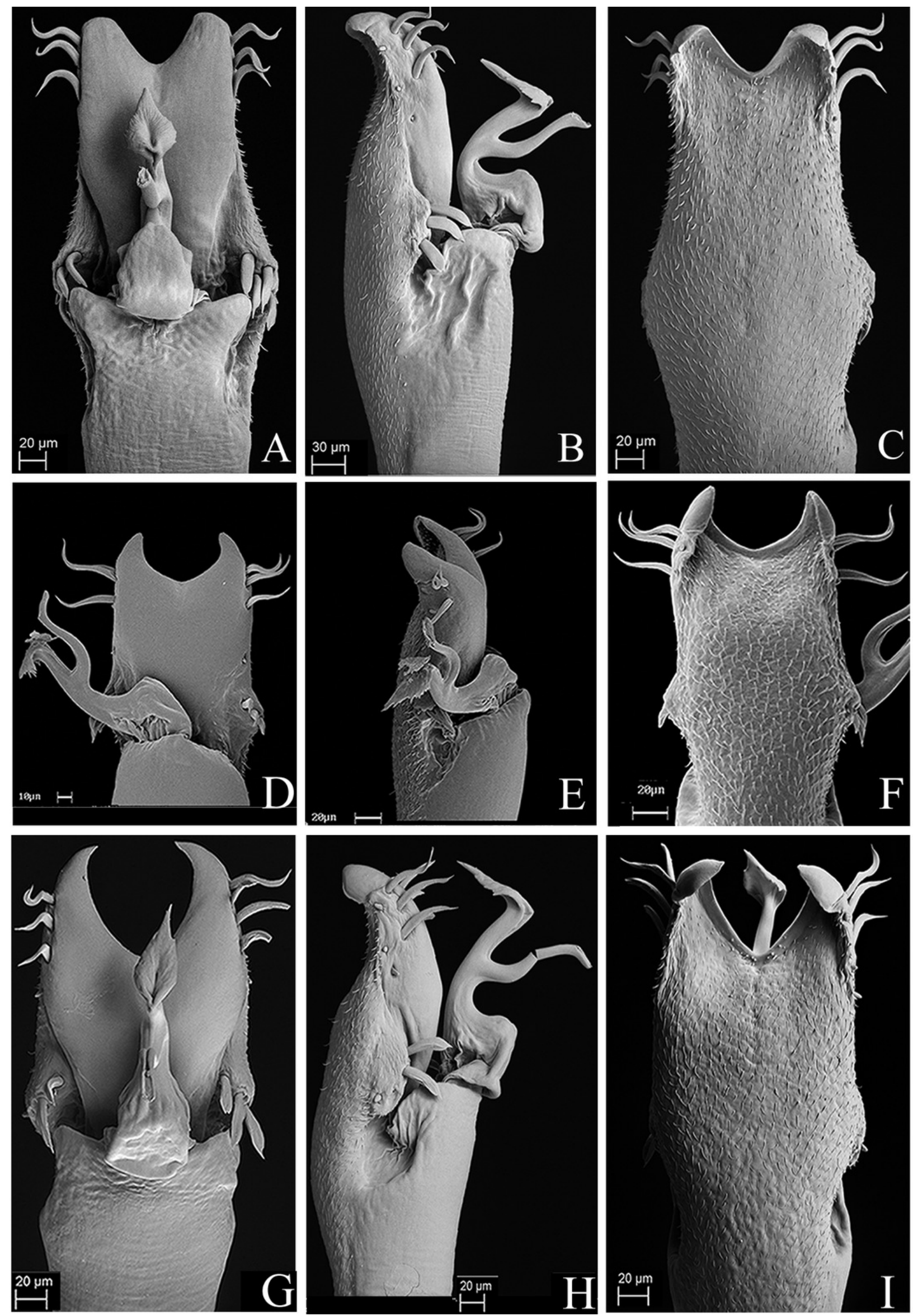

Peer) reviewing PDF | (2020:08:52148:2:0:NEW 1 Jun 2021) 


\section{Figure 14}

Male genitalia of the new species.

A - C. Dorsal, right lateral and ventral views, respectively, of the penis of Mischonyx minimus sp. nov. paratype (3649). D - F. Dorsal, right lateral and ventral views, respectively, of the penis of Mischonyx tinguaensis sp. nov. paratype (2361). G - I. Dorsal, right lateral and ventral views, respectively, of the penis of Mischonyx intervalensis sp. nov. paratype (0099). 

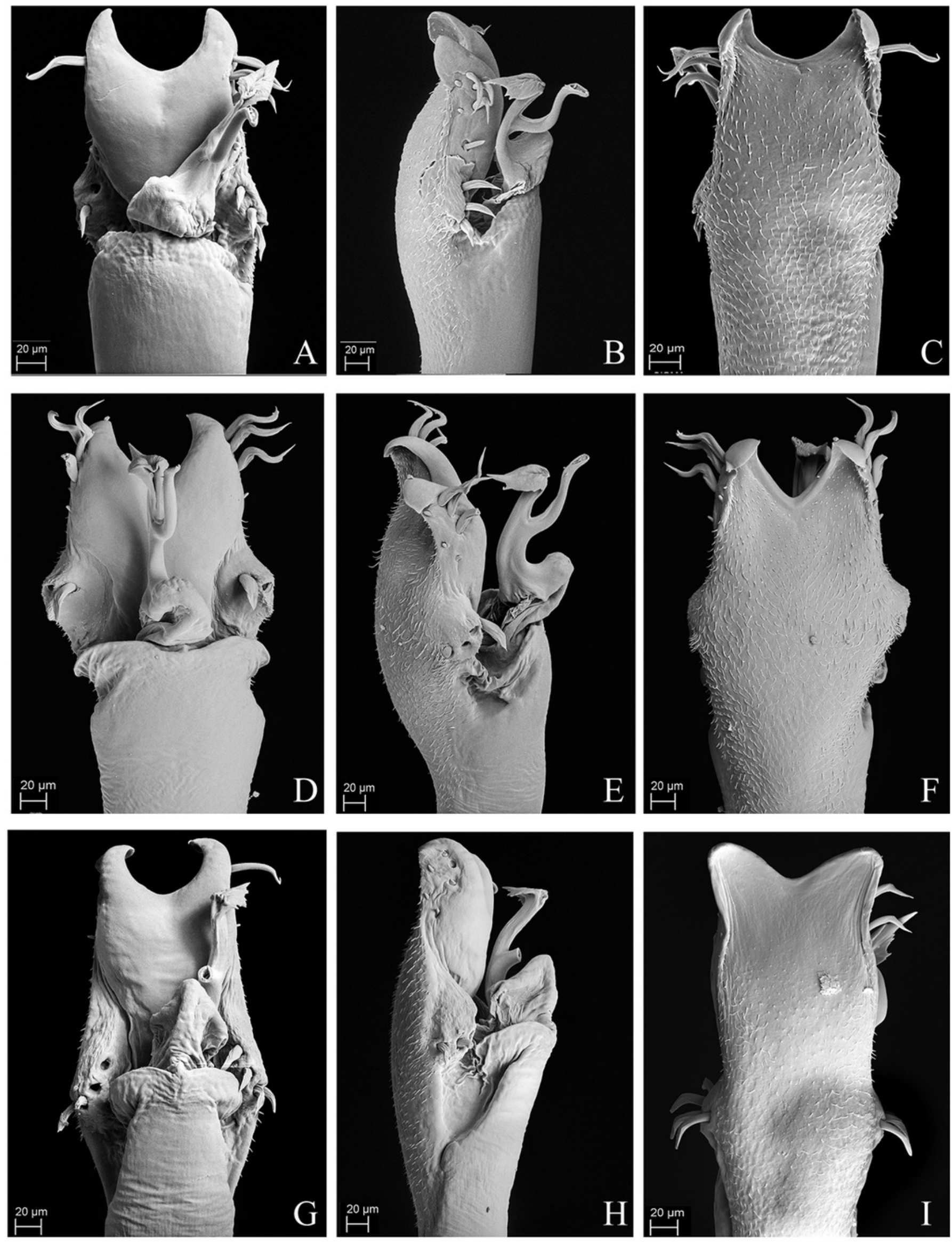


\section{Figure 15}

General geographical distribution of Mischonyx species.

Legends are in the right of the image. The red line represents the Tropic of Capricorn and the black grid represents the full meridians and parallels.

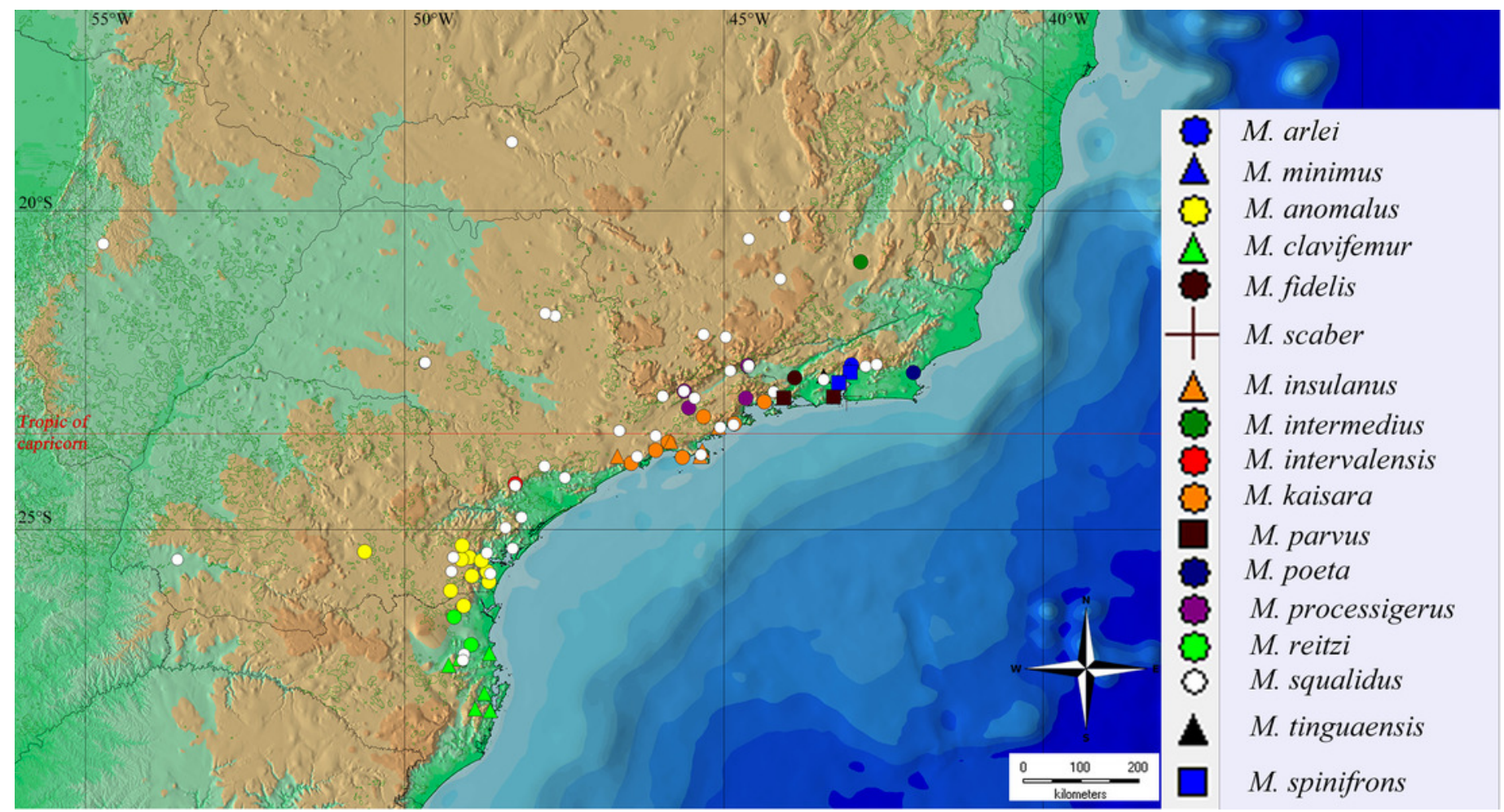




\section{Figure 16}

Bayesian molecular dating (BM).

The values near the nodes are their respective node ages and the bars on each node are the 95\% HPD values of each one. The colored clades are according to their location, respective to each Area of Endemism. Light green: PR; yellow: SC; Red: SSP; orange: SMSP; blue: Org; dark green: Esp; purple: Boc; brown: LSRJ and M. squalidus. Images on the right are individuals of the species indicated with arrows.

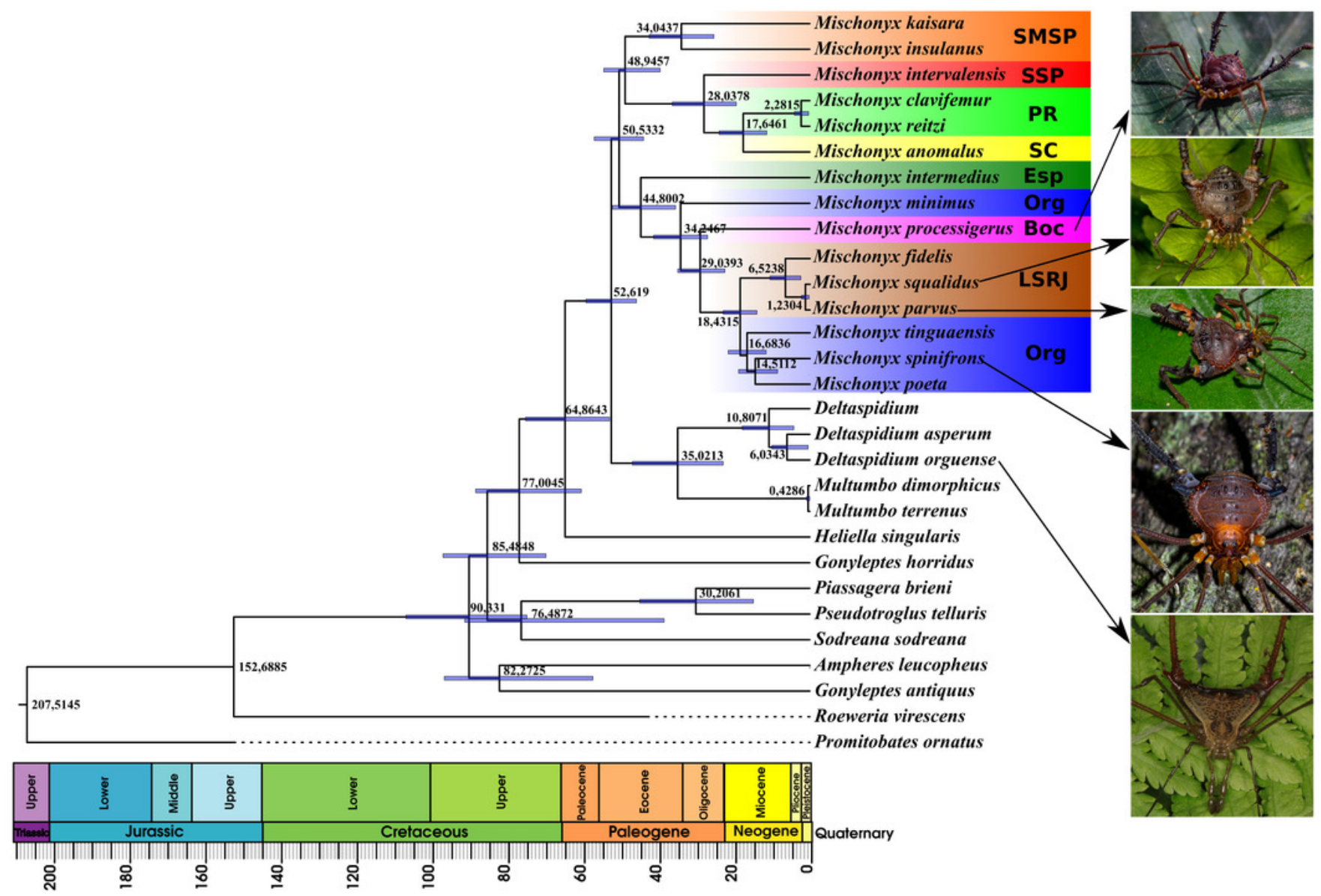




\section{Figure 17}

Total Evidence Maximum Likelyhood hypothesis topology (ML3).

A. Mischonyx clade; B. external group. The numbers near the nodes are their respective bootstrap values. Unambiguous synapomorphies are represented in the squares. The numbers below each square is the character and the numbers inside the squares are plesiomorphic-apomorphic character-states. Red square = unique, homoplastic; blue square = non-unique, homoplastic; white $=$ ambiguous; black $=$ unique, non-homoplastic. The color of the clades are according to their location, respective to each Area of Endemism. Light green: SC; yellow: PR; Red: SSP; orange: SMSP; blue: Org; dark green: Esp; purple: Boc; brown: LSRJ and M. squalidus. 


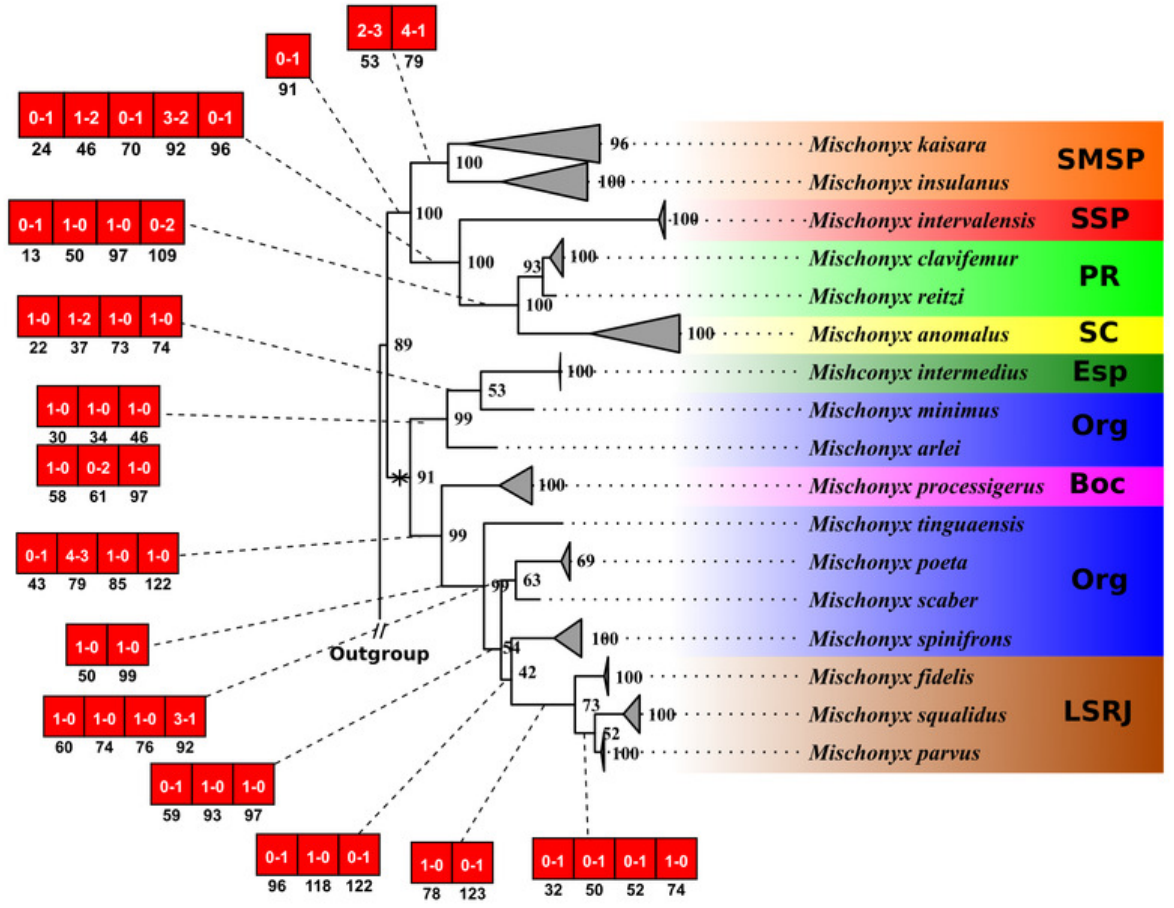

B

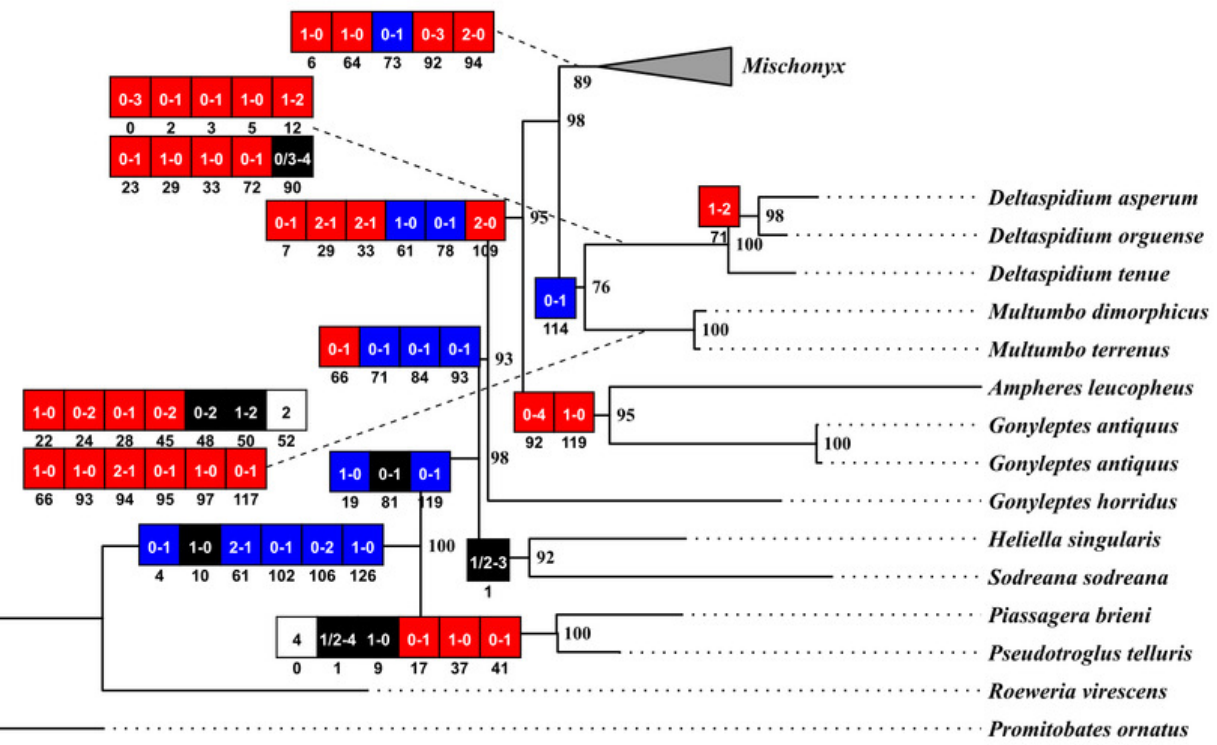




\section{Figure 18}

Total Evidence Parsimony (MP3) and Bayesian (B3) phylogenetic hypothesis.

A. MP3, values on each node are their respective bootstrap/Bremer values; B. B3, values on each node are their respective posterior probability. The color of the clades are according to their location, respective to each Area of Endemism. Light green: SC; yellow: PR; Red: SSP; orange: SMSP; blue: Org; dark green: Esp; purple: Boc; brown: LSRJ and M. squalidus. 


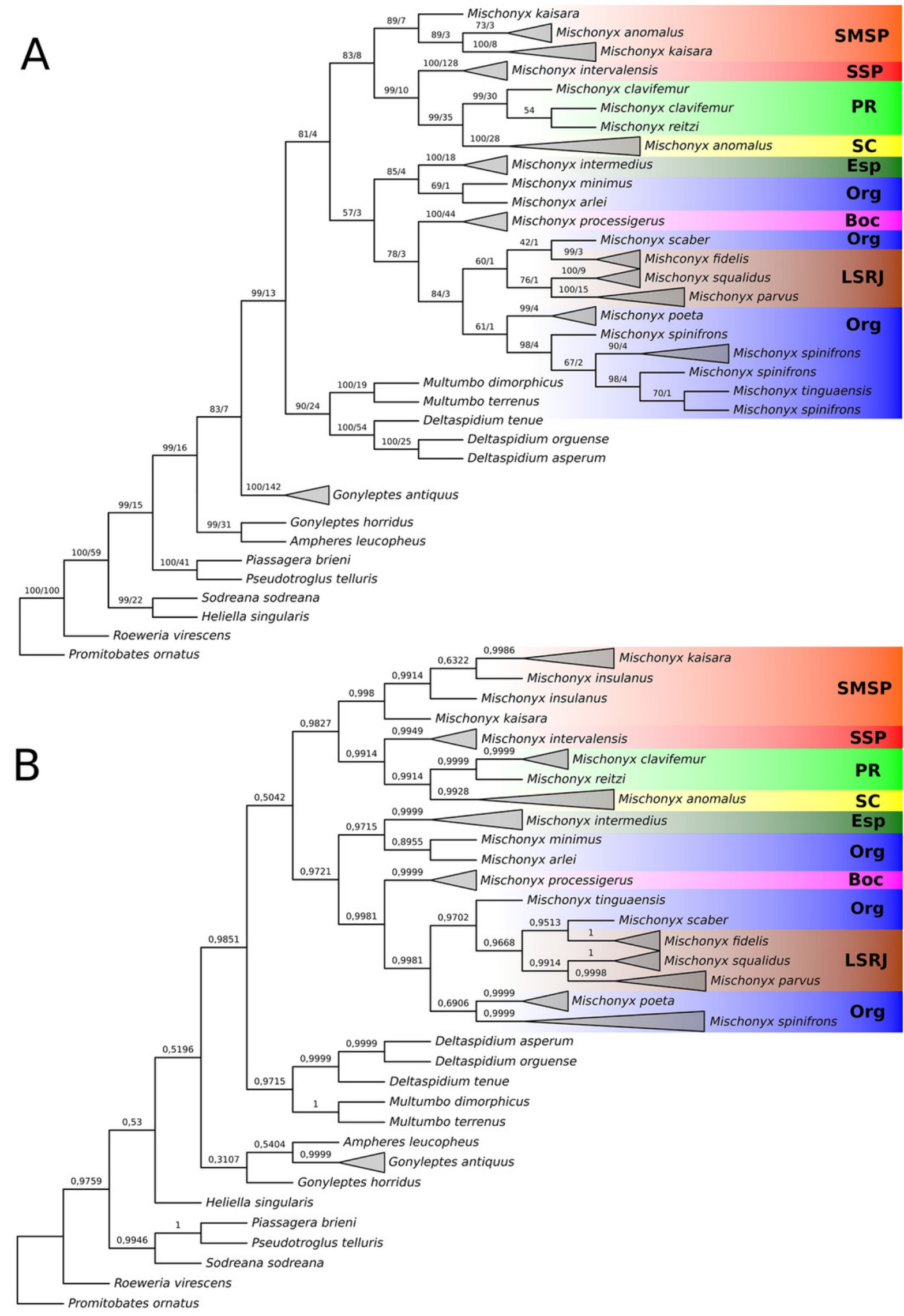


Figure 19

Mischonyx minimus sp. nov. male holotype drawings.

$A$, dorsal view; $B$, lateral view; $C$, dorsal view of the right leg; $D$, retrolateral view of the right leg. The tubercles painted in gray are whitish in ethanol. Scale bars $=1 \mathrm{~mm}$.

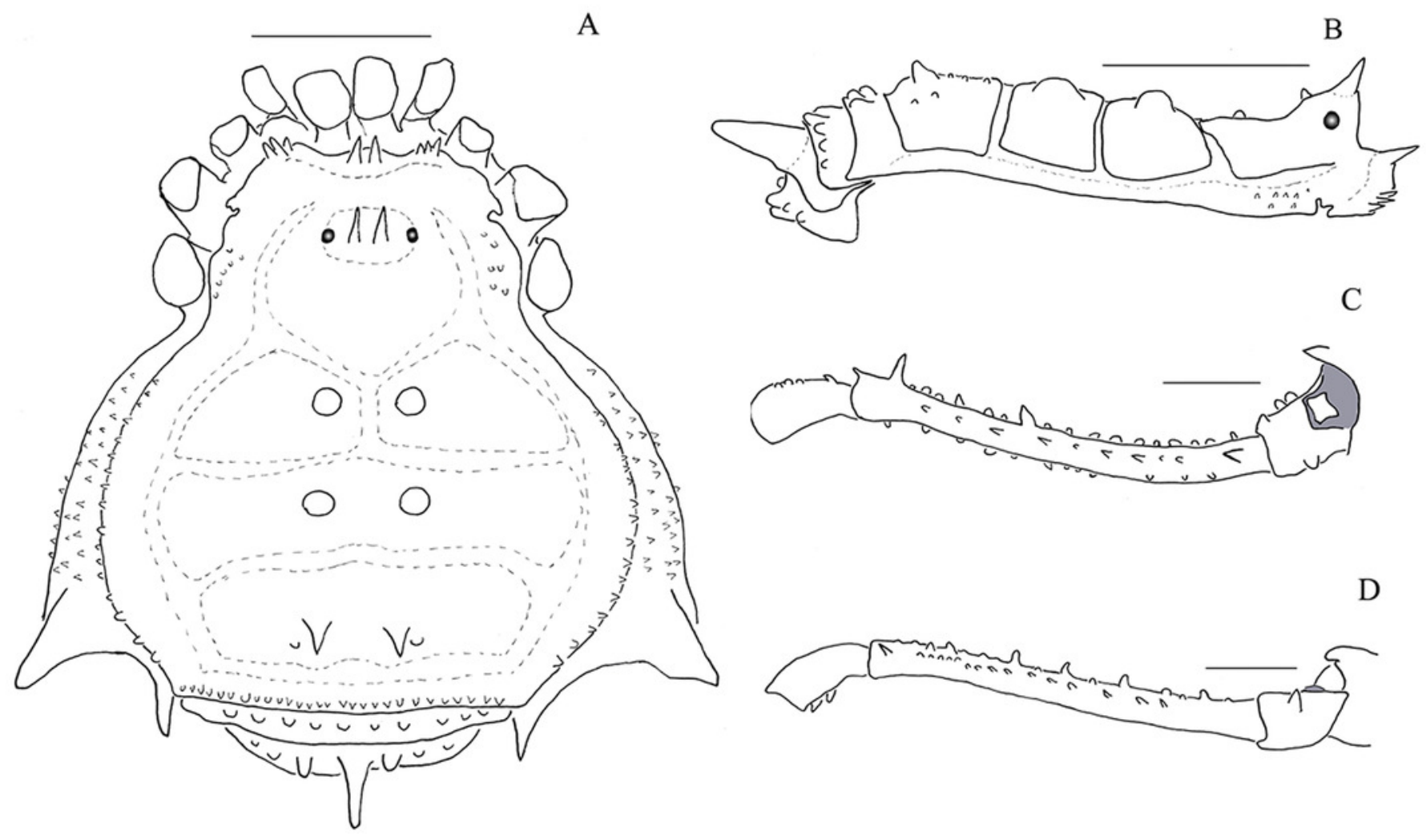


Figure 20

Mischonyx intervalensis sp. nov. male holotype and female paratype drawings.

A, C, Male holotype, dorsal and lateral view, respectively; B, Female paratype, dorsal view; D, E Right leg of the male holotype right, dorsal and retrolateral view, respectively. Scale bars $=$ $1 \mathrm{~mm}$. 

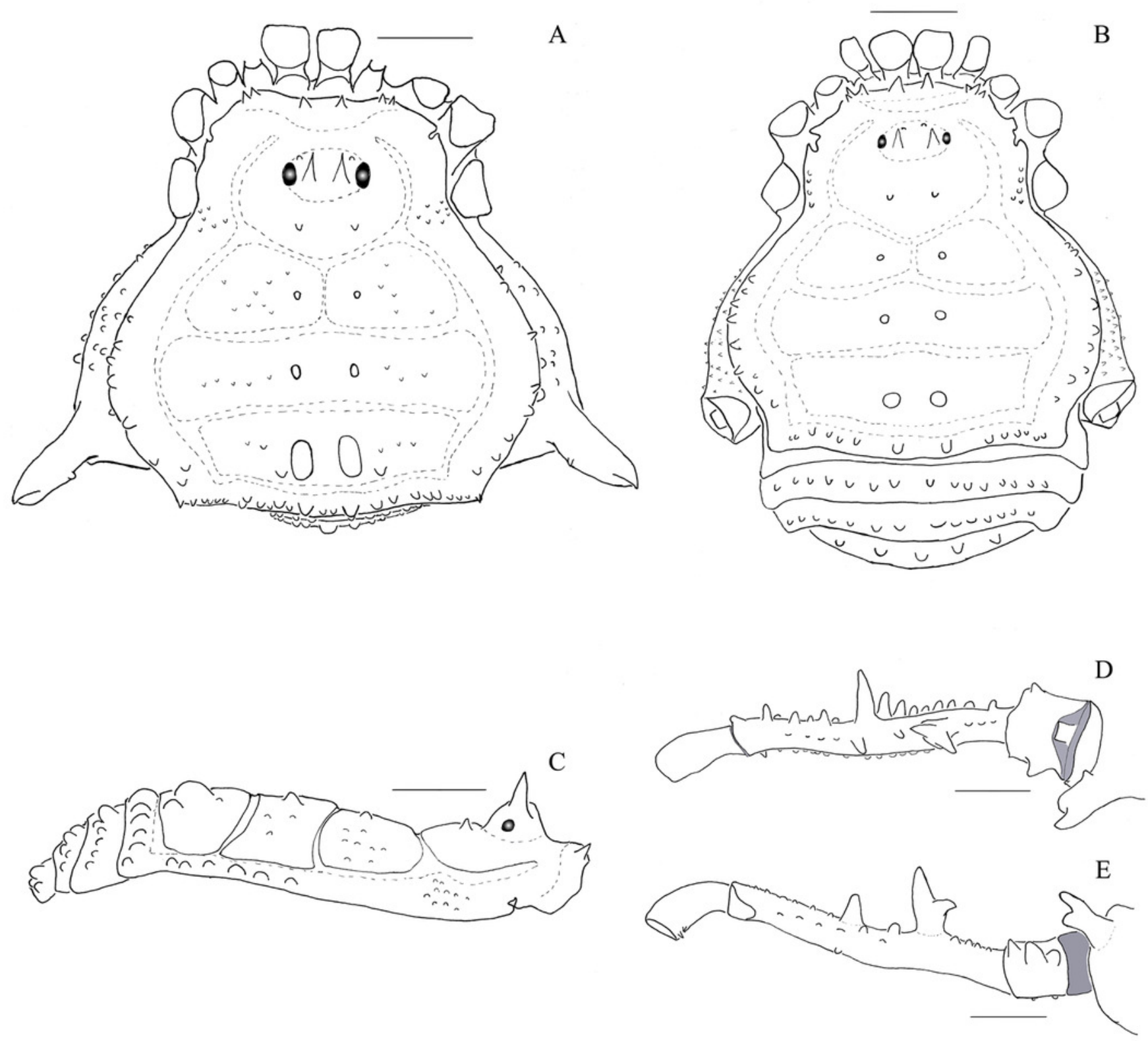
Figure 21

Mischonyx tinguaensis sp. nov. male holotype and female paratype drawings.

A, C, Male holotype, dorsal and lateral view, respectively; B, Female paratype, dorsal view; D, E Right leg of the male holotype right, dorsal and retrolateral view, respectively. Scale bars = $1 \mathrm{~mm}$. 

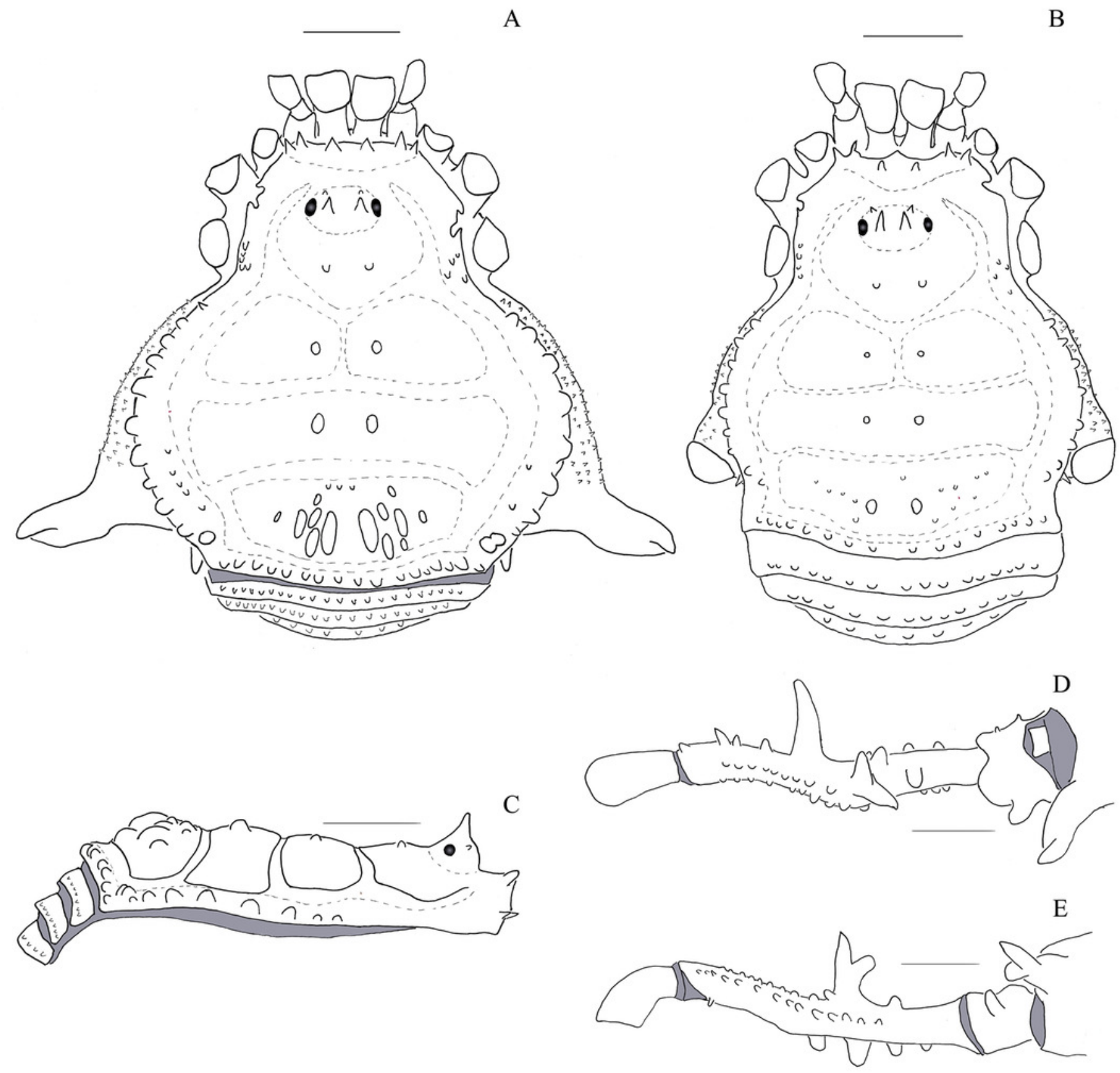
Figure 22

Penis of Mischonyx reitzi.

A - C. Dorsal, right lateral and ventral views, respectively, of the penis of Mischonyx reitzi Scale bars $=1 \mu \mathrm{m}$.
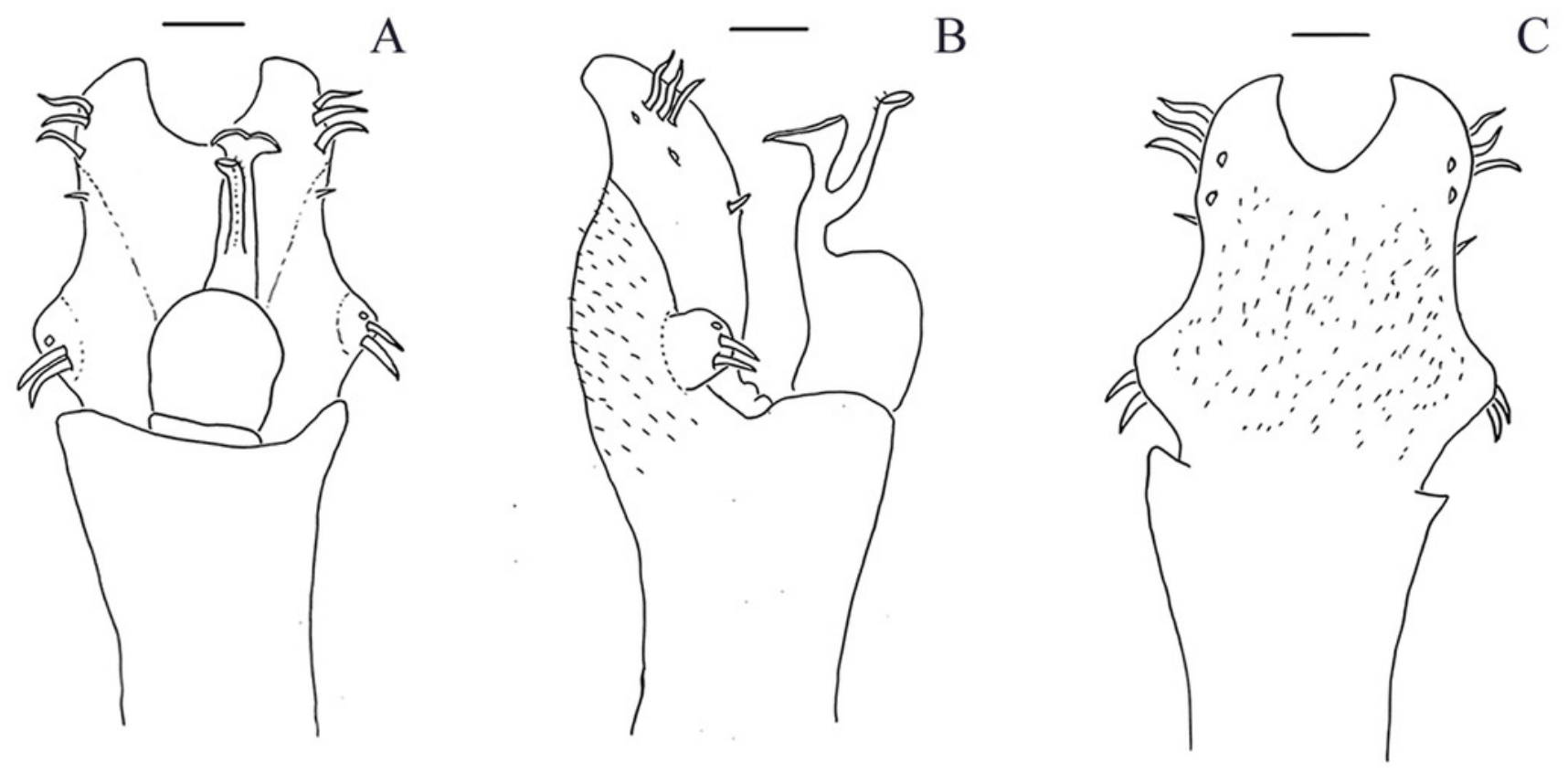